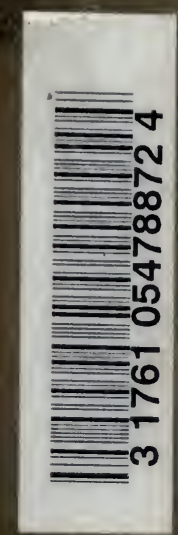


<smiles>C1=CC=C1</smiles>

Toronto University Library

Presented by

Royal Astronomical Society. through the Committee formed in The Old Country to aid in replacing the loss caused by The disastrous Tire of February the 14 th 1896 


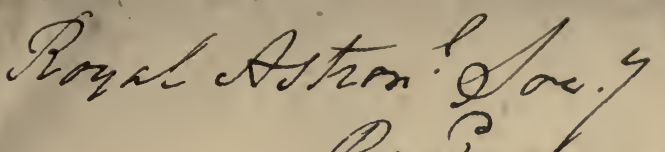

Re 32 lonag 183 



\section{THE UTILITY}

or

\section{THE KNOWLEDGE OF NATURE CONSIDERED,} WITH REFERENCE TO THE

GENERAL EDUCATION OF YOUTH. 
"We content ourselves with the knowledge of the tongues, on a little skill in philology, or history perhaps, and antiquity, and neglect that which to me seems more material, I mean Natural History, and the Works of the Creation : I do not discommend, or derogate from those other studies: I should betray mine own ignorance and weakness should I do so; I only wish they might not altogether justle out, and exclude this. I wish that this might be brought in fashion among us." RAx, The Wisdom of God manifested in the Works of the Creation,

Part i. p. 197-8: Fifth Edit. Lond. 1709. 
$S$
$B 82744$

\section{THE UTILITY}

OF THE

\section{K NOW LEDGE OF NATURE}

\section{CONSIDERED ;}

WITH REFERENCE TO THE INTRODUCTION OF INSTRUCTION

IN THE PHYSICAL SCIENCES

INTO THE

GENERAL EDUCATION OF YOUTH :

COMPRISING, WITH MANY ADDITIONS, THE DETAILS OF A PUBLIC

LECTURE ON THAT SUBJECT, DELIVERED AT

HAZELWOOD SCHOOL, NEAR BIRMINGHAM, OCTOBER 26, 1830.

BY

E. W. BRAYLEY, Jun., A.L.S., LECTURER ON NATURAL PHILOSOPHY AND NATURAL HISTORY:

TEACHER OF THE PHYSICAL SCIENCES AT THE SCHOOLS OF HAZELWOOD AND BRUCE CASTLE.

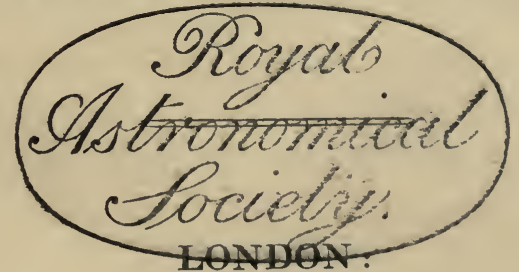

BALDWIN AND CRADOCK, PATERNOSTER ROW: AND J. DRAKE, BIRMINGIIMM.

1831. 


\section{Richard taylor,}

PRINTER TO THE UNIVERSITY OF LONDON, KLD LIUN COURT, FLEET STRELT.
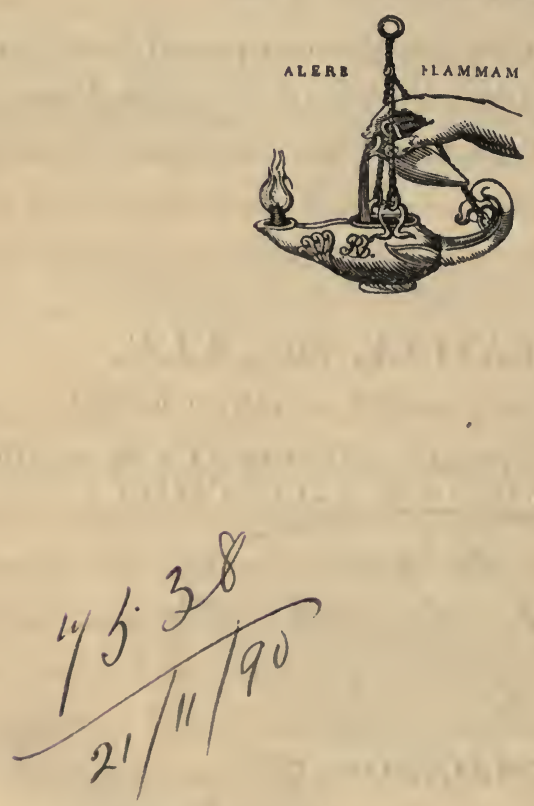


\section{ADVERTISEMENT.}

Messrs. HiLl, the Conductors and Proprietors of Hazelwood School, near Birmingham, and of the branch establishment at Bruce Castle, Tottenham, near London, being desirous of adding the study of the Physical Sciences to the various departments of liberal education, as conducted in those establishments, I was engaged by them, in the autumn of 1829 , to give instruction in those sciences, and, in general, to superintend the business of the new department, thus introduced into the Schools. After some degree of experience had been acquired of the arrangements necessary for adapting the truths of science to the apprehension of youth, and to the business of the Schools, and ascertaining, to a certain extent, the influence of those truths on the minds of the pupils, it was determined, by the Conductors and myself, that publicity should be given, to our views respecting the introduction of instruction in the Physical Sciences, into the General Education of Youth, in a Public Lecture, to be delivered by me at Hazelwood, and to be subsequently printed, for distribution among the friends of the pupils at both Schools, and published, for the information of those who are interested in the progress of Education, and for that of the scientific world. I accordingly 
delivered a Lecture upon the subject, at Hazelwood, on the 26th of October last, which was honoured with the attention of a numerous auditory. Upon the details of this lecture the present Memoir is founded.

The principal object of the following pages, is, to explain, to persons of every class, the objects and the utility of the Physical Sciences-of those branches of knowledge, to which the investigation of universal nature has given birth-considered as forming a department of Liberal Education. In order to accomplish this intention, I have endeavoured, when entering into detail upon any subject of a scientific nature, to interweave, with the technical terms and forms of expression necessarily employed, such explanations and remarks, as appeared requisite, for the purpose, not only of adapting the work for the perusal of those persons who may be unacquainted with the subjects of which it treats, but also of rendering it interesting to them. For this purpose, likewise, I have sometimes disregarded the precision of scientific nomenclature; when it seemed probable that a more general mode of expression would render any statement more readily intelligible to the general reader. But $I$ have attempted, at the same time, by the introduction of Notes, in which I have examined certain subjects in a more precise manner, and occasionally suggested new views respecting them, to evince, to those readers who may be already proficients in science, that my own views are not wholly incommensurate with the actual state of natural knowledge, and also to claim, in some degree, the character of a cultivator as well as that of a teacher of science. The main object I had in 
view required me to disregard attention to originality, whenever either facts or opinions derivable from sources already before the public were calculated to assist me in attaining that object; but I have ac. knowledged my authorities throughout, except in cases in which the facts related might be regarded as having become the general property of science. The greater number of the illustrations employed, however, will I apprehend be novel to many readers; while some of them, I believe, will be found so, even by the cultivators of science and literature.

It will perhaps excite surprise in the minds of scientific readers, that I should have confined my illustrations of the utility of scientific knowledge, almost exclusively, to Physics, disregarding the many striking and important facts which might have been adduced from the history of the Mathematical Sciences. Those facts, however, I have purposely omitted: the object before me was to explain the importance of the Physical Sciences, considered in themselves, and with respect to their forming part of the liberal education of Boys; the importance of pure Mathematics, in School-Education, is already fully appreciated, and they have always constituted a principal department of instruction at Hazelwood and Bruce Castle.

The subject just adverted-to leads me to mention another, which is connected with the view I have taken of the importance of uniting the knowledge of Physics with that of Mathematics. On reconsidering what I have observed, in p. 55, on the relative value of the scientific investigations which have been pursued, in this country, and on the Continent, 
respectively, during the last thirty years, I am apprehensive that some of the expressions I have used, may lead the mathematical reader to regard my allusion to MM. Fourier and Poisson, as involving a depreciation of their contributions to science. This, however, I beg leave, altogether, and in the most distinct manner, to disclaim:-nothing can be further from my intentions. The investigations contained in the Théorie Analytique de la Chaleur of Baron Fourier, and many others by the same analyst, are as far above my depreciation as they are above my praise ; the same character applies to M. Poisson's researches on the mathematical laws of electricity and magnetism, and, with some exceptions, to his investigations of the equilibrium of fluids and the figure of the planets, \&c. My meaning, in the passage referred-to, is simply this: - that, under the circumstances I have mentioned, the manner in which science has been cultivated, and the branches of science which have been pursued, in this country, during that portion of the century which has elapsed, have proved at least of equal, if not of superior advantage, to the welfare of the human race, to those which have been pursued on the Continent, and that, down to the present time, no just cause for regret has existed, whatever change may now be desirable. And that a change is now not merely desirable, but absolutely necessary, to our preserving our just station among the cultivators of universal science, I have distinctly avowed my opinion.

If, on the other hand, I should have mentioned any of the living cultivators of science to whom I have had occasion to allude, and with some of whom I have the 
pleasure and the honour of being personally acquainted, in terms which their own feelings would lead them to disallow,-if even I should appear indecorously "to assume the right of arbitrator where praise only can be bestowed," it must be remembered, as my apology, that one of my objects has been, to endeavour to convey a due appreciation of the importance of scientific pursuits, to those who may as yet be unacquainted with their nature, and that, to assert my own opinion of the merits of the various researches which I have mentioned, was inseparable from that design.

It is requisite to add a few words upon the degree of responsibility which attaches, respectively, to the parties who have concurred in this publication. For the views and statements contained in the following pages, while they are made with the perfect sanction of Messrs. Hill, I alone am responsible. With respect to the Department of Instruction in the Physical Sciences, as forming a portion of the business of the Schools, so far as it has actually been or may yet be conducted by myself, the responsibility, for the accuracy of the views of science imparted to the pupils, and the choice of proper apparatus and illustrations, is also mine; while, for the provision of apparatus and materials, of every description, as well as for the routine in which the instruction must be given, and for the amount of time allotted to the various duties of the department, Messrs. Hill are alone responsible. I have undertaken, merely, to give instruction, and generally to superintend the arrangement and use of the means of tuition placed at my disposal, in the capacity of Teacher of the Physical Sciences. 
Lectures on Animal and Vegetable Physiology, and on the History of Organic Nature, in general, will in future be delivered, at certain intervals, to the pupils at Bruce Castle, by Dr. Southwood Smith, Lecturer on Physiology at the University of London; and Lectures on Chemistry, and on the History of Inorganic Nature, by myself.

Edward William Brayley.

Bruce Castle, Tottenham,

March 15th, 1831. 


\section{CONTENTS.}

\section{\$1. INTRODUCTION.}

Civilization defined.-The definition illustrated by a sketch of the rise and progress of the Arts of Navigation and Naval Architecture.-Application and utility of the Steam-Engine in Navigation.-Sir H. Davy on the practical results of the progress of the Physical Sciences.-Note on the nature of Animal Electricity.-Present aspect of Society with respect to the application and cultivation of Natural Knowledge.Chemistry.-Geology.-Controversy in Geology, arising from the publication of Mr. Lyell's work.-Establishment of the Zoological Society.-Discoveries in the natural arrangement of Animals of Mr. W. S. Macleay.-Reasons which determined the Conductors of Hazelwood and Bruce Castle to introduce instruction in the Physical Sciences into those Schools.-Objects of the present Memoir. . . . . . p. 1 The Knowledge of Nature regarded as a means of expanding the Intellectual Faculties . . . . . . . . . p.13

\$2. Importance of Scientific Knowledge in the Improvement of the Arts and Manufactures.

Mr. Watt's inventions for the improvement and application of the Steam-Engine achieved by a series of scientific investigations.-Note on Lectures on the Steam-Engine delivered at Hazelwood.-Mr. Barlow's Correcting-plate, for counteracting the derangement of the Compass by the local magnetic attraction of ships, constructed and applied upon principles discovered by a scientific inquiry.-Recent improvements in the manufacture of Glass for optical purposes, effected by a scientific process devised and accomplished by Mr. Faraday. - New manufactures requiring the possession of scientific knowledge. . . . . . . . . . p. 14

\$3. Utility of the Knowledge of Nature in the Conduct of the Ordinary Affairs of Life.

Importance of Chemical science in the counteraction of poisons. -Ready means pointed out by it of detecting oxalic acid, when mistaken for Epsom salts. - Geological situations of common 
Coal in the British Islands.-Fruitless and expensive attempts to discover coal, precluded by geological information.-Note respecting a practical rule on this subject.-Inadvertent use of spurious Oak in ships, arising from the want of knowledge of Botany.-Ravages of 'Timber-eating Insects in the Forests of Germany and in the Parks of London.-Means of preserving Timber-trees from insects pointed out by Natural History. - Ultimate utility of the abstract Philosophical history of nature in the affairs of life. . . . . p. 34

\section{$\S 4$. Importance of Combining with Mathematical Acquire-} ments a Knowledge of the Principles and Substances of the Material World.

Inadequacy of the attention hitherto given to this subject, in School-Education.-Its probable cause.-Facility of making considerable attainments in pure mathematics without any enlarged acquaintance with the phænumena and history of nature.-Injurious consequences of this. - Recently alleged inferiority of Great Britain in the higher walks of sci.* ence examined. - Mathematical knowledge of the Ancient Egyptians, and their success in the cultivation of certain arts ; -the Physical sciences apparently unknown to them . . p. 51

\$ 5. General Utility of Combining the Knowledge of $\mathrm{N}_{\mathrm{A}}$ ture with the Pursuits of Classical Literature, and tie Advantages Specificaliy Derivable from that KnowLedge, in the more Profound Chass of Investigations of the History, the Languages, and the Arts of Civilized Antiquity.

The scholastic study of certain Greek and Latin authors an indispensable means of acquiring those languages.-Allusions to the phænomena of nature by those authors.-Importance of explaining such allusions to the student.-The writings of the philosophers and historians of Greece and Rome contain evidence of a more perfect and accurate observation of nature than was formerly supposed.-Examples.-An error in Burgh's Lunar Tables discovered from a statement of Diodorus Siculus, by a modern astronomer.-Precise and complete scientific knowledge required for the elucidation of ancient authors.-Exemplified in the history of the inquiries respecting the epoch of the solar eclipse predicted by Thales and recorded by Herodotus-that epoch fixed by astronomical computation, by Mr. F. Baily.-Advantages of uniting classical with scientific attainments in profound literary inquiries.-Splendid and interesting discoveries in Archæology recently achieved.-Rapid and complete success of the late Dr. Young in deciphering the Egyptian Hieroglyphics.The process employed by him analogous to a profound and 
extensive inquiry in Physical Science.-Dr. Young's success mainly attributable to his uniting classical with scientific knowledge.-Tardiness and comparative indecision, in some of its earlier stages, of the deciphering of the cunciform inscriptions of Persepolis.-The decipherers of the Persepolitan characters possessed of learning, but not of science. p. 60

Utility of academical education in preparing the mind for the study of the physical sciences.-Mr. Conybeare's remarks on the subject.-Causes of that utility.-Advancement of Geology by the students of the Universities of Oxford and Cambridge.-Researches of Professors Buckland, Daubeny, and Sedgwick.--Inference respecting the successive changes of surface undergone by the globe, deducible from the researches of Prof. Sedgwick, and of Messrs. Murchison and Lyell. . . . . . . . . . . . . p. 78

$\$ 6$. System of Instruction in the Physical Sciences Pursued at Hazelwood and Bruce Castle.

Course of Instruction in the Physical Sciences.-Methods of Instruction.-Lectures.-Arrangements for their delivery.Lectures on Geology, Meteorites, and Zoology. . . . p. 80

Lectures on Chemistry.-Syllabus of a Course of Lectures delivered at the Schools, on the Supporters of Combustion and the Simple Combustible Substances.-Oxygen.-Note on the propriety of abstaining from experiments on living animals in the instruction of youth.-Composition of atmospheric air.-Azote.-Difference between mixture and combination. - Note on the arrangement of this Course.-Chlorine.-Note on attention to atomic theory in teaching Chemistry.-Iodine. - Bromine.-Carbonic acid gas.-Chemical History of Respiration.-Simple Non-metallic Combustibles.-Hydrogen. -Sulphur.-Phosphorus.-Carbon. . . . . . p. 84

Syllabus of a Course of Lectures on Vegetable and Animal Chemistry.-Sugar.-Process of refining that substance.Different varieties of Sugar.-Note on the various modes of existence of Chemical compounds in the various groups of Animals and Plants.-Chemical composition of Sugar.Chemical history of Starch.-Note on the production of the columnar structure by the Contraction consequent on Desiccation.-Chemical history of Germination.-Chemical history of Malting.-Properties of Alcohol or Pure Spirits of Wine.-Chemical history of Vinegar.-Production of Vinegar from Wood, and the Cliemical composition of those substances compared. - Note on atomic constitution of Lignin.-Lectures on Animal Chemistry.-Chemical history of Ammonia.-Composition of Animal Substances.-Note on that subject.-Physiological and Chemical history of the Blood.-Albumen.-Respiration. . . . . . p. 96 
Authorities employed in preparing the Lectures.-Mechanism of the Class-Instruction in Physical Science. - ClassBooks.-Means of ascertaining the progress of the $\mathrm{Pu}$ pils. . . . . . . . . . . . p. 108

\section{\$7. Conclusion.}

Summary.-The arguments employed applicable to every kind of Education.-The Schools of Hazelwood and Bruce Castle, intended as preparatory seminaries, in every department of Study, for the Universities and Public Institutions for Professional Education. - Suggestion respecting the study of the Physical Sciences by Youth.-The extent and rank of that department of study in the Schools dependent on the public estimation of its value. . . . p. 114

ERRATA, \&c.

Page 20, line 19 from the bottom, after "on each side of this section," insert "arranged in a corresponding manner."

Page 23, line 13, for "while " read "when."

"having the same form." ters."

Page 27, line 7, for "eleven inches" read "eleven inches and three quar-

Page 61, line 3, for " them " read "it."

Since the observations in p. 27 were printed, Sir James South, having filled the Chair of the Astronomical Society for the period of two years, has, in conformity with the statutes, retired from the Presidency, in which office he has been succeeded by the Bishop of Cloyne, Dr. Brinkley.

Since p. 79 was printed, Professor Sedgwick, having filled the Chair of the Geological Society for the same period, has, in conformity with the regulations of that body, retired from the Presidency, in which he has been succeeded by Mr. Murchison. 
THE UTILITY

OF

\section{'THE KNOWLEDGE OF NATURE, \&c.}

Civilization may be defined to be that state of human existence, in which Man so disposes the objects of nature which are subject to his use, as to enable him either to controul, or to evade, the action of those natural powers which would otherwise injure him, or interfere with his supremacy over those impediments to his happiness which are inseparable from his material constitution; and for the final cause, that, being in the one case enabled to substitute those powers for his own bodily labour, and in the other, relieved from their injurious operation, he may, by the cultivation of his higher intellectual and moral faculties, so increase in wisdom and goodness, as to attain the highest degree of happiness he is capable of enjoying; both in this world, and in a future eternal state. The Civilization attained, is proportionate to the degree of perfection with which those natural powers are controuled, or made subservient to the welfare of mankind ; and all those secular pursuits of the human race which tend to augment the true happiness of the individual, while they contribute at the same time to the welfare of society at large, are resolvable, either directly or indirectly, into the controul or resistance of the power's of nature, the acquisition of that degree of knowledge concerning them, which is necessary, effectually to subdue them, or to counteract their injurious influence, $-\mathrm{nr}$ the review and illustration of the Moral History of Man. Such, I conceive, if we regard the entire human race, are the ends for which every department of natural knowledge, whether of quantity and form, of substance, or of organized being, every species of profane literature, and all the arts of life, are cultivated. Everything man has in view as desirable, in any condition of existence, is designed by him either to contribute to his well-being in this world, - to the healthy and secure enjoyment of all his means of gratification, 
whether of the senses or of the mind,-or, by enabling him, in a more perfect manner, to apprehend and comply with the requirements of Revelation, to conduce, as preparative means, to his eternal happiness.

Since abstract propositions necessarily convey any sentiment in a dense and concentrated form, so as not always to be immediately apprehended by the mind; and since the contemplation of any truth, as manifested to the view in the actual transactions of life, always enables us more clearly to understand it, we will examine the definition just given of the state of Civilization, by applying it to an art, which is peculiar, in its most successful cultivation, to the people of highly-civilized countries. I mean the art of Navigation;-that by which man is enabled to convey himself, his property and his means of enjoyment, over the trackless ocean, to distant regions of the globe; either by means of the winds and the waves, or in opposition to their resistance to his course.

When, in the earliest conditions of human society, the comfort of man was invaded, either by some of the powers of nature he was unable to resist, or by the disorderly passions, or unjust encroachments, of his own species, he would naturally endeavour to escape from the situation in which he experienced such suffering. If the intervention of a stream, or that of an arm of the sea, which was too deep for him to wade through, or too wide for him to swim over, interrupted his flight, he (probably after observing light bodies, such as twigs and fragments of bark or of wood, floating on the water, and perhaps supporting small animals) would hollow the trunk of a tree, and floating in this, allow the tide or the current to drift him to the opposite bank. Frequently, he would be in danger of being carried down the stream; and to prevent this, he would employ his hands, in order to impel his canoe in the right direction, by the resistance of the water to their motion. The fatigue which this exertion would produce, when long-continued, would lead to the substitution of a branch rudely fashioned to the resemblance of an arm and a hand,to the formation of a paddle; which would greatly increase the safety of the voyage. Having gained this stage in Navigation; having, by the exertion of his faculties on the objects around him, thus contrived to escape from persecution, to overcome the obstruction to his progress caused by the stream, and to obviate the effects of the wrong direction of the current; he would be led, in the course of time and experience, to still further improvements. When more than one individual, and especially when many individuals were desirous of crossing the waters, larger trees would be hollowed to receive them; 
and since very little experience in the use of the paddle would show, that the canoe might be impelled, by its means, in still water, or even, by due exertion, in opposition to a current, this larger bark would in time become a galley, swiftly impelled over the waters, by numerous oars. It becoming necessary, in the further progress of Civilization, which had in other departments of human action been simultaneously proceeding, to embark still greater numbers of men and greater stores of property, two excavated trees would be united longitudinally, as exemplified in the double canoes of certain islanders in the Pacific Ocean at the present time; portions of other trees would afterwards be added; and at length it would be found, that a number of pieces of timber, properly framed and prepared, might be so united together, as to form a much stronger and more convenient vessel than the mere trunks of trees; and thus would arise-thus in fact actually arose-the art of Naval Architecture.

But while all this was effecting, equal improvements were made in the form of the vessel, as adapted to impulsion through the resisting waters. The early navigators, whose lives and property were dependent on the security and rapidity of the voyage, would be very keen observers of every circumstance attending it; the utility would soon be perceived of giving a peculiar form to the fore-part of the vessel, so as to enable it readily to divide the waters through which it had to pass, and afterwards to throw them off on each side; the nature of this form, as the properties of curves became known in the progress of Mathematical Science, were rigidly investigated; and at length, by uniting a knowledge of the resistance of fluids to bodies passing through them (acquired by the combination of long experience with experimental research), with still more profound mathematical conclusions, the hollowed tree of the savage voyager became exchanged, for the immense and elaborate structure of timber, possessing the form of what is called the Solid of Least Resistance, which the Indiaman and the Manof-War now exhibit.-During these refinements of the art, however, many others of equal value were proceeding, with equal steps: in the infancy of navigation a method of converting the force of the wind, which must at first have proved a serious obstacle, into a means of progress on the waters, would have been found, in the stretching of the skin of an animal, or perhaps the broad leaf of some tropical plant, upon a pole or frame set up in the boat. In certain states of the wind it would be necessary to take this down, in order to avoid the upsetting of the bark; the next step of improvement would be, so to suspend the skin or the leaf, as to enable the boatman 
to change its position from time to time, according to the direction and force of the wind; and at length became perfected the system of masts and sails, - the sails so constructed and suspended as to be inclined, at any desired angle, to the axis of the vessel and the course of the wind, and to expose to the impact of the wind any required amount of surface, whether great or small,-which now constitutes the rigging of large vessels. We will here pause awhile in the career of improvement, to notice what had thus been effected in the progress of Civilization, agreeably to the definition with which we commenced.

The space occupied by the waters of the globe was practically reduced to insignificance by the means of traversing it thus afforded: the interruptions and sources of danger arising from the tides and from currents in the water, were overcome; and the force of the winds, originally, and during a considerable advance in navigation, frequently an impediment, as well as an occasion of shipwreck, converted into the most swift and certain means of progress from one quarter of the globe to another. To dwell on the immense effect of this perfection in the arts of Ship-building and Navigation, on every other department of civilized life, is needless : it is too well known to require detail: the liberty as well as the worldly and the moral prosperity of the British nation have been essentially dependent upon it, among other causes; and the same means have enabled us to extend our power, and in some degree, we may hope, the true moral sources of that power, to so immense a colonial population.

But one great desideratum in navigation still remained: the direction of the winds and the tides being often opposite to that in which it was necessary or desirable to proceed, and it being, in many cases, equally impossible to evade or to overcome the force of the winds, great delay and hindrance were often the result, and the impediment of "contrary winds" was for a time insuperable.

The means, however, of overcoming this obstacle, to a great extent, were soon at hand. The knowledge of the metals and their uses, especially of iron; that of mineral fuel, and that of the properties of the vapours into which liquids are converted by heat, particularly of those of steam, or the vapour of water, had during the period of these advances in the nautical art, occupied much of the attention of mankind. By the just use and direction of this knowledge, was obtained, at length, an immense regulated power, capable of any desired mechanical application, and possessing, virtually, some of the attributes of intelligence, in consequence of its consisting, in fact, of in- 
numerable powers of nature, combined by the intelligence of man; and we behold in the introduction of what is called STEAM-Navigation, an example of the most perfect degree of Civilization; in the evasion and controul, by the due exertion of the human faculties, of the brute forces of nature, which in themselves are too vasi and resistless to be within the grasp of human strength. Dispensing with the aid of the winds and the tides; or accepting so much of it as may be exactly suited to his designs, or, if they prove adverse to his wishes, defying them; - the seaman places in the solid of least resistance, which the construction of his vessel presents, an Iron Machine, which, set in motion by the vapour of water, agreeably to principles of chemical and of mechanical science profoundly investigated, imparts that motion to a wheel of paddles, (how different from the single paddle of the savage boatman!) which impels the vessel through the water with a swiftness and a certainty, equalled by few operations of the arts, and scarcely exceeded by any.

Since the delivery at Hazel wood of the Lecture of which the present memoir is an amplification, I have met with a passage in the "Last Days of a Philosopher" - of the late Sir HuMPHRY DAvy, which is in all respects so apposite to my present purpose, and presents a view of the subject so similar to that which I have taken, that it would be neglecting an efficient means of enforcing the arguments $I$ am about to offer, were I to omit its introduction in this place. The important part which was taken by its lamented author, in the progress of those sciences, the influence of which on the fortunes of mankind he commemorates in these reflections, will be remembered with interest by all; by many, with interest, deepened by regret, that a mind capable of such achievements in the conquest of nature, should have been withdrawn from this sphere of its activities-from our admiration and our friendship, comparatively so few in years.

"'The practical results of the progress of physics, chemistry, and mechanics," says Sir Humphry Davy, "are of the most marvellous kind; and to make them all distinct, would require a comparison of ancient and modern states: ships that were moved by human labour in the ancient world, are transported by the winds; and a piece of steel touched by the magnet, points to the mariner his unerring course from the old to the new world; and by the exertions of one man of genius [JAMES WATT], aided by the resources of chemistry, a power which by the old philosophers could hardly have been imagined, has been generated and applied to almost all the machinery of active life-the Steam-engine performs not only the labour of horses. but of man; by combinations which appear almost possessed 
of intelligence, waggons are moved by it, constructions made, vessels caused to perform voyages in opposition to wind and tide, and a power placed in human hands which seems almost unlimited. To these novel and still extending improvements may be added others, which, though of a secondary kind, yet materially affect the comforts of life; the collecting from fossil materials the elements of combustion, and applying them so as to illuminate, by a single operation, houses, streets, and even cities. If you look to the results of chemical arts, you will find new substances of the most extraordinary nature applied to novel purposes; you will find a few experiments in electricity leading to the marvellous result of disarming the thunder-cloud of its terrors, and you will see new instruments created by human ingenuity, possessing the same powers as the electrical organs of living animals *. To whatever part of

* Sir Humphry Davy here alludes either to the Electrical Battery, the instrument for accumulating common electricity ; or to theVoltaic Pile, the instrument, of more recent discovery, by which we accumulate that kind of electricity which is most commonly known under the appellation of Galvanism. The action of the former, when weakly charged, was compared by $\mathrm{Mr}$. $\mathrm{Ca}$ vendish, to that of the electrical organs of the Torpedo (or Crampfish, and Gymnotus (or Electrical Eel): while Volta, when he invented, or rather discovered, the instrument, having very different properties and powers, which bears his name, but which is more commonly, though with less propriety, termed the Galvanic Battery, imagined that he had made a perfect resemblance of the electrical organs of those fishes.

From Sir Humphry's "Account of some Experiments on the Torpedo" (his last production of an exclusively scientific nature) we should infer that $\mathrm{Mr}$. Cavendish's conjecture, with respect to that animal at least, was nearest to the truth. Sir Humphry found, that the electricity of the Torpedo, like that of the weakly charged battery, did not in the slightest degree affect the needle in the magnetic electrometer, while the smallest and weakest voltaic combinations, "but in which some chemical action was going on," produced an immediate and permanent deviation of the needle. These experiments, Sir Humphry observes, though he draws the inference with great caution, "seem to show a stronger analogy between common and animal electricity, than between voltaic and unimal electricity : it is however," he continues, "I think more probable that animal electricity will be found of a distinctive and peculiar kind."

It must at the same time be remarked, that the form of the Voltaic pile, which latterly appeared to its inventor to fulfill the conditions of the electrical organs of the Torpedo, and which, as mentioned in the paper just quoted, he exhibited to Sir Humphry Davy, at Milan, in the summer of 1815, has not yet been shown to affect the magnetic electrometer; and from its not decomposing water, as well as from the nature of the imperfect conductor in it, which was honey, or a strong saccharine extract, there is room to suppose, that (like some of the piles constructed by M. Zamboni?) it may be devoid of sensible chemical action, and therefore that it will not affect the magnetic needle. Should this prove to be the fact, we must probably consider the electricity of the Torpedo to be Voltaic : that is, to be of the same kind as that developed by the Galvanic Battery.

As these pages are intended for the perusal of those persons who may 
the vision of modern times you cast your eyes, you will find marks of superiority and improvement; and the results of intellectual labour, or of scientific genius, are permanent, and incapable of being lost. Monarchs change their plans; Grovernments their objects; but a piece of steel touched by the magnet preserves its character for ever, and secures to man the dominion of the trackless ocean. A new period of society may send armies from the shores of the Baltic to those of the Euxine, and the empire of the followers of Mahomet may be broken in pieces by a northern people, and the dominion of the Britons in Asia may share the fate of that of Tamerlane

not be familiar with subjects of this kind, as well as for the consideration of those whose interest in the discussions of science is founded on the knowledge of their objects and importance, I have thought it right to give the explanation with which this note commences, lest Sir H. Davy's allusion to artificial instruments stated to possess some of the powers of living animals, should be misunderstood, or appear a Promethean flight, unwarranted by a just appreciation of the limits of human power. The subject of animal electricity is one of great interest in a scientific point of view, and on that account the above remarks have been extended beyond the length required by the object now explained. It is right to mention, in conclusion, that the first suggestion of determining the nature of Animal Electricity, by ascertaining its relations to magnetism, was made by Professor Cumming, of Cambridge, in a notice published in the Annals of Philosophy, several years prior to the date of Sir Humphry Davy's researches on that subject. See Phil. Trans. 1829, p. 15 ; or Phil. Mag. \& Annals, N.S. vol. vi. p. 81 : and Ann. of Phil. N.S. vol. x. p. 151.

The preceding allusion to Professor Cumming's suggestion was written from memory; but the subsequent perusal of it in the Annals of Philosophy, as above, has rendered it expedient to add a further remark on the subject.

"If this animal electricity be similar to common electricity," Professor Cumming observes, "it is to be expected that it will be capable of unagnetizing a needle inclosed in a spiral, but not of causing deviation in the galvanoscope; if it resemble galvanism, we may expect both effects;" and after mentioning Mr. Cavendish's experiments, he subjoins, "I should, therefore, anticipate froin the Torpedo, magnetic action resembling that from galvanism."

The experiment with a neeủle inclosed in a spiral does not appear to have been made; but we have seen that the electricity of the Torpedo is incapable of affecting the galvanuscope (or magnetic electrometer), and so far, therefore, contrary to Professor Cumming's inference from Mr. Cavendish's experiments, but in agreement with what he expected would be the case on one view of the subject, animal electricity has been found to resemble, not galvanic, but common electricity. From the foregoing summary it is clear that new researches are required on this subject, which is equally interesting and important to the electrician and the physiologist. The properties and relations of both common and voltaic electricity of low tension, are at present involved in considerable obscurity; and in the actual condition of this inquiry, it may not be unphilosophical to suppose that the provisional opinion above given, in agreement with that of Volta, that the electricity of the Torpedo is similar to that of certain forms of the Voltaic Pile, may be compatible with Sir H. Davy's view "that animal electricity will be found of a distinctive and peculiar kind." 
or Zenghis Khan; but the steam-boat which ascends the Delaware or the St. Lawrence will be continued to be used, and will carry the civilization of an improved people into the deserts of North America, and into the wilds of Canada. In the common history of the world, as compiled by authors in general, almost all the great changes of nations are confounded with changes in their dynasties, and events are usually referred either to sovereigns, chiefs, heroes, or their armies, which do in fact originate from entirely different causes, either of an intellectual or moral nature. Governments depend far more than is generally supposed upon the opinion of the people, and the spirit of the age and nation."

If we now survey the actual condition and aspect of society, with reference to the prirciples of intellectual civilization which we have considered, we shall find it to present an immensely diversified prospect of the application of the Knowledge of Nature-of the Physical Sciences, to use the language of technical literature-to the promotion of the happiness of mankind; and of the acquisition of that knowledge, for this purpose. We have seen how the hydrodynamic principle of the resistance of fluids, the mathematical laws of curves; the knowledge of the winds and the tides, of the metals, of motion, and of vapours, (which are included in different branches of the sciences of astronomy, pneumatics, mechanics, and chemistry ;) have been rendered available to the happiness of the human race in the progress of navigation; and within the last few months only, a great and successful effort has been made to exchange the comparative tardiness of even the most considerable speed, derivable from the muscular power of animals, in travelling by land, for the celerity of mechanical impetus, obtained by the Steam-engine: I allude, of course, to the Liverpool and Manchester Rail-road, and to the Steam-carriages by which it is traversed. To turn our attention to other branches of human industry:-In the erection of bridges and piers, the incompressibility of stone has been exchanged, to a great extent, for the superior resistance to pressure of iron,-an article extracted from minerals by human labour directed by chemical knowledge-and, by a further refinement in construction, we have in some cases substituted, in such erections, the tenacity of iron, for its own incompressibility, thus obtaining augmented strength, with still greater diminution of weight, and proportionate increase of stability:-we have dispensed, in a great degree, with the raw vegetable matter and the prepared but not altered fat of animals, formerly universally employed for obtaining what we call artificial light; and now procure that essential to our comfort, from the combustion of gas-a species of air-obtained by the chemical action of heat, either upon 
coal, or upon the very animal fat formerly itself burnt to obtain light ; and distributed, (by a combination of the pressure of water with that of the atmosphere,) from the places of its manufacture to those required to be supplied, with greater perfection and certainty, than that, even, with which water is distributed by the water-works of our most populous cities.

In the Healing Art we find that the chemist has extracted from some of the most important medicines, the distinct principles from which they derive their curative activity. In the discovery and use of Quinine, the essential active constituent of Peruvian Bark, we witness an improvement in the administration of medicines, which is probably the precursor of many others, that will supply the means of diminishing the amount of human suffering, from disease, to an indefinite extent; from the energy with which such essences (as we may without empiricism call them) of powerful medicines will act upon the constitution, when separated from the inert substances, with which, as they occur in nature, they are invested. -A volume might be written in review of similar instances of the present application of scientific knowledge, to the increase of enjoyment, or the alleviation of misfortune.

If we consider the present aspect of society, with reference, specifically, to the cultivation and extension of Natural Knowledge, we shall discover a scene of equal activity and equal interest. The laws which govern the insensible motions of the particles of matter-which regulate the action of the gases composing the air we breathe, and the water which is almost equally essential to our existence, upon each other, and upon other bodies; laws, which, when developed, teach us how to extract the metals from bodies in appearance entirely dissimilar from them, and to procure from the waters of the ocean a condiment for our food-I allude of course to those which it is the province of Chemistry to investigate-these now form the basis of an extensive department of literature, and have become an almost indispensable branch of polite knowledge. The science of Geology,-examining the arrangement and composition of the masses and strata of rock, of stone, and of earthy matter, which constitute the mountains and the plains, and all the solid crust of the earth, together with the remains of animals and plants which they include, whether of extinct or still existing species, - has also produced a literature of its own, and become an almost necessary branch of general information. And, while I am yet speaking, a controversy just commenced, is proceeding in this science, which, probably for many years forward, will continue to engage the attention of the intellectual world in general ; to a greater de- 
gree, perhaps, than any which has taken place among scientific men, since the memorable discussions respecting the infinitesimal analysis, (pronounced by the late Professor Playfair, "the greatest discovery ever made in the mathematical sciences,") between the two original though independent authors of that discovery, Newton and Leibnitz, and their respective followers. I allude to the controversy which the publication of Mr. Lyell's "Attempt to explain the former changes of the Earth's Surface, by reference to causes now in operation"* is now calling forth; and which, with much temper and judgement, has been commenced, on the opposite side, by Mr. Conybeare. The former geologist contends, and other acute observers will support him, that all the geological phænomena with which we are acquainted, indicate a uniform and constant operation of the same causes, in the production of the present state of the globe, acting, from the earliest period to the present, with the same intensity, and under the same circumstances. The latter will maintain, doubtless with the aid of many associates in the investigation of nature, that there has taken place a great though gradual change in those respects, and that the successive periods in the formation of the world, as we now behold it, have often given rise to such new circumstances, as must, in a very great degree, have modified the forces which were originally in action. To pretend even to institute a comparison between the leaders of the great mathematical controversy of the last century, and the leaders, or those men of science who nuay probably hereafter become the leaders, of the geological controversy we are about to witness, would on the present occasion be as irrelevant as it would be arrogant and invidious. But I may be permitted to say that no controversy has ever taken place, more pregnant with important consequences to the value of natural knowledge, than that which has just begun. It will ultimately involve the determination, of to what extent, and in what manner, the physical sciences are to be considered as means of research, into the Wisdom of God, as manifested in the works of creation: For, it will consist, essentially, in the discussion of this question,-Whether any indications can be discovered in the earth, either by immediate observation, or by induction, of the processes by which the matter composing it assumed the planetary form, or of those, by which, having become a planet, it was prepared for the habitation of man; or Nот. Full, free, and fair discussion, by those who are profoundly acquainted with the phænomena of nature, can alone educe the

\footnotetext{
* More generally known, perhaps, by the more prominent part of its title,
} "Principles of Geology." 
truth; while every thinking member of society, who becomes acquainted with this controversy, in all its bearings, will feel himself deeply interested in its progress*.

The sciences by which we are made acquainted with the phænomena of organized existence, - those of Botany and Zoology, have also become objects of extensive interest and of general importance. Public Institutions and Societies have been founded to assist in the promulgation of them, and numerous publications, on every scale of detail and illustration, present their truths to the reception of the people at large. To Zoology, or the natural history of animals, in particular, the attention of the public in general in this country has recently been strongly directed; and the magnificent collection of animals of every class and every clime, in the Vivarium (or Menagerie) and the Museum of the Zoological Society, are still extending this attention and interest among all ranks of the community. And it must not be forgotten, in adverting to these facts, that this popular zeal for the cultivation of zoological science, originated in the avidity with which the proposition of the late Sir T. Stamford Raffles for the establishment of a public institution for the advancement of Zoology, was received by a small circle of naturalists, whose attention had been strongly directed to the discoveries in the natural arrangement of animals, announced, a few years before, by $\mathrm{Mr}$. W.S. Macleay; a naturalist, to the importance and value of whose purely scientific labours we shall again have occasion to allude. The impetus was given by the zeal, the munificence, and the public spirit, of Sir Stamford Raffles; but the momentum which has brought the Zoological Society to its present state of importance and utility, has been acquired from the influence of Mr. Macleay's discoveries, on the kindred minds of contemporary students of nature, with whatever li-

* The opinion above expressed of the importance of the controversy in geology, which has now first arisen in a truly definite and adequate form, is not founded on the perusal of Mr. Lyell's work only. Every one who is conversant with the progress of geology, both in this country and on the Continent, for some years past, must be aware that the materials for a profound and extensive controversy have been gradually and insensibly accumulating ; especially in the inquiries concerning the origin and history of the crystalline rocks; the respective geological limits of the transition, secondary and tertiary strata ; the comparative as; well as the positive value of mineralogical and zoolugical characters, in identifying or discriminating formations geographically distant from each other; the discussions on the formation of valleys and water-courses; \&c. \&c. Mr. Lyell's publication has been the means of bringing this controversy fully before the public; but at the same time, with the exception of what its author may have derived from the Pythagorean system, as expounded by himself, and of what he has avowedly adopted from Dr. Hutton and others, that most interesting work must be regarded as perfectly uriginal. 
mitations his conclusions may have been adopted, by some of them.

The aspect which society thus presents, with respect to the pursuit or application of Scientific knowledge, the increase of the number of professions, either dependent altogether on the acquirement of such knowledge, or into the qualifications for success in which it enters in a considerable degree, and the demand which society now makes for some degree of acquaintance with the objects and powers of nature, from persons of every station and employment, but especially from those who are destined to take an active share in the direction of its concerns; - these, in conjunction with some other considerations hereafter to be mentioned, are the reasons, which, I am authorized to state, have determined the Conductors of the Schools of Hazelwood and Bruce Castle, to introduce instruction in the Physical Sciences, especially in those of Chemistry, Natural Philosophy (including Astronomy and Mechanics), and Natural History, as one of the essential departments of the Education which it is their duty, no less than their pleasure, to impart. Education, in an extended sense, but still confined to that of youth, may be defined, the intellectual and moral cultivation of their minds, in order to prepare them for performing, with intelligence and alacrity, the duties which will be required from them in mature life; and in the faithful and efficient discharge of which, in all their relative degrees of utility, their happiness, throughout life, must essentially consist. Among the duties which the rising generation of the present age will be called upon to discharge, when they have arrived at maturity, it is manifest, from the aspect of society we have just examined, will be many, which will involve or require the possession of Scientific knowledge. It is the professed endeavour of the Conductors of these Schools to impart the Education I have just characterized. 'They are therefore desirous, so far as they may succeed in communicating to the public an estimate of the value of philosophical attainments, corresponding with that which exists in their own minds, to blend, with this Education, so much of instruction in the Knowledge of Nature, especially in Natural Philosophy, Chemistry, and Natural History, as will prepare the minds of their young charges for the duties, involving the possession of such knowledge, which they may in after-life be called upon to perform.

Part of the objects of the present memoir, those of reviewing the aspect of society, with relation to the cultivation and use of the Physical Sciences, and stating the grounds 
on which this department has been introduced into the Schools, have now been accomplished: there remain to be fulfilled, - to offer some observations and facts indicating the intrinsic importance of the Knowledge of Nature-or in other words, of the Physical Sciences, as forming a department of General Education; to describe what has already been done in the fulfillment of the Conductors' designs in this respect, and to explain the means and the methods which have been adopted for its performance.

There are several points of view, under which we may consider the intrinsic utility of the Knowledge of Nature. We may regard it as a means of expanding the intellectual faculties in general, in subservience to Theology; and in protection of the mind from that kind of superstition which is consequent on ignorance of the laws of nature. It may be viewed in its immediate relations to the arts and to manufactures. We may consider its importance in the conduct of the ordinary affairs of life, whether as affecting the happiness or comfort of individuals, or that of society at large. The value of uniting the Physical with the Mathematical Sciences may be enforced; and finally, we may urge some arguments, showing, not merely the general utility of combining a knowledge of Nature with the pursuits of Classical and General Literature, but also the advantages specifically derivable from it, in the most profound investigations of the history, the languages, and the arts of civilized Antiquity.

It is unnecessary to enter at much length into the utility of the Knowledge of Nature as a means of expanding the intellectual faculties in general, since this is now generally acknowledged. By a kind of common consent, grounded in the Divine Command, "Replenish the earth and subdue it; and have dominion over every living thing that moveth upon the earth ;" and confirmed, as it would seem, by a common perception of the truth involved in the epithet, Man is called "6 the Lord of the Creation." And it would be improper, on the present occasion, were I to refrain from contributing my testimony to the justice of this confirmation, from all that I have been able to acquire of Natural History. The entire amount of knowledge hitherto attained by philosophers, of the organization, mutual relations, and reciprocal dependence on each other, of all created things, in each of the three kingdoms of nature, appears to me to concentre in this testimony:That inorganic bodies in general were created to serve as bases for the structure-as substrata in general for the existence-of organized beings-the Mineral for the sake of the Vegetable and Animal kingdoms-and these, -indeed the 
'whole of Nature, for the sake of Man. But if Man be the Lord of the Creation, it is manifestly important that he should have some knowledge of the beings subject to his authority. It is the province of the Physical Sciences to impart this knowledge. An acquaintance with the forms exhibited by the objects of nature, with the substances of which they consist, and the mutual action of these latter on each other, and with the indefinite variety also of those objects, which constitutes each of the three kingdoms of nature, imparts a peculiar species of precision and firmness to the deductions of the intellect; distinct and very different from that which is communicated by the abstract Mathematical consideration of form and quantity, in the study of Arithmetic, the higher species of Calculus, and Geometry, but not less important, I am disposed to urge, as an element of a rightly-constituted mind. The understanding which has by this means received instruction, in the properties of the irresistible force which has been conferred upon many of the powers of nature, will be disposed, from the manifestation of Omnipotent Wisdom they display, more readily to entertain an intelligent belief in the miraculous exertions of the same Power recorded in the Sacred Scriptures; and reciprocally, the mind thus instructed in the laws of nature, will learn at the same time not to confound the operation of these, in the constant succession of natural phænomena, with miraculous or supernatural interposition; and will be preserved, by such discrimination, from the inroads of superstition.

With respect also to the importance of Scientific knowledge as a means of improving the arts and nanufactures, when possessed by those who are engaged in such pursuits, it is scarcely necessary, at the present time, to make many observations. Since the greater number of the useful arts depend for their success either on the application of certain powers of nature to the substances manufactured, or more immediately on the properties of those substances, considered in themselves, it is manifest that a correct and definite knowledge of those powers and substances must eminently conduce to success in manufacturing the latter; especially when new wants of society require nuvel applications of material. But it will be useful to state a few examples of the improvements which have been made in certain branches of manufacture and the useful arts, arising, in a direct manner, from scientific knowledge.

Mr. Watt's inventions for improving the Steam-engine (for this is the only correct term which can be applied to them) have so often been referred to-as examples of the value of scientific knowledge in the useful arts, that an allusion 
to them on the present occasion may appear to be trite and common-place. I have reason to believe, however, that the popular impressions on the subject, at present existing, are defective, if not erroneous; and that the general estimation of the importance of philosophical attainments derived from them, is not adequate to the real merits of the case :-that the example afforded by Mr. Watt's achievements is far more striking and instructive than is commonly imagined. On this account I will briefly review the train of investigation by which " this potent commander of the elements, - this abridger of time and space," as he has been poetically denominated in reference to the effect of his inventions on the welfare of society,-was led on to that construction of the Steam-engine, which has worked such stupendous effects. I shall do this nearly in the terms in which I have already explained it to my elder pupils at Hazelwood; which will enable the reader, in conjunction with some examples I shall submit to him in the sequel, to judge, in some degree, of the manner in which their instruction, in the Physical Sciences, has been conducted.

In the winter of the years 1763-4, Mr. Watt was employed by the Professor of Natural Philosophy in the University of Glasgow, Dr. Dick, to put in order a working model of a Steam-engine upon Newcomen's or the atmospheric construction (the only one which had down to that period been devised), in which the piston, giving motion to the machine, was raised by the expansive force of the steam rushing into the cylinder, and a vacuum being produced by the condensation of the steam in the cylinder, by the injection of cold water, the piston was forced down again by the pressure of the atmosphere upon its upper surface; thus completing one movement of the machine, and being prepared to repeat it*. When Mr. Watt had repaired this model, and set it to work, he found that the boiler, though large in proportion to the cylinder, was barely able to supply it with steam for a few strokes of the piston per minute; and that a great quantity of water was required to be injected into the cylinder in order to condense the steam. It soon occurred to him that the cause lay in the fact, that the little cylinder (of only two inches dia-

* For all practical purposes the steam engine (constructed as above described) must be considered as originating with $\mathrm{Mr}$. Newcomen ; " the introduction of a moveable diaphragm," as Mr. Davies Gilbert has philosophically remarked, in his second paper on the efficiericy of Steam Engines (Phil. Trans. 1830), " between the active power and the vacuum or less elastic medium, being essential to the very principle of the machine as a moving power." The only material improvement it had received, down to the time of Mr. Watt's inventions, consisted in the automatic opening and shutting of the valves. 
meter and six inches stroke or range of motion of the piston) exposed a greater surface to condense the steam, than the cylinders of larger engines did, in proportion to their respective contents. By shortening the column of water in the pump worked by the engine, and by thus diminishing its weight, lessening the amount of work to be performed, less steam and less injection-water were required, and the model worked at a proper speed.

The purpose for which the model was put into Mr. Watt's hands was thus accomplished; and with this result an ordinary workman would have been satisfied. Mr. Watt, however, having now become aware of the great consumption of steam by the engine, his inquiring mind was impelled to make a more accurate investigation of the causes of this consumption, in which he proceeded in a manner truly philosophical. He ascertained, from experiments made with boilers of various constructions, that the quantity of steam obtained in a given time from boiling water, is neither in proportion to the surface of the water, nor to the quantity of the water, as had been supposed, but that it is in exact proportion to the quantity of heat which enters into the water, and depends on that alone; and he discovered, further, that the heat which enters the water depends chiefly on the quantity of surface exposed to the action of the fire; or, in other words, to the size of the bottom of the boiler and of the other parts of it on which the fire plays. He likewise determined the weight of coal required to be burned in order to evaporate any given quantity of water. Being convinced that great errors existed in the statements that had been previously made of the increase of bulk in water when converted into steam, he proceeded to examine this point by experiment; and he discovered that water, converted into steam having the same heat as boiling water, was expanded to 1800 times its former bulk; or, as a rule for ready approximate calculation, that a cubic $i n c h$ of water produced a cubic foot of steam. He constructed a boiler to be applied to his own model, which would show, by inspection,-by merely looking at it, the quantity of water evaporated, and consequently would enable him to calculate the quantity of steam used, in every stroke of the engine. This quantity he now proved to be several times the cylinder-full. He also observed that whenerer an attempt was made to improve the vacuum in the cylinder, by throwing in more injection-water, the power gained did not increase in proportion to the expenditure of steam. It occurred to him that the cause of this was the boiling of water, in a vacuum, at very low heats, (then recently determined by Dr. Cullen, to be under 100 degrees of Fahrenheit's 
thermometer); and consequently, that at greater heats, the cold injection-water itself was made to boil, and converted into steam, in the cylinder, and resisted the descent of the piston. The great consumption of steam by the engine, Mr. Watt now clearly perceived, proceeded from its being chilled and condensed by the coldness of the cylinder, (and that in a greater degree in proporton to the quantity of injectionwater employed), before that vessel had become sufficiently heated to retain it in an elastic state-to prevent its condensation into water: this determination led immediately to the practical conclusions, that, in order to derive the greatest advantage from this agent, the cylinder should always be preserved as hot as the steam that entered it; and that, when the steam was condensed, it should be cooled down to 100 degrees of Fahrenheit, or lower, in order to render the vacuum complete and to preserve it in that state. Early in the year 1765, the fortunate thought occurred to him, in consequence of the steady and continued application of his mind to the subject, of accomplishing this object, by condensing the steam in a separate vessel, exhausted of air, and kept cool by the injection of cold water; between which and the cylinder a communication was to be opened, while the cylinder itself was to be kept constantly hot, so that the steam which entered it would always remain steam, while it continued in the cylinder. No sooner had this design occurred to him, than the means of effecting it presented themselves to his mind in rapid succession; and thus was achieved the invention which was the main foundation of the fame Mr. Watt subsequently acquired; and which has since been applied, with so much labour and ingenuity, to the advancement of human affairs*.

- The above review of the successive steps by which Mr. Watt proceeded to his great improvement upon the principle of the Steam-engine, is derived, with a few omissions and verbal alterations, from the details on that subject given in the memoir of Mr. Watt, published in Professor Napier's Supplement to the Encyclopædia Britannica; and which, that gentleman informs us, in an editor's note to the article, he received "from a quarter which entitles him to state, with the utmost confidence, that it contains an accurate and faithful account of Mr.Watt." As first delivered at Hazelwood it formed part of the concluding lecture of a brief course on the Steamengine, addressed, as mentioned above, to my elder pupils in that establishment. They had been prepared for these details, by some familiar experiments on the production and condensation of vapours ; the boiling of liquids at low temperatures when relieved from the pressure of the atmosphere, as evidenced by a modification of the instrument called the Pulse-glass; the explanation and use of Dr. Wollaston's instrument showing the fundamental principle of the Steam-engine; a sectional drawing of Newcomen's engine, and other appropriate means. The progress and final result of Mr. Watt's investigations was illustrated by sectional drawings; and by a moving sectional diagram of his double-acting engine, which had been constructed by Mr. Edwin Hill, now of Bruce Castle, in the year 1821 . 
What I would point out as most worthy of observation in the detail just given, is the fact, that Mr. Watt arrived at his grand result,-namely the introduction of a vessel to condense the steam in, separate from the cylinder of the engine,-by a series of investigations conducted for the purpose of ascertaining the means, by which steam might be employed, as a prime mover, with least expenditure of fuel. And, highly-gifted as he was by nature, had he not brought to the undertaking much knowledge of mechanical philosophy, previously acquired, and had he not united with his own results during its progress, the chemical facts respecting the formation and nature of vapours discovered by some of his contemporaries, (especially Dr. Black and Dr. Cullen, ) his success, there can be no doubt, would have been far less perfect. We have seen how philosophical was the manner in which he conducted the inquiry-how cautious the induction by which he was led from one result to another-and how solid he rendered every conclusion at which he successively arrived, before he made it a foundation for further progress. Every step in his progress was a scientific inquiry, demanding, for its adequate and successful prosecution, a comprehensive acquaintance with whatever had already been made known upon the subject; great judgement in the institution of experiments, with steadiness and accuracy of manipulation and observation, in conducting them; and equal sagacity in deducing from their results the facts or the law he was desirous of ascertaining. To those, then, who are destined to engage in manufacturing pursuits-especially at this eventful æra in the moral and political worlds, when the very existence of civilized communities appears to depend on the development of principles in political œconomy, hitherto unknown or unregarded, and on the achievement of new conquests over nature in providing the means of life-to those persons, no species of information can be more important, it would appear from the history of Mr. Watt's discoveries, than that of Natural Philosophy and Chemistry. With a general knowledge of business, of accounts, and of the details of their respective pursuits in commerce or in trade, they will be qualified for ordinary success, so far as just qualifications for it can be imparted by instruction; but unless they combine with these some insight into the principles upon which their processes of manufacture are conducted, they will be unable to effect improvements, which their more enlightened rivals will introduce; and they will consequently be unable to compete with them, in the sale of their manufactures*.

- As some readers of this nemoir, who may be fully prepared to appreciate the importance of Mr. Watt's improvements in the construction of 
In tracing the progress of the arts of Ship-building and Navigation, in the remarks on the intimate nature of that change in the pursuits and conduct of the human race termed Civilization, with which I commenced, the influence of the adoption of the compass in directing vessels at sea, and that of some other improved means of guidance over the waters, successively employed, were purposely neglected; on account of the length to which my introduction must have been extended, had those points been duly considered. But a portion of the history of these subjects I shall now introduce, in some detail, because, while it affords a remarkable example of the utility of scientific knowledge in advancing the useful arts, it is also at present far less known than it deserves to be.

I allude to the discoveries in the science of Magnetism, by which Mr. Peter Barlow, of the Royal Military Academy, at Woolwich, has been enabled to counteract the effect on the compass, of what has been termed the Local Attraction of vessels, which, but for the masterly investigation of that natural philosopher, would, ere long, have rendered it necessary, either to dispense with the application of iron in the construction and equipment of ships, or to have abandoned the use of the compass in navigation, as having become not merely nugatory, but under certain circumstances absolutely mischievous.

"Of the numerous interesting facts with which philosophy has been from time to time enriched," observes a writer in the Edinburgh Philosophical Journal, of whose historical statements on the present subject I shall avail myself, "by far the greater number may be traced to some fortuitous or accidental circumstance; and it belongs perhaps almost exclusively to the nineteenth century, to boast of some valuable discoveries,

the steam-engine itself, may not be aware of the total extent of our obligations to him in connexion with that machine, I have subjoined an extract on the subject from Mr. Davies Gilbert's paper, quoted in a previous note :

" Greatly as we are indebted to Mr. WATT, [for the improvement in the steam-engine described in the text above,] our obligations to him are still greater for originating and carrying almost to a state of perfection, the application of steam as a moving power to machinery, in all the complicated and varied uses of mechanical inventions in this country.

"In effecting this most important object, the double engine was first brought into use, the extremely ingenious contrivance for producing parallel motion was invented, and the principle of centrifugal force enabled an apparatus called a Governor to regulate a supply of steam inversely prcportionate to the velocity which might at any instant be required; and the use of fly-wheels, perfectly understood in theory, became subservient to the regularity of motion, and to the gigantic efforts of our most ponderous machinery. We owe further to Mr. WATr the introduction, at least into general use, of what is termed bevelled geer." - Philosophical Transactions for 1830, p. 127. 
which, independent of chance, have resulted from scientific investigations and experiments directed to a specific object. Of these, the Safety-lamp of Sir H. Davy, and his present chemico-electric guard to the copper of vessels, and the Correcting-Plate of Professor Barlow, form memorable examples; and in all these cases, the value of the discovery is only equalled by the extreme simplicity of the application."

Nearly seven hundred years have now elapsed, since the compass began to be employed, in Europe, as a nautical instrument; and yet it is only within a short period that an imperfection has been discovered in it, which detracts much from its real value for such a purpose; namely, that, with the ship's head at different points, the needle does not continue to point in the same direction; the difference, in some cases, being so great as to lead to the most fearful errors and uncertainties. The general nature of this effect will be understood, by considering, that the upper parts of all masses of iron attract that end of the compass needle, which, when freely suspended, dips below the horizon, that is, the north end in the northern hemisphere of the earth, and the south end in the southern hemisphere. Now, in vessels of all kinds, the iron which enters into their construction or equipment, is nearly symmetrically disposed with respect to the longitudinal section of the ship. Supposing the ship to be divided from stem to stern, equidistant from the sides, by a mathematical plane, such as would be formed if the vessel were so cut in halves, but the halves not separated from each other, there is an equal quantity of iron on each side of this section. When therefore this section is in the magnetic meridian of any place, or in other words, when the direction of the freely-suspended needle is the same as that of the section, which can only happen when both point to the magnetic north and south, then the action of the iron in the vessel is either coincident with, or directly opposed to, the magnetic action of the earth: in either case the lateral direction of the needle is not disturbed,-it is not drawn either towards the east or towards the west. But when the ship's head is on any other point of the compass, and particularly when it is towards the east or the west, the two forces acting on the needle, that of the earth and that of the iron of the vessel, being exerted nearly at right angles to each other, one drawing the needle towards the north, and the other drawing it towards the east or west, it becomes drawn more or less'out of its natural position, according to the direction of what is called the resultant of these two forces; that is the mean direction which results from one of them drawing the needle one way, and the other drawing it the other 
way. If these two forces are equal, then supposing the ship's head to be toward the west, the needle (disregarding the variation) would point due north-west; if the attraction of the earth exceeded the local attraction of the vessel, it would point nearer north; if the attraction of the vessel exceeded that of the earth, it would point nearer west. The consequence of this is, that the course shown on ship-board by the compass differs from the actual course of the vessel, by a quantity equal to the whole of this disturbing force, and which, in some cases, amounts to two or three points of the compass, that is to $20^{\circ}, 30^{\circ}$, or $40^{\circ}$, but varying with every position of the ship's head, and with every change of situation upon the earth, from one pole to the other. This appeared to take place according to laws which bade defiance to every attempt to unravel them.

This local attraction of the vessel had been gradually increasing, at first by small degrees, but afterwards in an angmented ratio, from the period when iron was first employed in considerable quantity in naval equipment; and it was in consequence of this gradual increase that the cause of error remained so long unnoticed. Some obscure allusions to such an effect are recorded by Dampier, Cook, and one or two early French navigators. The cause was first distinctly pointed out by Mr. Downie, a Master in the Royal Navy, in 1794. A few years after this (the amount of iron employed in vessels increasing almost every year), the lamented Captain Flinders noticed the attraction more minutely: he was the first to trace its connection with the dip of the needle, and to point out that the effect was different in quality, on the contrary sides of the magnetic equator, and increasing in quantity, as the dip in either hemisphere increased. The inquiry, however, was again lost sight of, till Mr. Bain published his valuable treatise on the "Variations of the Compass," in which the fatal consequences attending this source of error are placed in so clear a point of view, as to strike the most indifferent and uninformed reader. Subsequently, pig-iron became employed for ballast, the weight of which in some vessels exceeded three hundred tons ; an immense surface of iron was also introduced by the admirable invention of iron-tanks, to supply the place of the old water-casks. Moreover, in the construction of the ships theniselves, the knees, or crooked parts fixing the beams to the sides; the sleepers, or timbers supporting the decks, as the joists in a house support the floors; and even the riders, or interior ribs, are often all made of iron. Hempen cables have also been supplanted by those of iron; and attempts were making, a few years since, to employ 
gun-carriages of the same material. When the late Arctic Expeditions were first in contemplation, the local attraction of the vessels in those seas was one of the objects to which the attention of the officers was particularly directed. The results of the experiments made in these instances, are given by Captains Ross and Parry in the accounts of their respective voyages; and the amount of the disturbing force was found to be such, as to call for some prompt and efficient remedy; the difference of bearing of an object having been found by Captain Sabine to be at least $50^{\circ}$, or nearly $4 \frac{x}{2}$ points of the compass, merely from a change of position of the ship's head from east to west; so that while the compass indicated the vessel to be sailing due east, she might in reality be proceeding due north-east.

It is true that seamen depend very little upon the reckoning by compass, while they can make the requisite astronomical observations; but as it frequently happens that many days may pass without their obtaining such observations, it could not but be of considerable importance to them, in such cases, to possess the means of making the nearest possible approximation to their true place. It is not in the open sea, however, that the compass, at the present time, is of the greatest use; it is in the navigation of narrow channels, in piloting ships by means of charts and bearings, and in marine surveying, that it finds its most valuable application: in these instances nothing can supply the place of the compass, and it was manifestly important, in such cases, that its directive power should be freed from all irregularity. Every reader, whether a nautical man or not, must be aware of the great amount of error, and fatal consequences, which might arise in a few hours to a vessel in the Channel, in a dark and blowing night, having for its only guide a compass subject to an error of $14^{\circ}$ in opposite directions at east and west, (which was actually the case, from the effects of local attraction, with the Griper, when at the Nore,) the very courses on which she would be endeavouring to steer; "and who can say," Mr. Barlow himself observes, "how many of the mysterious wrecks which have taken place in the Channel are to be attributed to this source of error, of which the most recent, that of the Thames, Indiaman, is a serious example. This vessel, besides the usual materials, guns, \&c. had a cargo of more than 400 tons of iron and steel; and it may easily be imagined that such a cargo would produce an effect on the compass at least equal to [that of the iron in] the Griper and Barracouta [another ship on which experiments were made] ; and this alone would be quite sufficient to account for the otherwise unaccountable circumstance, that 
after leaving Beachy Head in sight at 6 o'clock in the evening, the vessel should have been wrecked upon the same spot at 1 or 2 o'clock in the morning, without the least apprehension of being at ail near shore."

Such being the alarming effects of the otherwise greatly improved construction of ships, resulting from the extended use of iron, Mr. Barlow undertonk the investigation of the subject, with the view of correcting the errors thus introduced. At this time, little or nothing was known of the mathematical laws of magnetic attraction, on a knowledge of which, however, it was clear, that the discovery of a method of counteracting the evil would immediately depend.

It had previously been ascertained, indeed, that while a compass needle was placed near the upper end of a bar of iron, the north end was drawn towards the bar, and that near the lower end, the south end of the needle was drawn towards it; and it consequently followed, that there must be some intermediate point in which the effect of both ends was neutralized. It was also known that a large mass of iron had a more powerful attraction than a smaller mass; and that the effect was greater, as the distance between the iron and the compass was less; but no explicit and connected laws governing these effects had been enunciated. To establish such laws was therefore the first object of $\mathrm{Mr}$. Barlow. He ascertained by experiments with a solid iron ball, placing his compass about it in every direction, that by causing the compass to descend in any vertical line from above to below the ball, it always passed through a point in which the iron had no effect upon it. By continuing his researches, he found that all these points were situated in the same plane; which he called, therefore, the plane of no attraction, and that this plane formed with the horizon an angle equal to the complement of the dip of the needle, descending from the north towards the south, whence he called it the magnetic equator. That this ought to be the case when the needle had its natural dipping position, might easily have been foreseen; because then the iron would be symmetrically disposed with respect to the two poles of the needle; that is to say, there would be an equal quantity of iron operating on each pole; but that it should still be the same with the horizontal needle, was a fact as novel to Mr. Barlow at the outset of his inquiries, as it proved to be important in all his subsequent researches. Having traced this circle on his iron ball, and assuming the direction of the dipping needle as a principal axis to it, its extremities forming the north and south poles, he was immediately in possession of an ideal magnetic sphere, by which he might accurately indicate the relative po- 
sition of the iron and the compass in all his future inquiries; and to this happy and philosophical idea he is doubtless indebted for much of the remarkable success, with which his experiments were ultimately attended.

A compass placed in any point of the plane of no attraction, or equator, of this sphere, will be uninfluenced by the iron ball, and will preserve its natural magnetic direction. But as soon as the compass is removed out of this plane, the needle is found to deviate from its original bearing; its south end being drawn towards the ball when the needle is below the plane, and its north end being drawn towards the ball when it is above the plane. And in every case the deviation follows a determinate law, so that the amount being given in any one case, it may be computed for all other cases.

This was an immense step towards the development of the mathematical laws of magnetism, hitherto almost unknown, but it was not all that was required. It was requisite also to know what was the law observed at different distances. Subsequent experiments enabled Mr. Barlow to demonstrate, that while the position, as to latitude and longitude, was the same, the tangent of the deviation was proportional to the cube of the distance; a law, however, which it is unnecessary to my present object to pause in order to explain. Lastly; it remained to be found, when the position and distance were the same, what was the law of deviation, as it depended upon the magnitude of the attracting body. In the pursuit of this inquiry a most unexpected result was obtained. It appeared, in the first place, that the tangent of deviation was proportional to the cube of the diameter, which might naturally be expected in solid balls, being merely a case of the law last stated; but this law was found to obtain also in hollow shells: in fact, the most solid ball was found to be no more than equal in power to a shell of the same dimensions; although even the thickness of the shell should not exceed one-twentieth of an inch. In other words, it was thus ascertained that the magnetic power of masses of iron resides on the surface only. And Mr. Barlow demonstrated, further, in a subsequent series of experiments, that these laws have place not only in balls and shells, but also in masses of iron of all forms and dimensions; the centres of action, in all cases, being referred to two points, (the two magnetic poles,) indefinitely near to each other, in the general centre of attraction of the mass disturbing the compass.

These laws being determined, the application of means indicated by them, to the correction of the local attraction of vessels became equally rapid and certain. To repeat the lan- 
guage of my introductory remarks:-Mr. Barlow, having given a rational form to the laws of magnetic attraction, which thus acquired a basis in his mind, all that remained was to dispose the appropriate species of matter, in an order corresponding to those laws:- Since the action of any mass of iron or system of masses of iron may be referred to two points, indefinitely near to each other, in the general centre of attraction of such mass or system, it followed that, in a ship, all the action might be referred to a fixed point in the vessel, and that the line joining that point and the pivot suspending the needle, would be fixed in position, as regarded the ship, in all parts of the world; and secondly, since the whole magnetic power of iron resides only on the surface, it is easy to procure a plate of that metal, of inconsiderable weight, that shall have, when placed near the compass, an effect upon the needle equal to that of the great mass of iron, or collection of masses, in the vessel, situated at a greater distance; and if also the centre of attraction of this plate be fixed in the line above mentioned, then in whatever direction the vessel is placed, or in whatever part of the world the observation may be made, the plate will always produce a disturbance on the needle equal to that of the ship; so that by obtaining the one by observation, the other, that is, the disturbance produced by the ship, becomes known. Hence, whatever may be the law by which this disturbing power is governed, or whatever may be the dip of the needle or the direction of the ship's head, the plate and the iron of the vessel attract the needle with the same force, both in quantity and in direction, and the one becomes known by the observation made on the effect of the other. The plate is to be fixed at a certain depth and distance in the line of no attraction of the vessel *.

Accordingly, such an instrument, called "Barlow's Correcting-Plate," has been introduced into the service, for the purpose of thus counteracting the local attraction of vessels; and its efficacy having been tried by the most experienced navigators, in every part of the world, it has been found most perfectly to answer this purpose. Few inventions, however perfect in theory, have proved so perfect in practice as this; a result the more remarkable and interesting, on account of the original difficulties of the subject, and the purely philosophical grounds of the practical application.

In this, again, we have an example of what abstract science can effect, indeed of what it has effected, for the advancement

* Edinburgh Philosophical Journal, vol. xi. p. 65 et seq. Ample details of Mr. Barlow's researches will be found in his "Essay on Magnetic Attractions." 
of the arts of life; for every improvement in navigation, especially to an insular people,

"Whose march is o'er the mountain wave,

Whose home iz on the deep,"

tends in a clirect manner to increase the value of every species of manufacture, by facilitating its diffusion over the globe; and indirectly, in ways which are too many and too obvious to admit of or require our particularizing them.

One other example, still more recent in its history, must conclude my present illustrations of the importance of scientific knowledge in the arts. This relates to the improvements which, called for as well as accomplished by Science, have been effected in the manufacture of glass for optical purposes.

Perfect as is the manufacture of glass for all ordinary purposes, and extensive as is the scale upon which its production is carried on, there is yet scarcely any substance of artificial production, in which it is so difficult to unite all the qualities which are required, to satisfy the wants of science, and of those arts which are directly connected with it. The general transparency, hardness, sensibly-unchangeable nature, and varied powers of refracting and dispersing the rays of light, possessed by this substance, render it a most important agent in the hands of the philosopher who is engaged in investigating the nature and properties of light. When, however, he desires to apply it, according to the laws he has discovered, in the construction of perfect instruments, and especially in that of the achromatic telescope, it is found liable to certain imperfections, not essential indeed to its constitution, but almost always arising in its manufacture, which frequently become fatal to its use in such instruments. These imperfections interfere so greatly with the application of the glass, and are so difficult to avoid, that the progress of science is often impeded by them, by the difficulty which arises of constructing perfect instruments of great power. For example: $\mathrm{Mr}$. Dollond, one of our first opticians, has not been able to obtain a disc of flint-glass four inches and a half in diameter, fit for the object-glass of a telescope, within the last five years, or a similar disc five inches in diameter, within the last ten years.

On this account the object-glasses of powerful telescopes not only constitute by far the most expensive part of them, (several hundred pounds and even a greater sum having been paid for a single lens), but render the entire cost of such instruments so high, as to remove them beyond the means of many persons, who are equally desirous, and well qualified, to use them, with success and advantage, in the promotion of science. From the difficulty in the cultivation of astronomy thus 
arising, Mr. P. Barlow has been led to turn his attention to the substitution of fluids for flint-glass, in the construction of large object-glasses; and he has had great success in the use of this most ingenious expedient; though it is probably one which would be immediately abandoned were perfect glass to be obtained. On the same account, the recent acquisition of a lens of flint-glass, of eleven inches in diameter, by the President of the Astronomical Society, (Sir James South,) has created a sensation in the world of science, which those who were unacquainted with the enormous difficulty of obtaining a lens of that magnitude, fit for use in a telescope, would be altogether unprepared to appreciate.

These difficulties have induced some persons to labour hard and earnestly for years together, in the hope of surmounting them. Among them were ingenious manufacturers and workmen, and profound men of science. But the former, however skilful in the practical details of glass-making, were unacquainted with the true causes of the imperfections they were desirous of removing; and it happened that the attention of the latter was directed rather to the obtaining of a stock of perfect glass for present and individual use, than to such an improvement of the manufacture, as would place the acquisition of such glass within the means of all who were qualified to apply it. The result was, that although some perfect glass in large pieces was produced by the late M. Guinand, an ingenious artist of Bâle, and by the late M. Fraunhofer of Munich, an optician, and an original discoverer in optics, of the highest merit; yet the knowledge of the means of producing perfect glass which they acquired, seems to have been altogether practical and personal, a matter of minute experience, and not of a nature to be communicated to others. It is certain, at all events, that down to the end of the year 1829, the public were not in possession of any instructions relative to the method of making homogeneous glass fit for optical purposes, beyond what had been possessed before either M. Fraunhofer, or his ingenious contemporary, had commenced their respective operations; and it seemed doubtful, in this country, (to use the words of a recent writer on the subject, when describing his own researches upon it, to which I shall immediately advert,) whether the meritorious foreigners I have named " ever attained a method of making such glass with certainty and at pleasure, or have left any satisfactory instructions on the subject behind them."

Such, within these few years, were the exigencies of science with respect to the manufacture of glass for optical purposes, and such was the progress which had been made in endea- 
vouring to meet them. A strong desire, however, was excited, that some more efficient means of improvement should be adopted, which the increasing devotion to Astronomy among us, manifested by the institution and prosperity of the Astronomical Society of London, had undoubtedly been mainly instrumental in producing. Accordingly, in 1824, the President (then Sir H. Davy) and Council of the Royal Society, to which body the public interests of science are in a manner committed by the nation, appointed a Committee for the improvement of glass for optical purposes, consisting of Fellows of the Royal Society, and of members of the Board of Longitude, an official body afterwards dissolved by Government. Experiments were accordingly made under the direction of this Committee, and as it soon appeared that they would require to be pursued unremittingly for a long period, in the following year a SubCommittee was appointed, to whom the direct superintendance and performance of experiments were entrusted. This Committee consisted of $\mathrm{Mr}$. Herschel, the son of the late astronomer of that name; Mr. Dollond; and Mr. Faraday, the Director of the Laboratory of the Royal Institution, whose duty it became to investigate particularly the chemical part of the inquiry; for which, certainly, no chemist in this country, and perhaps no one in Europe, could be more adequate. Early in 1829, Mr. Herschel retired from the Committee, when about proceeding to the Continent. 'The requisite chemical experiments were conducted entirely by Mr. Faraday; and since the month of September, 1827, at that scientific establishment, the Royal Institution, which has been distinguished, successively, by the discoveries, or important researches, of Sir H. Davy, and Mr. Brande, and of late years by those of Mr. Faraday himself. In order to convey an adequate idea of the improvements in the manufacture of glass for optical purposes which have been effected by the Sub-Committee I have named, and-so far as the direct application of chemistry is concerned-by the knowledge, the skill, and the ingenuity in the arrangement and combination of instruments and agents, of Mr. Faraday, I shall briefly describe those characters of ordinary glass, which interfere with its successful application to the more delicate purposes of optical and astronomical science.

The general properties of transparency, hardness, and a certain degree of refractive and dispersive power, which render glass so valuable as an optical agent, are easily obtained; but there is one condition, essential in all delicate cases of its application, which is not so readily fulfilled; to obtain, namely, a perfectly homogeneous composition and structure. Although every part of the glass may in itself be as good as possible, 
yet, unless it be of uniform constitution, the parts do not act in conformity with each other; the rays of light are deflected from the course they ought to pursue, in passing through it, and the piece of glass becomes useless. The streaks, strix, veins, or tails, which are seen within glass otherwise perfectly good, result from a want of this uniformity of constitution: they are visible only because they bend the rays of light which pass through them from their original rectilinear course, and they do this because they consist of a glass having either a greater or a smaller refractive power than the neighbouring parts.

The effect of these irregularities being so powerful, when observed only by the naked eye, it may easily be supposed to what an injurious extent their influence must extend, in the construction of telescopes, and instruments of a similar nature. For in such instruments the faults I have described are not only magnified many times, but the effect is to give an erroneous representation of the object viewed, with the error equally magnified; when the very point which the observer is desirous of attaining (and which it is necessary he should attain before science can be promoted by his means) is to examine that object with the utmost accuracy. It is accordingly found that these striæ are the most fatal faults of glass intended for optical purposes.

The improvement required by science, it must be remembered, is not merely an improvement upon the success ordinarily attained in producing glass in some measure fit for optical purposes; it is the attainment, with respect to the constitution of the glass, of absolute perfection, - to obtain glass as homogeneous and uniform in its nature as pure water, in which every particle shall possess the same refractive power, and the same relations to light in general.

Now the striæ, and the fainter differences of texture which affect the utility of the glass, are not owing to impurity in its composition. The glass, either of the streak or of the neighbouring parts, would be equally good for optical purposes, were it all alike. It is the irregularity which constitutes the fault; and hence, with respect to the existence or non-existence of striæ, a particular composition is of very little importance. As glass is always the result of a mixture of materials which have different refractive and dispersive powers, and which retain those different powers when melted, it is evident that striæ must exist at some period during its preparation. Mr. Faraday, therefore, was not required so much to invent a glass differing in composition fiom ordinary glass, or to produce one by combining the constituents of ordinary glass accurately in those proportions which are found, by analysis, to 
exist in specimens of tried and acknowlerged good glass, " as to devise and perfect a process," to nse his own words, "by which the striæ period should be passed over before the glass is finished, and the formation of fresh strice be prevented." Now what is called fint-glass is at once the most useful for optical purposes, and the most difficult to be obtained in a homogeneous state. The oxide of lead, which enters largely into its composition, and which is essential to its value for optical purposes, has properties of its own, and also confers properties on the glass, which are very conducive to the formation of striæ. Hence, in the manufacture of this glass, it is required that the mixture of the materials shall be far more perfect, than in that of other kinds of glass, such as plate- and crown-glass, which do not contain oxide of lead; and yet it unfortunately happens that everything tends to make it much less so. The oxide of lead being very heavy, and at the same time very easily melted, when heat is applied to the mixture it melts and sinks to the bottom, leaving the lighter materials to accumulate at the top. Its own powerful action on light, which renders the refractive and dispersive powers of the glass so great, is so different from that of the other materials, that the variation in composition thus caused by its weight, immediately becomes evident, and in becoming evident it becomes mischievous; - the action of the glass upon light ceases to be uniform. The oxide of lead also, uniting qualities at once so useful and so injurious, imparts to the glass the property of dissolving earthy matters from the crucible or melting-pot in which it is made, occasioning also by this means that very irregularity in composition which produces striæ; " whilst the comparative levity of the matter dissolved at the sides and bottom, and the ascending currents at the hottest parts of the crucible, are constantly mixing this deteriorating portion with the general mass."

The difficulties which are thus introduced into the manufacture of flint-glass fit for optical purposes, compelled the Sub-Committee of the Royal Society to consider the possibility of making glasses perfectly distinct from those ordinarily in use, which, at the same time that they possessed the high dispersive power enabling them to replace flint-glass, might also have such fusibility as would allow of their being perfectly stirred and mixed, and might be retained, without alteration, in such vessels as could be procured of any desired size.

The borate of lead, formed by the union of the acid of borax with the oxide of lead, and the same metallic salt chemically combined with silica or the pure earth of flints, were the substances which, after some trials, were found to offer such rea- 
sonable hopes of success as to justify a persevering series of experiments. The metal platinum, on account of its infusibility and inalterability by heat, its resistance to solvent action, and the readiness with which thin plates of it might be made to assume any desired form, was looked to as the material from which the vessels intended to be used might be fabricated. It was soon ascertained that a range of proportions between the three ingredients boracic acid, silica, and protoxide of lead was permissible, which gave much command. over the properties of hardness, colour, weight, refractive and dispersive power, \&c., and yet remained within the required range of fusibility. Platinum, also, was ultimately found to answer perfectly the purpose of retaining the fluid glass; for though at first it was continually liable to failure, yet it was eventually ascertained that neither the glass itself, nor any of the substances entering into its composition, separate or mixed, had the slightest action upon it. "Finally," observes Mr. Faraday, "it was found that several kinds of glass formed of these materials, were in their physical properties fitted to replace flint-glass in the construction of telescopes, in some cases apparently even with advantage; since which time the experiments have been unremittingly pursued." To detail, or even to enumerate, the various expedients, characterized equally by science and by ingenuity, which were adopted by Mr. Faraday in the manufacture of this new species of glass, would far exceed the prescribed limits of the present section of this menoir. It is requisite to state, however, that he has principally worked with a silicated borate of lead, consisting of silica, the acid of borax, and protoxide of lead or litharge. The materials are first purified, then mixed, fused, and made into a rough glass, which is afterwards finished, and annealed, (or allowed to acquire a regular and uniform tension of its parts, by slow cooling, ) in a tray of platinum*.

* The composition of this " heavy optical glass," as it is called by Mr. Faraday, is accurately as follows, by weight:

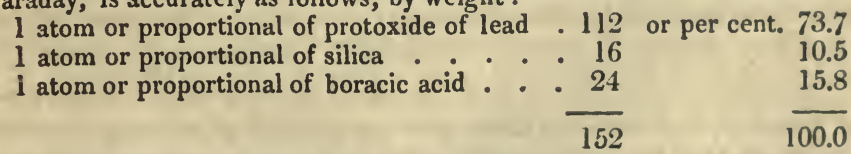

For the purpose of giving a familiar explanation of the subject, litharge has been mentioned above, as the form in which the oxide of lead is employed in the preparation of this glass. But in order to avoid the possible result of misleading any one who might be induced to make any provisional experiments on the subject, from the perusal of these remarks, it may be useful to state, that Mr. Faraday was obliged to abandon the use of litharge, as well as that of red-lead, on account of the particles of metallic lead contained in the former, and of the impurities existing in both. He found it necessary 
By these means Mr. Faraday has prepared homogeneous plates of heavy optical glass seven inches square and eight pounds in weight; he can thus at pleasure obtain, and he has placed it within the power of others to obtain, with equal certainty, a glass perfectly frec from stria, unexceptionable in hardness, and having less colour than the crown-glass constantly used in the construction of telescopes: "but it is," he observes, "the simultaneous absence of all striæ and bubbles, with at the same time that degree of hardness and colour which will render the glass fit for optical purposes, that I am aiming at, and that I trust shortly to obtain*."

Unlike the cases before recited of the inmportant benefits conferred upon the cultivators of the useful arts by scientific knowledge, the manufacture of the new species of glass is not yet complete. Glass has been made, and telescopes have been manufactured with it; still greater improvements however will undoubtedly be effected; and much more time must be expected to elapse before the investigation can be considered as finished; - but a decided step has been gained, directly by the resources of science, in the manufacture of glass for optical purposes.

In this case it may be observed, as in that of the invention of Mr. Barlow's Correcting-Plate, that what was beyond the power of the arts and their professors to effect, has been ac-

to purify the oxide of lead by converting litharge into a nitrate, and subjecting it repeatedly to crystallization. This salt was then used in making the glass ; 166 parts being used for every 112 parts of oxide required to form the glass.

* Nearly all the information contained in the above sketch of the recent improvement in the manufacture of glass for optical purposes, has been derived from $\mathrm{Mr}$. Faraday's Bakerian Lecture on that subject, published in the Philosophical Transactions of the Royal Society for 1830), Part I. In this paper are given full and efficient instructions to those who may desire to manufacture optical glass. The inquiry, it will be remembered, was undertaken solely for the interests of science, which are the interests, in a certain respect, of mankind at large, and its results, so far as it has yet proceeded, have been made public accordingly. In agreement with this design, it is stated in the Bakerian Lecture, that down to the period of its communication to the Royal Society, "The attention [of Mr. Faraday and his colleagues] has been devoted, as it still must be for a while, to the establishment of a process, which, competent to produce with certainty a glass fitted for optical purposes, may have the philosophy and practice of every part so fully ascertained, as to be capable of description in a manner sufticiently clear to enable any other person, with moderate care, to obtain the same results without the labour of long and tedious investigation."

But although the information above given has been derived from $\mathrm{Mr}$. Faraday's Bakerian Lecture, it has been so materially altered by abbreviations and in arrangement, that that gentleman must not be considered accountable for any statements I have given, but those which are distinguished by quotation marks, unless they shall be verified by reference to the Bakerian Lecture. 
complished by the application of pure science. Guinand the artizan, and Fraunhofer the optician, both of whom must have depended for success, as it would appear, on circumstances in the production of flint-glass, which can very rarely happen, or which can produce but a very small quantity of perfect glass, when a very large one is formed of that substance, in its ordinary state, succeeded in manufacturing only a small stock of the material of which they were in search. The mere manufacturer, upon the large scale, unenlightened by chemical knowledge, could never have arrived at a competent insight into the causes which produce striæ, and which apparently must continue to produce them, in flint-glass. The chemist alone could have devised and executed the production of a new kind of glass, the constitution of which, as a chemical combination, will enable the manufacturer partly to avoid the causes of striæ, and partly to remove them when formed.

The utility of imparting a knowledge of Chemistry and Natural Philosophy to youth, when destined to take an active share in manufacturing business, may perhaps appear in a stronger light, from the details just given, than from any others which I have yet offered. Mr. Faraday has described the process by which he has obtained a homogeneous glass, with the utmost clearness and perspicuity; he has enabled any other person, who shall accurately and minutely follow his instructions, to do what has been done at the Royal Institution, without incurring the laborious prefatory experiments and investigations which the "Glass Committee" have had to undertake. But it would be impossible for a glass-maker, unacquainted with chemistry, to follow these instructions; the oxide of lead is to be purified, the purity of the boracic acid is to be ascertained; in all probability the silica also will require purification; all which are strictly chemical processes. And even if the maker of optical glass could rely upon the chemical manufacturer for these articles, the process itself requires the possession of some degree of chemical knowledge for its successful performance; and especialiy to enable the conductor of it to apply the principles and general rules of practice laid down by Mr. Faraday, to the particular exigencies of his own operations. The minute holes which often exist in the platinum vessels employed, are to be closed by little patches of that metal soldered with gold; an oxygenating atmosphere must be maintained about the glass, while remaining fused in the finishing furnace; the current of fresh air supplying this atmosphere must first be cleansed from dust and soot, by passing close to the surface of acid or saline solutions, or else striæ will be formed in the glass; and many more 
precautions are necessary, requiring chemical knowledge justly to appreciate and provide for, and chemical skill effectually to take. A demand for this glass will certainly be created, eventually, giving new scope for the employment of capital, and new means for the acquisition of wealth; but to the profitable investment of this capital, and the secure acquisition of this wealth, some degree of scientific knowledge will be indispensable.

Many more instances might be pointed out, in which the refinements of modern civilization are producing or tending rapidly to produce, New Manufactures;-new applications of the powers and materials of nature, - suggested and first executed by science, - to the physical and intellectual wants of mankind. 'The inventors or discoverers of these new articles, it is certain, will in few cases become the manufacturers of them : their duties in society are of a different kind; when the means of producing the desired articles have been attained, and the new facts of science connected with the production of them developed, and systematically united with the Knowledge of Nature previously existing, the subject will cease to be specifically interesting to them, and will be regarded merely as a part of the science which may have been concerned in it. Hence, in almost all such cases, a new department of industry will be opened for those destined to engage in business; to success in which, however, as just intimated, with respect to the manufacture of optical glass, some portion of the philosophical knowledge of Nature will be essential.

I must now proceed to offer some arguments and illustrations towards evincing the utility of a knowledge of Nature in the conduct of the ordinary affairs of life, whether affecting the welfare of individuals or that of society in general ; and in which the tradesman, the merchant, the soldier, the agriculturist, and the nobleman, may possess either a common, or a particular interest.

The argument derived from the obvious supremacy over the other subjects of creative benevolence and wisdom, which the rational faculties of Man confer upon him, is nearly as available in the present case, as we have found it to be, in supporting the position of the intrinsic value of the Physical Sciences, in strengthening and expanding the intellect. The world of nature is manifestly designed to be subservient to human life, in all its degrees and relations; this is as much the case, or even in a greater degree so, with respect to the requirements of mere healthy existence and the innumerable minor concerns of every-day life, than it is with respect to the articles which man extracts from nature, and adapts by labour to his 
necessities or his enjoyments. The mixture of two gases having opposite properties, which forms the atmosphere, is essential to conscious natural existence; the chemical combination of one of these gases with a third aëriform body forms the water without the presence of which that atmosphere would be irrespirable, and the human body an inert mass : an affection of matter perpetually excited by the sum, aud adapted to reception in our visual organs, is the means by which the forms and colours, and through them the distances and magnitudes, of created objects are made known to our delighted perceptions.

To be acquainted with this world of nature must therefore be essential to human happiness. Man does not possess the instinctive perceptions of the brute creation, which would have been incompatible with that analytical thought, by the exercise of which he acquires his noblest distinctions. He must obtain a rational knowledge of the beings which are subject to his use, and of those, also, which, when uncontrouled, are destructive of his comfort. And in fact the stock of knowledge which every one, from the infant savage to the hoary chief of the tribe, and from the unlettered peasant to the profound philosopher, insensibly acquires, for self-protection, and as a ground for the acquisition of knowledge of higher importance, is of this kind. It is a part of the Knowledge of Nature. The knowledge which leads man to refrain from contact with fire, and from precipitating himself into the waters; that which induces him to screen himself from the wind by the erection of a wall, and to keep off the rain by extending a roof from that wall;all this is a part of the knowledge of nature.

But it is not this degree only of acquaintance with natural things, which is required by man, when arrived at a state of refined existence. It then becomes necessary, not merely for his happiness as a refined being, but for his very existence in that state, that he should acquire a knowledge of the intimate nature and properties, not only of the objects of creation immediately surrounding or affecting him, but of those also which are remote and beyond his direct controul ; and in proportion to his advancement in Civilization will be the extent and the elevation of the "Knowledge" he will be required to possess, and to wield as "Power" over the boundless domain which has been committed to his authority.

To proceed, however, from argument to illustration. The preservation of life is the first object with every man. But he may be deprived of life, - to review but a minute fraction of the sources of that deprivation which surround him,-either when inhaling "the vital air,"-by a noxious quality imparted to it by another gaseous substance, in undue quantity; by 
assuaging his thirst with an apparently refreshing draught; or when satisfying his hunger, or gratifying his palate, with seemingly the most innocent and grateful viands. To the action of Poisons, whether aëriform, liquid, or solid, his life may become a sacrifice. How is he to avoid this danger? or how, when he has incurred it, and is beginning to suffer from its cause, is he to be preserved from the fatal termination of its influence? The answer is, - by the knowledge previously acquired of the nature of poisons, and the means of administering antidotes to them, or otherwise counteracting their effects. And this knowledge must be sought by means of many departments of Physical Science: chemistry, natural history, anatomy, and medicine must each furnish their contributions, before the nature and mode of action of the poison can be understood; and these points must be known before any effectual antidote or remedy can be applied. Accordingly, such a knowledge of many poisons has been acquired, and so great is its extent, that it constitutes a distinct object of pursuit, among the cultivators of the medical sciences, under the name of Toxicology; and M. Orfila, in France, and Dr. Christison in our own country, may be named as men of science devoted to this branch of philosophical inquiry. Many volumes have been published on the history of poisons, of which the works of these Professors are the latest, and perhaps the most valuable.

It is not to be understood from this representation, that I intend to infer that every man should become a Toxicologist. I have merely offered the foregoing statement to prove how important and how necessary is the knowledge of poisons to mankind; and to enforce the propriety of the acquisition, by every man, of some degree of information with subjects of this kind. How often do we hear of the death of labourers and servants, by suffocation, in consequence of their descending incautiously into old wells and pits long secluded from the atmosphere. A slight knowledge of chemistry would have preserved their lives, by teaching them, first, that a species of air destructive of life (carbonic acid gas) is almost always evolved in such situations; and, secondly, that whenever present, it may be entirely removed by a few pailfuls of a mixture of quicklime and water, thrown into the pit; or even still more simply, though not with so much certainty, by the agitation produced by pouring down a quantity of water alone. This science also would have taught them, that the air which is unfit for respiration will not allow a candle to burn in it; and the simple expedient of letting down a lighted candle attached to a cord, would have detected the presence of the noxious gas in the first instance, and ascertained whether it had been entirely 
removed, or not, when means for that purpose had been adopted.

Within these few years many valuable lives have been lost, by Oxalic Acid having been mistaken for Epsom salts (sulphate of magnesia), and administered as a medicine instead of them. This acid scarcely exists in nature, in an active state; but the refinements of Civilization, while they apply so many natural objects to the increase of human enjoyment, require, as means, the use of many deleterious substances, some extracted from nature, others, as is usually the case with oxalic acid, produced by art. These facts, again, evince that general refinement and general scientific knowledge, should be commensurate. The science of Chemistry here also offers a means of detection and an antidote. All the powerful acids, and oxalic acid is one of them, have the power of expelling carbonic acid from its combinations, the bases of those combinations uniting, as it were by preference, with the stronger acid. If there be any doubt, therefore, whether the white salt which has been purchased or found among medicines, and part of which may have been taken as medicine, be Epsom salts or oxalic acid, let it be stirred up in water, or still better dissolved in hot water. Then let some powdered chalk (identical, in a chemical point of view, with the lime which has absorbed the noxious gas from the suffocating well) or whiting be mixed with it. If it be oxalic acid, the mixture will immediately froth up, with a hissing noise, both occasioned by the escape of carbonic acid gas; if no such effect is produced, it certainly is not oxalic acid.

In this manner may an acquaintance with the facts of chemical science either relieve the mind from agonizing apprehension, or confirm the necessity of procuring medical assistance for the preservation of life. The same science, should oxalic acid really have been taken into the stomach, will furnish an antidote, in the very substance employed to detect the poison. The poisonous action of the powerful acids arises from their corrosive effects on the coats of the stomach; when united with bases into salts, they lose their peculiar properties, and the corrosive one among them. The oxalic acid thus loses its corrosive power by combining with the lime of the chalk, with which it forms an inert and harmless substance, the oxalate of lime. The carbonic acid gas which it expels from the chalk, though fatal when respired - when taken into the lungs-is harmless in the stomach. If, therefore, chalk or whiting, mixed with water, be administered to the party who has swallowed oxalic acid, before the poison has had time to exert its destructive effects, those effects may be prevented, and life preserved.

It may be alleged that such useful facts as these may be 
borne in mind, and applied, should occasion arise, without the necessity of any scientific knowledge of chemistry being acquired. This may in some degree be true, but it is far more probable, as the experience of many will testify, that if they are learned merely as insulated facts, unconnected with a definite system of similar facts, they will not be remembered. While, on the other hand, a person who has acquired an outline of the leading facts of chemical science, cannot fail to be prepared to meet the necessity we have supposed. It would only be a portion of his system of knowledge, that oxalic acid might be distinguished from Epsom salts by observing its action upon chalk; and another portion of that system, that the same substance is an antidote to the poison. A person unacquainted with chemistry might readily forget these facts; while to the mind of one who had been instructed in that science, they would always be present and always available on necessity.

The foregoing are a few among many cases that might be cited, of the utility of natural knowledge in the preservation of human life. We will now direct our attention to some of those concerns which involve the acquisition and preservation of the means of life ; in trade and the sale of natural property, in commerce, and in war.

Vast sums of money have been expended in our own country and in others, and great disappointment and chagrin excited, by fruitless endeavours to discover mineral coal in situations where even a superficial knowledge of the structure of the earth's crust, as explained by Geologists, would have shown it could not possibly occur. Many of the strata of stone, of clay, and of sand, constituting the geological formations which appear to be of comparatively recent origin, occasionally include substances externally resembling coal, derived from vegetable matter by the agency of water and of chemical affinities, modified by compression and the contact of earthy bodies. The accidental discovery or exposure of these, has led to the supposition that they were connected with beds of true coal, such as those of Newcastle or of Staffordshire, existing still deeper in the earth; and the immense utility of that mineral, together with the value it confers upon estates from which it can be raised, and the importance it gives to the surrounding country, have induced the proprietors of the land to commence expensive, and sometimes ruinous operations in search of it. A few thin beds of some of the imperfect carbonaceous substances I have mentioned, or of slaty clay containing bituminous matter, have occasionally been met with, in the progress of these searches; and being, as at first, con- 
founded with indications of true coal, the futile mining has been continued, until stopped by the increasing charge, or by the acquisition, at an enormous price, of that knowledge of the non-existence of coal in such situations, which might have been obtained by a few days' study of Geology, or which some early instruction in the principal facts of that science, would have impressed, indelibly, upon the mind. Now among the geological formations which are developed in Great Britain, there are at most two only which include beds of this mineral that can be worked with commercial advantage. One of these is the Great Coal-Formation, situated between the two series of strata called by geologists, respectively, the New Red Sandstone and the Old Red Sandstone; the other is the lower division of the assemblage of clays, sands, and free-stones, called the Oolitic series; which lies above the new red sandstone, and consequently is much higher in the series of strata than the great repository of coal just mentioned. The coal-field of the Eastern Moorlands of Yorkshire, and that of Brora* in Scotland, belong to the latter formation; but it is the former on which the manufacturing industry of this island principally rests ; the coal-fields of the midland counties of England, of Northumberland and Durham, of Cumberland, and the principal coal-fields of Scotland, are situated exclusively in it. I have mentioned the deposits of coal in the Oolitic series, in order to be philosophically correct in my statement on the subject ; but in a commercial point of view they are insignificant; and although the beds in Eastern Yorkshire have long been known, an eminent geologist, after enumerating the various positions in the earth in which carbonaceous matter occurs, so lately as the year 1822, thought it necessary to conclude with the following explicit caution :-

"In thus stating the occasional occurrence of carbonaceous beds in other formations, [than the Great Coal-Formation above mentioned, ] it is necessary carefully to guard against the error of supposing that any supplies of this mineral, capable of being profitably worked, are to be found anywhere without the limits of the coal-district of which we are now treating; an error that has led to much waste of capital in fruitless speculation. The local deposits above mentioned [those of the plastic clay, the Oolites, \&c.] are objects of Geological curiosity, not of statistical interest.$+ "$

- For the authenticated knowledge of the true geological position of the Brora coal, we are indebted to Mr. Murchison, to whose extensive researches in Geology much of our present improved acquaintance with the more recent regular strata is due :- - see Transactions of Geological Society, Second Series, Vol. ii. pp. 293, 353.

$\uparrow$ Conybeare : "Outlines of the Geology of England and Wales," p. 329. 
Three years only have elapsed, since a circumstance occurred, to myself, which strongly impressed my mind with the utility of geological information to landed proprietors, in relation to this very subject. In the course of a geological examination of the Brill hills in Buckinghamshire, which are composed of strata belonging to the upper oolitic system, capped by the iron-sand, a still more recent deposit, I was surprised, when descending the hill on which is situated the village giving name to the entire group, towards a chalybeate spring which rises in the vale separating that from the neighbouring eminence of Dorton Camp, to observe a shaft, which had been sunk into the hill-side, and the heaps of clay, \&c. that had been raised from it, together with the remains of the whim or horse-windlass used for drawing them up. I was informed by an inhabitant of Brill, practically well acquainted with the geology of this chain, and with the mineral substances it affords, that an attempt to discover coal had been made in this spot, and that the shaft before me had been sunk to the depth of 116 feet, but that nothing more than bituminous shale (slaty clay impregnated with mineral pitch) had been found. This result a Geologist would immediately have anticipated; and my own examination of the strata in the vicinity, though I met with nothing previously unknown to science, rendered it stil! more surprising that true coal should ever have been expected to be discovered in them. What rendered the case more striking was the circumstance, which I also learned on the spot, that the same person who had conducted this unprofitable attempt, had also conducted two others, at Sunning Well near Oxford, and at Bagley Wood, near Farringdon in Berkshire; -in all three instances in the same stratum, (the Kimmeridge Clay of Geologists, ) and, in all, at the expense of the proprietors of the land*. I shall now quit the subject with the simple remark, that in every case of this description which I have mentioned or alluded-to, the expense, the mortification, and all the other evils inseparable from an abortive attempt to obtain a valuable material, would have been avoided, had those who were legitimately interested in them, possessed some definite acquaintance with the Geology of the British Islands $\%$.

- The latter two of these attempts are mentioned by Mr. Conybeare, " Outlines," p. 178.

+ Should this memoir fall into the hands of any persons who may be about to institute researches for coal, in consequence of having observed the supposed indications of its existence alluded to in the text, an additional caution may be found useful, which will also serve to show, that the knowledge required, in order to avoid being misled into operations so expensive and so unavailing, can be communicated only by instruction in the science of Geology.

Geologists and chemists have informed us, that every species of bi- 


\section{The departments of Natural History to which that term, popularly, is more particularly applied-those of Botany and}

tuminous or flaming coal (and probably also some kinds of coal that do not flame) has been derived from vegetable matter, the chemical elements of which have been caused to assume a new arrangement, while its organic structure has been obliterated, by the slow operation of chemical affinities, after the deposition upon it of the earthy matter, now forming the shales and sandstones, with which the beds of coal are interstratified.

It might be supposed from this, - and the supposition, theoretically, would not be unresisonable, - that the occurrence of imperfectly bituminized substances (such as bituminous wood, jet, \&c.) must often indicate the proximity, perhaps at a greater depth in the earth, of coal, resulting from the perfect bituninization of similar deposits of vegetable matter. But a more extensive acquaintance with the facts discovered by Geology, would show this supposition to be fallacious ; for it appears, almost universally, that the occurrence of lignite, or bituminized wood, even when the process towards converting it into coal has proceeded so far as to obliterate the ligneous texture, is in fact an indication that no true coal will be found in the vicinity, or, at least, in the same formation; while, on the other hand, wherever the latter mineral is found, the lignites are absent. This latter fact may be readily accounted for, by a more perfect theory; for since coal is the result of the completion of that process, by the operation of which, to a limited extent, the conversion of vegetable matter into lignite is effected, the inference is obvious, that the latter will not be found, under circumstances which have been adequate to the production of the former, by the completion of the same process. The fact itself is of such universal prevalence, in this country at least, that, as Mr. Winch has shown, (Ann. of Phil. vol. xi. p. 68, while the petrified trunks of trees found in the Whitby Alum-Shale, which is the equivalent to the lias forming in other localities the lowest member of the Oolitic system, have their bark converted into jet, (the most highly mineralized of all the lignites;) those which occur in the sandstones of the Great Coal-formation, have their bark changed into common or true coal.

Some part of the coal of Brora and Eastern Yorkshire appears to form the only exception to this rule. The bulk of this coal, though worked in both localities, and in the latter to an extent comparatively great, is a highly mineralized lignite. But "it may be considered," Mr. Murchison observes, in the paper quoted in a former note, "one of the last links between lignites and true coal, approaching very nearly in character to jet, though less tenacious than that mineral ;" and he also states, as might have been expected from these characters, that in some places it is indistinguishable, either chemically or mineralogically, from ordinary coal.

This exception, however, like the coal-deposits which afford it, is important merely in a philosophical point of view ; for it is, as we have seen, a portion only of this combustible, - the whole of which is insignificant in statistical value, - that assumes the character of true coal.

With respect to the British Islands then, the practical rule appears to be valid, that wherever imperfect coal or lignite is found, perfect or true coal does not occur.

In illustration of this rule may be mentioned the celebrated deposit of lignite, at Bovey Heathfield, in Devonshire, the lower beds of which closely resemble, in appearance, common coal; while the entire aspect of the formation is that of a miniature coal-field. Here the strata have been bored through to the depth of two hundred feet, in search of coal, nothing however but clay having been met with, below the known beds of lignite; 
Zoology, will also furnish evidence of the utility of the Physical Sciences in the conduct of the ordinary affairs of life.

Nothing is of more vital importance to us, as Britons, than the welfare of our Naval force; in this every one is interested, and many, as growers of the timber employed in its construction, builders of the ships, manufacturers of the articles used in their equipment, or officers entrusted with their command, are deeply and immediately concerned in it. Some facts have recently come to light, pointing out the true cause of the evils apparently arising from a deterioration in the quality of the timber of which the ships in the Royal Navy have of late been constructed, the occurrence of which a little Botanical knowledge would have precluded. There are in England two distinct species of Oak, the Quercus Robur of Linnæus and of Botanists in general, and the Quercus sessiliflora. The former of these trees, which is the true British Oak, affords a closegrained, firm, solid timber, rarely subject to rot; the other a more loose and sappy timber, very liable to rot, and not half so durable. The latter species is supposed to have been introduced, some two or three ages ago, from the continent, where the oaks chiefly belong to it, especially in the German forests, the timber of which is known to be worthless.

The fact of the existence in our plantations of these two species of Oak, differing so considerably in value, has long been known to Botanists. It was noticed so early as the time of Ray-above a century ago, and Martyn, in his Flora Rustica, as well as the late President of the Linnæan Society, Sir James E. Smith, in his Flora Britannica, have added their testimonies to the fact. Our planters and purveyors of timber, however, appear to have had no suspicion of it; for "the impos-

and the entire geological history of the formation, as well as that of the surrounding country evinces the non-existence of coal in the vicinity.

How far the same rule may be practically applicable to the continent of Europe, remains to be ascertained. In consequence of the paucity of deposits of true coal, beds of lignite, \&c., which, in Great Britain, would be merely of very limited local interest, are, in many countries, objects of commercial importance. In some places, also, true coal occurs, sometimes in beds of great thickness, in certain formations, (on account, as it would appear from the researches of Messrs. Murchison, Sedgwick, and Lyell, of the prodigious scale on which they are developed,) the equivalents of which, in the British Islands, contain merely some insignificant layers of lignite. See Proceedings of Geol. Soc.; or Phil. Mag. \& Annals, N. S. vol. vi. p. 137, and vol. vii. p. 50, and 359 ; \&c.

All the lignites, it may be added, assume, when pulverized, a red or brown ferruginous tinge, while true coal works into a black powder; and, when burnt, the former exhale, in a greater or less degree, a vegetable odour, which is not emitted by the latter in combustion, being peculiar to the imperfectly bituminized substances. 
tor abounds, and is propagated vigorously in the New Forest and other parts of Hampshire, in Norfolk, and the northern counties, and about London; and there is but too much reason to believe that the numerous complaints that were heard about our ships being infested with what was called, improperly enough, dry-rot, were owing to the introduction of this species of oak into the naval dock-yards, where, we understand," observes a writer in the Quarterly Review, " the distinction was not even suspected." Here again a scientific knowledge of the subjects connected with the profession of the planters, and other parties concerned in this supply of spurious oak to our shipwrights, would have prevented the mischief. The science of Botany teaches that the Quercus sessiliflora may be distinguished from the Quercus Robur, the true Naval Oak, by the following characters: "The acorn stalks of the Robur are long, and its leaves short; whereas the Sessiliflora has the acorn stalks short, and the leaves long: the acorns of the former grow singly, or seldom two on the same footstalk; those of the latter in clusters of two or three, close to the stem of the branch*."

A striking train of instances in which the importance of Entomological knowledge is displayed-of that science, the study of which has of late years furnished results so important in the progress of Natural History,-may be shown in the history of those insects, which, in their larva or grub state, attack and destroy the trees of the forest. To employ, with some slight modification, the language of a distinguished Entomologist, whose attention, some years since, was officially called to the subject by Government, so little attention has hitherto been paid to the causes of disease in trees, that few persons ever think of attributing it to any other origin than one entirely vegetable, or, in other words, to the constitution of the plants themselves. Yet in every case, perhaps, in which the disease is infectious, and particularly where it is confined, in a plantation or forest, to the individuals of one species of tree,as to the Elms, or to the Oaks, - we may pronounce with certainty that it proceeds from the attacks of some insect. Every species of tree,-nay indeed every species of plant,_-seems to have one or more species of insect destined by nature to feed

- It is proper to observe that I make these statements, so far as the use of the timber of the Quercus sessiliflora in the Royal Navy is concerned, entirely upon the authority of the Quarterly Review, (Vol. xxxix. p. 22.) as quoted in the Library of Entertaining Knowledge ; Timber Trees, p. 6-7.

The Quercus Robur is figured and described in Sowerby's English Botany, vol. xix. tab. 1342; and the Qu. sessiliflora, in vol. xxvi. tab. 1845, of the same work. 
upon it; and when, from the combination of various causes, (such, for instance, as the weakness of vegetation in a particular air or soil, inattention to the evil at the proper time for effectually checking it, \&c.,) the number of insects which attack trees becomes increased beyond its due limit, we must either apply the axe without scruple to the seat of the disease, or make up our minds to submit to the utter destruction of our plantations.

Almost all timber-eating insects are comprised in three orders: viz. Coleoptera, or beetles; Lepidoptera, or moths, butterflies, \&c., and Hymenoptera, or bees, wasps, \&c. All these, in their youngest state, after leaving the egg, are worms or larvæ, and it is while they are in this stage of their life that they commit the direct injury to the trees, either by gnawing off the bark, or by devouring the wood. The communication of the disease to other trees is periodical; for when the worms or larvæ just mentioned arrive at their perfect or winged state-become butterflies, or beetles, or wasps, \&c., the mischief $d i$ rectly committed by them is comparatively trifling, and generally results, in fact, not so much from their voracity, as from their attempts to extricate themselves, and to arrive at the external air; or from their endeavours to commit their eggs to a proper nidus, or situation, and surrounding materials, proper for the vivification and support of the larvæ to be hatched from them. But as the insects are now winged, and are capable of depositing myriads of eggs, - the germs of as many devouring larvæ, the disease is thus dispersed throughout the neighbourhood of the tree originally infected.

From this general view of the subject, let us proceed to notice some of the ravages which insects have committed upon timber-trees.

The Pine forests of Germany have at various times sustained enormous injury from the attacks of a small Beetle, belonging to the genus Bostrichus, and named by naturalists the Bostrichus Typographus (Fab.) or Printer Bostrichus, on account of a fancied resemblance between the paths which it erodes in the trees, and rows of letters. This insect, in its preparatory or larva state, feeds upon the soft inner bark only of the trees; but it attacks this important part in such vast numbers, no fewer than eighty thousand larvæ being sometimes found in a single tree, that it is very far more noxious than any of those insects which bore into the wood itself; and such is its tenacity of life, that though the bark be battered, and the trec plunged into water, or exposed to a freezing temperature by being laid upon the ice or the snow, it remains alive and unhurt. The leaves of the trees infested 
by it first become yellow, the trees themselves then die at the top, and soon perish entirely. The ravages of this insect have long been known in Germany under the name of Wurm trökniss (decay caused by worms); and in the old liturgies of that country the Divine interposition to check its ravages is formally besought; it being mentioned in them under its vulgar appellation of " the Turk," a name bestowed upon it, probably, in allusion to the devastations which had before been committed in Hungary, and the adjacent eastern countries of Europe, by the Mohammedan conquerors of Constantinople : the application of that name to this species of decay is a circumstance which in itself sufficiently evinces the extent of its ravages, and the apprehensions entertained of them.

This pest was particularly prevalent, and caused incalculable mischief, about the year 1665 . In the beginning of the last century it again showed itself in the Hartz forests-it reappeared in 1757, redoubled its injuries in 1769; again appeared in 1780, and was neglected, and in three years afterwards had destroyed whole forests; the number of individual trees destroyed by it, in the Hartz alone, being calculated at a million and a half. The inhabitants of this extensive range of country were thus threatened with a total suspension of their mining and metallurgic operations, for want of fuel, and consequently with ruin itself, entirely dependent, as they were, upon those branches of the useful arts. At this period these Bostrichi, when arrived at their perfect state, in the form of winged beetles, migrated in swarms like bees into Suabia and Franconia, there to commit similar ravages. At length, after these repeated injuries, the powers of nature interfered to mitigate the evil, which want of scientific knowledge, (as we shall presently show, had allowed to gain so alarming a head. Between 1784 and 1789 , in consequence of a succession of cold and moist seasons, the numbers of this scourge were sensibly diminished. It appeared again, however, in 1790, and so late as 1796 there was great reason to fear for the few Fir-trees that were left*.

We will now turn our attention to another insect, belonging to the same natural family as the Bostrichus Typographus, the ravages of which were nearly producing similar though less extensive effects in our own country, until checked by the results of scientific knowledge.

Of the evil which we have just reviewed as affecting the forests of Germany, St. James's Park and Hyde Park, in Lon-

* Kirby and Spence, in "Introduction Entomology," edit. 1816. vol. i. p. 211 ; from Wilhelm, a3 quoted by Latreille, Hist. Nat. xi. 194. 
don, from about 1820 to 1824 , presented many examples. The Elm-trees in both of these "Lungs of London," as they have not unaptly been termed, and particularly in St. James's Park, were rapidly disappearing. In spring, the leaves were seen to sprout out from the venerable trunks in all the luxuriance of vegetation, when of a sudden they were blasted, as if by lightning, the bark fell from the stem, and long ere winter the finest tree perhaps in the Park was fit only for firewood. Whole rows thus disappeared, and were rapidly disappearing in the Mall and the Birdcage-walk, threatening entirely to destroy the antiquated appearance of the Park, associated with the recollections of times gone past.

As the persons who had the charge of the trees were entirely ignorant of the true cause of the mischief, and as it was clear that the trees died in consequence of being completely stripped of their bark, rewards were at first offered for the discovery of the delinquents who so mischievously barked them; but these were offered in vain. It was observed, however, -and the observation claims some credit for its ingenuity,-that no more of the tree was barked, from the ground, than what was easily within the reach of a soldier's bayonet; and this was sufficient to throw suspicion on some unfortunate recruits, of whom more than one was arrested, without producing any diminution of the evil. In vain too were persons employed to sit up during whole nights, watching for the enemy; the bark continued to be found every morning at the roots of the trees; and the park-keepers, after all their trouble, could only conclude, "that the bark fell off in consequence of something being placed on the trunks during the day-time" *. About the same period, the Elms in the Grove at Camberwell, near London,-a place consecrated in the memories of many persons by having been the residence of the late philanthropist Dr. Lettsom-were observed to be undergoing a similar process of destruction; and the proprietors being equally ignorant of its cause as in the instances I have just mentioned, the injury was ascribed to the effects of gas, escaped from the pipes for lighting the road, which had just been laid down; and legal proceedings, for the removal of this nuisance, were actually commenced against the Gas Company which had undertaken the supply.

Entomologists, it is true, had long been aware that the operations of insects were the cause of all this mischief ; unfortunately, however, they were not believed, until the disease had reached that pitch which threatened to make remedy hopeless. It was evident to those acquainted with the subject, that un-

* Philosophical Magazine, vol. 1xii. p. 253. 
less decisive measures were soon taken to resist the progress of the contagion, it was to be expected that not only every tree of this species in the Parks would be destroyed, but that the evil would be disseminated throughout the vicinity of the metropolis, to several plantations on the north of which it had already extended.

In this state of things, Mr. William Sharpe Macleay, an eminent Naturalist, profoundly acquainted with the history of Insects, was requested by Lord Sidney, the Ranger of the Parks, to draw up a report on the state of the Elm-trees in them, for the purpose of referring it to the Lords of the Treasury.

In this Report Mr. Macleay shows that all the havoc had been committed by a species of Beetle belonging to the same natural family as that which destroyed the Pines in Germany; and not more than one-sixth of an inch in length; called the $\mathrm{H}_{y}$ lesinus Destructor, or Destroyer Hylesinus*.

It appears further from the Report, and from other authentic sources, that from the end of March to September, but principally about the end of May and the commencement of June, this insect, distinguished by its polished black head and thorax, the head thickly covered with hair, and its brown wingcases, may be seen, in numbers, running over the trunks of the Elms. This is the animal in its perfect state. It may be seen also entering into holes, with which the bark appears perforated as though with a gimlet; it insinuates itself into these holes, or into the crevices of the bark, for the purpose of depositing its eggs. On stripping off a piece of the loose bark, we may easily at any season understand how the barking of trees is effected by these minute animals; for the surface of the wood thus exposed presents to the view innumerable impressions, or excavations, each consisting of a comparatively wide middle trench, with others much narrower, extending from it at right angles, but in a parallel direction to each other + .

* Has not the ingenious author of "Insect Architecture," in the Library of Entertaining Knowledge, confounded this insect with the Bostrichus Typographus (Tomicus Typographus, LATR.) where (p. 239) he reports the latter to have been found in the neighbourhood of London?

$+\mathrm{Mr}$. Macleay has accurately compared these impressions to impressions or casts of large and broad Scolopendræ, the insects commonly called centipedes, or hundred-legged worms. The details above given on the history of the timber-eating insects, formed part of the Public Lecture delivered at Hazelwood, and were illustrated by a transparency representing, on a much enlarged scale, the magnified figure of the Scolytus (Hylesinus) Destructor, given in Mr. Curtis's British Entomology (Vol. i. Plate 43.), with a plan, also enlarged from a figure in the same work, of the impressions made by the insects, and another drawing showing these impressions in section, as they would be exposed by a vertical section through the diameter of an infected trunk. 
The middle or body of this singular impression is the passage which has been formed between the bark and the wood, or rather within the thickness, to a certain extent, of both, by the female insect, depositing her eggs, on each side, in her course, until she is exhansted of them, when she dies, and may accordingly generally be found at the extremity of the channel; the deposition of her eggs being to her, as to most other winged insects, the immediate forerunner of death. From this tubular path, however, the larvæ which are hatched from these eggs, deposited very close to each other, in the shape of little white worms, or grubs, destitute of legs, proceed nearly at right angles, eating their way in smaller tubes parallel to each other, which, lying close together, serve effectually to separate the bark from the tree. The larvæ remain feeding in the tree, generally in this situation, throughout the winter. During that season, the sap of the tree being down, the bark adheres less firmly, the grubs work with greater facility, and the mischief is consequently augmented. About the commencement of spring they assume the Pupa or Nymph state-that condition or stage of their metamorphosis, which in butterflies we are accustomed to call the Chrysalis (from its golden colour in many of those insects); and before the end of spring, the bark of an infected tree begins to appear as if all its crevices were full of a very fine sawdust. - The last change of the insect takes place; and being now winged, it endeavours to arrive at the external air, for the purpose of propagating its species, and laying its eggs in other trees. Each hole, which now appears as if made with a gimlet, marks the exit of a perfect insect. In the first instance the voracity of the larvæ, and in the second, the endeavours of the perfect insects to liberate themselves from the wood, particularly when such attempts are made by almost incalculable numbers, soon occasion the bark to fall in large pieces. The consequence is that the new leaves only make their appearance to wither, and the tree perishes.

Now it is evident from these facts, that the tremendous ravages of these insects - these small beetles which thus render themselves more formidable to mankind than the strongest and most ferocious beasts of prey, might have been prevented, and the evil repressed at its commencement, had the possessors or inspectors of the trees been acquainted with the Natural History of the insects; and it is this knowledge alone which could have enabled them effectually to have done so.

We have found that in their perfect state-as winged beetles, the insects are the most formidable, having attained the power of propagating the disease from one tree to many others. But it is also from an accurate knowledge of them 
whilst in this state, that we can alone derive any hope of being able to counteract the mischief they occasion.

'The first thing, indeed, to be done, in all such cases, is to ascertain the species of perfect insect which occasions the disease. The experienced naturalist, from an examination in this respect of the worm or larva which he finds devouring the timber, is. able not only to ascertain the Order and the Family, but often the Genus, and even the Species of winged insect which has produced it. Thus, in the present case, an Entomologist, by certain characters he would see in the larva, the nature of which his scientific knowledge would point out to him, would be able to determine, in the first instance, that the larva belonged to the Order Coleoptera or Beetles; by others that it helonged to the Family of Beetles called Ptinida, from that which possesses their characters in the greatest perfection being called a Ptinus. By other circumstances he would ascertain that it must be referred to that Genus of Ptinidae which bears the name of Hylesinus; and lastly, from still more minute examination, he would find it to be the species Hylesinus Destructor, so named from its powers of destruction which we have already examined.

Having thus determined the species, or even the genus only of the insect, it becomes an easy matter to the Entomologist to know the season of its appearance. None of the timber-eating insects, his general knowledge of these animals informs him, remain alive, in their perfect or winged state, throughout the year, and they rarely remain so for more than eight weeks. $\mathrm{He}$ finds, therefore, that we may easily ascertain the proper time for cutting down those trees which are so much infected by larvæ as to preclude all hope of saving them; for it would obviously be the height of imprudence not to seize the only opportunity of preventing the annual dispersion of the disease, by destroying the brood of larvæ whilst yet in the tree. As soon as the metamorphosis has taken place, - as soon as the winged insect has made its appearance,-the mischief for the ensuing year is done. Time is thus lost, more trees are inevitably destroyed, and, what is an evil of far greater magnitude, the future eradication of the disease is rendered much more difficult.

Accordingly, from a knowledge of the subject, acquired, virtually, by an investigation of this kind, Mr. Macleay recommended that the trees in the Parks should be inspected twice every year, first in summer, when the perfect insect is on the wing; and secondly in winter, when those trees which were much infected he recommended to be cut down and burnt, with the larvæ in them, or at least fumigated so as 
to destroy the larvæ; for to rest content with having cut down the trees without destroying the larvæ, or even removing the trunks from the vicinity of the sound wood, would be, he observed, in reality, to do no good at all. The time hitherto selected for cutting down the dead Elms in the Parks had been just after all the mischief for the season had been effected; and when all these nurseries of Hylesini had sent forth their inhabitants to the air, for the injury of such trees as might have remained free from infection. With respect to the less infected trees, when the branches were diseased, Mr. Macleay recommended them to be lopt off and burnt; and for those with the trunks infected, he recommended a coating of tar mixed with train oil, applied to them in March*.

These recommendations were adopted, or similar means employed, and the remaining trees were happily preserved; and there can be no doubt, that, had the possessors of the forests in the Hartz been, in the first instance, acquainted with the true cause of the disease, those forests might in like manner have been saved.

From a review of the facts which I have related, we may draw several inferences, having a very direct bearing on the subject immediately before us. We observe, in the first place, that the want of Entomological knowledge,-the want of knowledge of the timber-eating insects, in particular,-was the cause of no means having been taken to check their ravages at the outset, either in the forests of the Hartz, or in the Parks of London. Secondly, that when the cause of the disease was so far known, the want of the knowledge of the circumstances attending the Metamorphosis, or change from the grub- to the winged-state, of the devouring insects, caused the trees to be cut down only at the wrong time,- the door to be shut when the thieves were gone, - and thus rendered this labour perfectly nugatory, or perhaps absolutely mischievous, by removing trees, already infected, which might have retained the insects from the sound ones.

This is merely a specimen, selected from among many others, perhaps equally striking, which might be cited, of the facts evincing the value of the knowledge of Natural History, in the ordinary affairs of life. But a stronger proof, I conceive, cannot be adduced. It may be observed, also, that it shows the value, not only of what is called a popular knoroledge of the subject, but that of definite and truly scientific information respecting the objects of nature, - that is, of an acquaintance with the Natural Sciences themselves, - not merely with

- Edinb. Phil. Journ, vol. xi. p. 123, et seq. 
such of the subjects as are known, at present, to be connected with human pursuits, but with the abstract philosophical history of nature, which, at first sight, may appear unconnected with obvious utility. Another fact concerned also supports this latter inference: Mr. Macleay's pursuits are those of the philosophical naturalist; he is engaged in the purely scientific cultivation of Zoology in general, and of Entomology in particular, merely as branches of science, and without any direct view to their utility in the affairs of life; and yet, when the application of such knowledge was necessary, he pointed out, from this abstract science, the proper and effectual means of preserving forests from these destructive insects.

I am now to offer some observations on the value of uniting a knowledge of the Physical with that of the Mathematical sciences. The utility of the latter is so well appreciated, their applications in commerce and in the arts, and the tendency of their higher branches to invigorate the reasoning faculties, together with their immense and indispensable use in Astronomy, are so well understood, and so extensively acted upon, in Education, by parents as well as by teachers, that they need no advocacy on the present occasion. But it may be doubted whether sufficient attention has been bestowed on the combination with Mathematical acquirements, of a knowledge of the principles and substances belonging to the material world, of which the forms and quantities which it is the province of the Mathematician to investigate, - so far as they have a real existence, - are merely the properties or attributes. The inadequacy of the attention hitherto given to this subject, so far as School-education is concerned, is connected, probably, with the supposition, that instruction in the Mathematics conveys a much more extensive knowledge of nature, or of the Physical Sciences, - than is actually the case. This supposition may have arisen from the circumstance, that the higher departments of Mathematical knowledge, in some branches, are almost necessarily interwoven, in tuition, with Astronomy and Natural Philosophy. It is the fact, however, that a small portion, only, of Astronomical science, can be thus taught; and the other branches of Natural Philosophy commonly interwoven with the more advanced propositions of Algebra and Geometry, include little more than elementary Mechanics, and certain laws or problems in Hydrodynamics and Pneumatics. That considerable attainments may be made in pure Mathematics, in the doctrines of quantity and of figured extension, without any enlarged acquaintance with the phænomena and history of nature, is a fact to which every man of science will give his testimony. One object of the present memoir, 
however, is to explain the importance of the views it advocates respecting Natural Knowledge, to those who may be desirous of furnishing the young people of whom they may have the charge, with that useful knowledge in which their own education may have been deficient. It may be expedient, therefore, to enter into some illustrations of this fact; and also to show that it is a fact which is to be lamented; or rather that mischievous consequences may arise from it, if the comparative facility of making such attainments in Mathematics alone, and their fascinating influence upon the mind, be allowed to divert the student from making parallel advances in Natural science.

Strong representations have of late been made, and, among other competent advocates, by the consummate Mathematician who now occupies the chair in the University of Cambridge once filled by Newton, of the paucity, in this country, of high Mathematical knowledge, as well as that of interest in the more elevated pursuits of those sciences which are immediately connected with it, such as Astronomy, and the more recondite departments of Material Physics. Our continental neighbours, as well as the philosophers of Germany and the North of Europe, have been held up as examples for our emulation, in this respect, which, it has been stated, we must for the present be content to follow, at an humble distance. That these representations are founded in truth, with respect to the particular branches of knowledge in question, cannot be doubted; and that they should be true, every lover of science in Britain will regret, while he will feel himself called upon to use his most strenuous endeavours, to remove this blemish from our national honour.

If, however, we take an enlarged view of the subject, in all its relations to the past history, and all its bearings on the actual condition, of science, and the use of science, we shall probably find our regret in some degree alleviated, and our hopes and prospects of the future considerably modified. We shall find, perhaps, that while a change in the manner of cultivating many branches of Natural Philosophy, in this country, is now unquestionably desirable, the past, on reviewing its results, in Great Britain, and on the Continent, respectively, is not to be lamented. How far the strong expressions which have recently been employed by Professor Leslie, when animadverting on this subject, may be warrantable, I cannot pretend to decide; but, in a memoir professedly vindicating the importance of the Physical Sciences, it may not be improper to quote the passage from the Lectures on Natural Philosophy, of the late Dr. Young, - an author, it will be remembered, who was possessed of equally profound attainments in Mathe- 
matics and in Physics,-with which Professor Leslie has enforced his observations.

"It must be confessed that, in this country, the cultivation of the higher branches of the Mathematics, and the invention of new methods of calculation, cannot be too much recommended to the generality of those who apply themselves to Natural Philosophy; but it is equally true, on the other hand, that the first mathematicians on the Continent have exerted great ingenuity in involving the plainest truths of Mechanics in the intricacies of Algebraical formulas, and in some instances have even lost sight of the real state of an investigation, by attending only to the symbols, which they have employed for expressing its steps." (Lectures on Natural Philosophy, vol. ii. p. 670.)*

Professor Leslie has himself remarked, in reference to the progress of science in England, that "perhaps few nations in Lurope have less availed themselves of the results of abstract science towards aiding and correcting the operations of practice t." This also is true; but it is a fact equally incontrovertible, that those operations of practice, which are of the greatest importance to civilized and refined society,-which are most eminently conducive to the happiness of the human species, - have been carried, among us, to a degree of perfection unknown in other nations. In the varied applications of science comprised in Civil Engineering, we have no equals: witness our Steam-Engines, our Machinery, our Bridges, our Canals, and-unless we have been equalled or perhaps even surpassed in Ship-building by the Anglo-Americans, in following the same track, and with the same intellectual resources as ourselves-our specimens of Naval Architecture. As we are a manufacturing and a commercial, so are we, preeminently, an experimental people : our own constructions have been made upon principles which have been discovered or regulated by experiment, and the validity of those principles has been proved by the experience of their application; while, in many cases, Continental structures, dependent on principles theoretically investigated, have shown, by their own instability, the inadequacy of the theories which had presided over their erection.

Examples of these facts may be found in the history of many public works; and that of Suspension-Bridges, will afford us. a striking one. In Great Britain, these structures have been

* "Dissertation Fourth; [prefixed to the seventh edition of the Encyclopredia Britannica;] Exhibiting a General View of the Progress of Mathematical and Physical Science, chiefly during the Eighteenth Century," by Professor Leslie : p. 616.

+ Ibid.p. 579. 
erected, upon principles deduced from the direct experimental investigation of the tenacity of iron, combined with an adequate knowledge and application of the peculiar properties belonging to the Catenarian curve; and although the latter subject presents some difficulties, arising from an alteration induced in the curvature of the chains, by the difference of the weight each link respectively supports, \&c., yet the SuspensionBridges of Britain have evinced, without exception, the stability of the principles on which they have been constructed. On the other hand,- to select an example from the works of one of the most distinguished engineers in France,-the most profound investigation of the theory of these structures (giving rise to an unqualified condemnation of the principles which have guided British engineers in their erection), in the hands of M. Navier, has not precluded the failure of the Suspension-Bridge erected by him over the Seine, opposite the Hôtel des Invalids, at Paris, from so simple a cause as the giving way of the attachments of the chains.

While, therefore, we agree entirely in the hope that the higher branches of Mathematical inquiry will in future be more extensively pursued among us, we may be permitted to infer, that the ardent cultivation of pure Physics in this country, such as the researches of Davy, and Wollaston, and Kater, the experiments on the strength and other properties of materials, instituted by the engineers of our great public works, the investigation of the properties of vapours, connected with the successive inventions for improving the steam-engine, the prosecution of Geology by the Geological Society of London, \&c. \&c., has had an important and beneficial effect, in contributing to preserve us from a too exclusive devotion to those analytical refinements, which, when applied to imperfect data, produce errors, which are injurious in direct proportion to the intrinsic elevation and consequent authority, of the methods of calculation employed.

It is with much hesitation that I have presumed to enter upon the merits of a question, at once of so much importance, and so much difficulty; but to say a few words upon it, at the present epoch of affairs in the scientific world, seemed essential to the objects of this memoir. Many facts illustrative of what I have remarked will occur to my scientific readers; and I may adduce one from a subject to which I have myself devoted considerable attention. Various theories have been devised to account for the phrnomena of those Meteors, which, under the sensible form of balls of fire, occasionally traverse the atmosphere, and cast down upon the earth masses of ignited iron, or showers of red-hot stones, forming a class of bodies termed, collectively, Meteorites. 'Two of the most eminent mathemati- 
cians of France, and one of our own countrymen, of equal rank in the abstract sciences, concurred, about twenty years since, in supporting a theory, in which these remarkable bodies were regarded to be projected from volcanoes in the Moon; and the English philosopher supported this theory in application to the detail of the phænomena presented by the meteors. Within these few years another mathematician of Britain, still living, has adopted, and supported in great detail, a theory first broached upon the Continent, that meteorites are fragments of the great planet supposed formerly to have revolved between the orbits of Mars and Jupiter, resulting from the convulsion by which it was separated into the four small planets now known to revolve in that interval. Now I can state with some confidence, that the grounds on which the detailed confirmation rests, of the former theory of meteorites, and all the grounds of the latter theory, are destroyed, by a rigorous examination of the physical history of the meteors themselves, and of the physical characters of the substances projected from them; and that had such an examination been entered into, in the first place, it would have been seen that neither theory was consistent with the facts. One of the foreign mathematicians alluded-to, it is true, was profoundly versed in almost every branch of physical inquiry; and the British philosopher last mentioned is also distinguished by his successful researches into the intimate constitution of material bodies, as manifested by their action upon light. But although it may hence be inferred, that profound attainments in physics will not always preserve the mind from the effects of a loo exclusive reliance on mathematical resources; yet it is manifest, at the same time, that in those habits of thought which are induced by the cautious and minute examination of sensible phænomena, we can alone expect to find an adequate corrective.

The union of mathematical and physical acquirements which is manifested in the works of Biot and Arago, and Fresnel, of Borda, and Bessel, and Gauss, presents us indeed with noble examples to follow. Without such union of knowledge the science of inorganic nature cannot now further proceed. But while Dr. Young remained for many years almost the only similar example in this country, and while Mr. Francis Baily, Mr. Herschel, and Mr. Babbage, have, until almost the present day, stood nearly alone as living instances of the same invaluable-combination of talent, the facts we have briefly reviewed may be considered, perhaps, as affording a sufficient apology for the British nation, for preferring the pure experimental physics of Wollaston and Davy, and their associates, to the refinements in abstract analysis of Poisson and Fourier; 
and for relying upon the practical results obtained by a Smeaton, a Rennie, and a Seppings, rather than upon the theoretical conclusions of a Navier or a Girard.

The ancient history of science affords a remarkable illustration of the comparative inefficacy of mathematical attainments, when uncombined with natural knowledge,-which, as possessing also much collateral interest, may be appropriately introduced in this place, and will tend to relieve what may have appeared, to some readers, a rather abstruse discussion.

It has been shown, by many writers, that the ancient inhabitants of Egypt possessed a high degree of mathematical knowledge, especially in Geometry; and some of the most important propositions in the collection known to us by the name of "Euclid's Elements," - a work equally honourable to that illustrious Geometer, as an editor and as an original author and inventor in this science, have been traced to certain philosophers of Greece, especially Pythagoras, 'Thales, and Plato, who received them frorn the Egyptian priests, while pursuing their studies in the colleges of Heliopolis and Thebes. But of the Physical sciences, as branches of knowledge (existing abstractedly from a mere practical acquaintance with the properties of natural substances employed in the arts which they practised, \&c.),-with the exception perhaps of some degree of acquaintance with Physical Astronomy-there is much reason to believe, on the other hand, that the ancient Egyptians were alnost entirely ignorant. Possessing, as is evident from their works, gigantic conceptions and unwearied industry, and induced, by their peculiar mythological tenets, to exert them in perpetuating to the remotest ages (they hoped for ever, though it should be but an eternity of the grave, ) the actually existing state of things, - to perpetuate themselves, and as it were the very time-being in which they lived, - they laid all nature under contribution to promote their singular designs. They acquired and exercised a most precise and accurate knowledge of the properties of all the objects of nature afforded by their country. They knew, for example, that the desiccation of the bodies of animals, or the expulsion of moisture from them, tended greatly to withdraw them from the operation of those laws of decomposition to which dead organized matter is amenable. They knew, further, that the impregnation of the body with bituminous and saline materials, and the filling of its cavities with aromatics, would prevent its destruction by insects and animalcula. They knew also that the exclusion of the air, ard the preservation of a uniform temperature, were necessary for the continuance, in its original 
form, of even the dried and prepared body; and, agreeably to this knowledge, they invested the body in many successive wrappers of linen and cotton cloth, which had been steeped in antiseptic solutions, and placed it, thus secluded from the air, and surrounded with bad conductors of heat, in a double case of wood, afterwards deposited in a catacomb excavated in the unchangeable rock. Accordingly, the mummies of their Royal personages and Priests exist to the present day, and frequently in a state as perfect as that in which they were received from the embalmers, by the relations of the deceased. A few years since, I had an opportunity of examining the mummy of an Egyptian female of rank, contemporary, it is probable, with Sesostris, which had been opened by Dr. Granville, and found to be in the highest state of preservation. Still more recently, a mummy in the possession of the Philosophical Society of Leeds has been unwrapped, and discovered in an equally perfect condition, not only with the limbs and flesh perfectly retaining their form and texture, but with the features uninjured; whilst the hieroglyphic inscriptions on the case, manifestly coeval with the embalming, declare the body to be that of a priest who must have been contemporary with Moses, and who might therefore have witnessed the departure of the Israelites from Egypt, about three thoulsand three hundred years ago.

Debased and ignoble must have been the ambition which could thus devote so much labour and ingenuity, to so worthless an object as the body which the life has abandoned; false and irrational must have been the dogmas which could have impelled the Egyptians to bestow, on insensate matter, a degree of laborious solicitude and misapplied knowledge, which, directed to worthy objects, might have refined and exalted the minds of the living. It may be supposed, however, from their almost wonderful accomplishment of this ambition, that they were profoundly skilled in many branches of Physical science; and that, without such skill, they could not have effected results so perfect and so extraordinary. But such was not the fact: there is no evidence whatever of their possessing any philosophical knowledge of the substances and principles they employed; - any acquaintance with the causes of the effects, produced by those means, in their operations. In a case of this description the absence of evidence is equivalent to express information. From all that we know of the Egyptians, whether as derived from the Greek authors, or from modern discoveries in the antiquities of Egypt, it would appear, that, as regarded the cultivation of the arts and the Physical sciences, they were a nation of practised manipulators, mechanics, and workmen, 
experienced in the sensible effects upon each other of the materials with which they operated, and empirically acquainted with their properties; but being, at the same time, entirely ignorant of their intimate nature and relations. In other words, that the Science of nature was unknown to them. They had observed, for example, pursuing the illustration just given, that a dead body became putrid unless its moisture was expelled; but they were ignorant that the cause which rendered this precaution necessary, was the tendency of water to promote the chemical action of the constituents of the body upon each other, by favouring their assumption of the liquid form, and also by suffering decomposition, and yielding one of its constituents (the oxygen) to them. They had found that the exclusion of the atmosphere was necessary, to effect the longcontinued preservation of organic bodies; but they did not know the ground of this necessity, in the circumstance, that the atmosphere, by the oxygen it contains, and the water which is diffused through it, is the great natural agent of decomposition. They knew that variations of temperature were unfavourable to the preservation of animal matter in its natural form, but they had no knowledge, that the cause of this lay in the fact, that the chemical affinities of the elements of such matter are greatly influenced by the heat to which it may be exposed, and that the changes of texture induced by alternations of temperature, permit a more complete operation of those affinities. They appear, in short, to have pursued the arts in a manner altogether empirical and without principles; a conclusion which is confirmed by what Diodorus Siculus and other historians have related of their mode of practising medicine, and some branches of the arts also, which are all, in our own times, intimately connected with scientific knowledge. It is probable, indeed, that this was at once originally the cause, and eventually, in an aggravated form, the consequence also, of the division of the Egyptian people into six hereditary ranks, each of which was confined, from generation to generation, to the exercise of the same general function in society as had been originally performed by it, whilst the individuals of whom it was composed, and their posterity, were equally restricted to the particular occupations of their respective progenitors. Whatever knowledge might be possessed by each class, was thus entirely traditive, and confined to itself, and never contributed to form a common stock of information. For arts pursued without principles, and without some degree of scientific knowledge of the materials and agents employed, though they might readily be transmitted from one manipulator to another, -as workmen at the present day instruct ap- 
prentices, by practising before them the methods of operation, - could not be reduced to didactic rules, nor described in language practically intelligible. Hence, the political system of the country provided for a succession of hereditary artists ; and hence, also, when that system was destroyed, by the successive conquests of Egypt by the Persians, the Greeks, and the Romans, the peculiar arts of the Egyptians were entirely lost. The recovery of some of the processes they adopted, is due, entirely, to the application of modern science to their existing results.

The late Mr. Flaxman, in his Lectures on that branch of the Fine Arts, which he cultivated with so much success, has attributed the want of anatomical details in the Egyptian Sculpture, together with its total deficiency in the grace of motion, to the imperfect skill of the Egyptians in Geometry. Regarding this statement to imply rather their imperfect application of that science, in agreement with some further inferences of Mr. Flaxman, to be mentioned presently, I am much gratified to find this confirmation of the views I have just stated, in the opinions of a Sculptor so profoundly versed in the history, as well as in the philosophy, of his own art. The want of application of Geometry to the arts, is correlative with the absence of Physical science, which has advanced, in every age, in direct proportion to the application of abstract mathematical knowledge, to the objects of nature and the pursuits of civilization. In the basso-relievos and paintings of the Egyptians, Mr. Flaxman observes, there is no perspective; and figures intended to be in violent action are equally destitute of joints and other anatomical forms, of the balance and spring of motion, the force of a blow, and the just variety of line in the turning figure. The cause of these defects he states to have been, want of the anatomical, mechanical, and geometrical science, relating to the arts of Painting and Sculpture.

These opinions are in exact agreement with the views I have offered. The manner in which the more perfect mummies have been eviscerated, shows, that the Egyptians must have been excellent manipulative anatomists, - skilful and accurate dissectors; their stupendous pyramids and temples evince their ability as practical mechanics, and we have seen that they were profound Geometers; but there was no Philosophy in their cultivation of the arts, and therefore no systematic combination of their separate knowledge of various natural objects, which could tend to refine the different arts they practised. Hence the art of Sculpture, as well as others, remained unimproved among them, until the Greeks, under the Ptolemies, introduced the study of the natural sciences, pro- 
perly so called, and, together with that, a degree of the animation and beauty which had resulted from its application to Sculpture by the artists of their own country*. The interest which has been imparted to the history and antiquities of Egypt, by the researches of modern travellers in that country, and by the discoveries in Egyptian literature of Young and Champollion, has induced me to enter at some length into the foregoing illustration of my present subject, evincing, as it appears to do, that high mathematical attainments are not inseparably connected with, or productive of, general scientific knowledge, and manifesting also, in the defective state of the Fine Arts among the Egyptians, the ill consequences of the non-application of mathematical science, as well as of the absence of definite and systematic Physical knowledge.

Agreeably to the order proposed at the commencement of this memoir, I am to terminate the consideration of the utility of Natural Knowledge, by endeavouring to show the general usefulness of combining information of this kind with the pursuits of Classical Literature, and also the advantages specifically derivable from it, in the most profound investigations of the history, the languages, and the arts of Civilized Antiquity.

Whether the study of the ancient languages of Greece and Rome, and that of the polity and literature of those countries, in conjunction with it, be pursued, in order to impart to the mind that general and comprehensive acquaintance with the two nations, and their deeds in arts and in arms, which has been regarded as an essential part of the character of the scholar and the gentleman; or whether it be cultivated for the information and sources of mental delight, to be found in

* The reputation acquired by the Alexandrian school of philosophy, and the success with which many branches of natural knowledge were cultivated by its disciples, among whom were Euclid, equally skilled in the science of Music as in Geometry, Hipparchus, the greatest astronomer among the ancients, Ctesebius, the inventor of the Pneumatic Pump, and others of equal celebrity, are not to be considered as indicating, in any degree, the previous existence of definite physical science in Egypt. They are attributable, entirely, to the influence of the philosophy and science of the Greeks; for which an opening was afforded by the sagacity of Alexander the Great, in fixing upon so advantageous a site for his new metropolis, after his conquest of Egypt, und which the subsequent establishment of the Musceum, or Scientific Institution, of Alexandria, by Ptolemy Soter, and the fostering care of his successors, greatly contributed to raise to that high degree of perfection which it attained in this school. But it was, at the same time, the high cultivation of Geometry by the Egyptians, in conjunction, doubtless, with their minute einpirical acquaintance with the properties of natural substances, which afforded the foundation on which so much natural knowledge was afterwards raised among them by the Greeks. 
the writings of the ancients, the scholastic study of certain authors, in each language, is indispensable; as a means of acquiring them. In these authors occur many allusions to the prevalent mythology of their times, to historical events, and to the manners and customs of their contemporaries, which have for ages past ceased to be intelligible to the unassisted reader. To remove this obstacle to their comprehension and profitable perusal, much Apparatus, - to use an expression equally technical in scientific and in philological research,has been devised and employed. Dictionaries and other works have been composed for the purpose of explaining these allusions; and specific instruction in the mythology and religious ordinances, the history and the customs, of the more celebrated nations of antiquity, is given, in the form either of Lectures or in that of Class-Lessons, in almost every Seminary of Education.

But even in the most familiar and popular works of Classical Antiquity used as School-Books, many other allusions are contained, to the objects of nature, and the opinions of the ancients respecting them. To explain these, or to impart to the pupils the means of explaining them for themselves, or for each other, in some degree, would certainly angment their interest in the study; and by enabling them to acquire more precise ideas of the meaning of many expressions employed by the respective authors, it would contribute to fix the immediate subjects of study more permanently in the mind. During my residence at Hazelwood, as Teacher of the Physical Sciences, many inquiries on such subjects have been addressed to me, either by pupils devoting much of their attention to Classical studies, or by teachers who had received them from such pupils in classes taught by them; and I cannot but infer from this circumstance, among others, that many advantages would arise from the union of Classical pursuits with a due degree of attention to the objects of Scientific research.

At the present æra, however, in the progress of universal knowledge, there exists a still more direct and more important reason for the union of Natural Science with Classical Literature. For many years past the investigations of Classical criticism, and the researches of Physical science, have been followed, separately, by individuals as well as by Learned Societies, with great ardour, and indefatigable industry; the age has been equally distinguished by Heyne, by Porson, and by Schneider, by Cuvier and by Davy. The result of these parallel advances in Literature and Science has been, - a result, however, which has not perhaps been so publicly and explicitly announced as its importance demands, - that the 
writings of the philosophers and historians of Greece and Rome, contain evidence of a much more accurate and perfect observation of natural phænomena than had before been suspected. It has been found that many of the objects and operations of nature have been described by the ancients, in such a manner, that the resources of modern science may be augmented, from the materials they have furnished, however mingled with inconclusive explanation, or encumbered with unfounded theory.

An interesting example of these facts, in which even the necessity of introducing a correction into the computations of modern astronomy, was shown by reference to the statements of two ancient historians, was communicated some years since to the Royal Society. Mr. Francis Baily, one of the most accomplished astronomers of the present day, whose talents, time, and fortune, are entirely devoted to the advancement of his favourite science, had entered into an investigation of the history of the Solar Eclipse, stated by Herodotus to have been predicted by Thales. In the course of this inquiry some curious facts were brought to light respecting another eclipse of the sun, which is recorded by Diodorus Siculus.

It is related by Diodorus, that Agathocles, king of Syracuse, when besieged in that city by the Carthaginian general Hamilcar, undertook the bold design of invading the Carthaginian territories in Africa, and thereby removing the seat of war from Sicily to that continent. He accordingly embarked a numerous army, and set sail for the African coast. The day after he left Syracuse, the historian relates, the fleet was terrified at an eclipse of the sun; which was so great, that, in the words of Diodorus, "it seemed exactly like night, the stars every rohere appearing." Such a degree of darkness as this is never produced either by a partial or by an annular eclipse. This, therefore, was evidently a total eclipse in the place where it was seen by the fleet of Agathocles. Mr. Baily ascertained by computation, that it happened on August 15th, in the year 310 B. c.; and he also computed its elements, or the quantities necessary to be known, before its extent in different parts of the earth, and other phænomena, could be determined. He found, from these elements, by a trigonometrical calculation, the place where the sun rose centrally eclipsed, and the path over the earth, of the centre of the moon's shadow, from that spot, to the place where the sun became centrally eclipsed on the meridian. By comparing the results thus obtained, with the fact, as related by Diodorus, he found that Agathocles would not, in any part of his course, (and much less at the commencement of it, as stated by the historian,) come within 
a considerable distance of the moon's umbra, or that portion of her shadow in which no part of the sun could be seen, or, in other words, in which the eclipse would be total.

The account given by Diodorus of the darkness in which the fleet of Agathocles became enveloped, is confirmed by Justin. It could scarcely be doubted, therefore, that the eclipse was really a total one, at the place where it was witnessed by the fleet. But in order that the phænomenon should accord with the fact, as related by those historians, the centre of the moon's shadow ought to be found to have passed over, or very near to, the island of Malta: that is, the latitude of the moon ought to be, at least, three minutes greater than it was stated to be in the Astronomical Tables, published by the French Board of Longitude, which Mr. Baily employed in his computations.

On account of this discordance, Mr. Baily expressed a doubt of the accuracy of the amount of what is called the secular variation of the moon's mean distance from her node (on which distance her latitude depends) as given in those tables, although it had been deduced from the formulæ of Laplace*.

To question the accuracy of some of the most correct tables of Astronomical quantities which had yet been produced, and on a subject possibly involving the skill of the greatest Mathematical Astronomer of modern times, on the authority of a Greek historian, might have seemed a step very hazardous to Mr. Baily's future reputation. The event, however, justified this apparent presumption, confirming at once the authenticity of the historian, and the accuracy of his astronomical commentator. A few years after the publication of Mr. Baily's researches, the French Board of Longitude printed a Supplement to the Lunar Tables he had employed; in which the quantities termed the mean epoch and mean motion of the supplement of the moon's node, were considerably altered, so as to bring the latitude of the moon within the limits he had suggested + . It was thus established by astronomical computation, in agreement with historical authority, that the eclipse in question hart in reality been a total one, at the place where it had been seen by the fleet of Agathocles. It is unnecessary to offer an extended comment upon this fact: nothing can show in a stronger degree the value of ancient history to the cultivators of science, nothing can better evince the utility of scientific knowledge to the cultivators of Classical Literature.

The same argument might be employed with respect to

* Phil. Trans. 1811 ; or Phil. Mag. vol. xxxviii. p. 368.

$\uparrow$ Phil. Mag. vol. lv. p. 100, note. 
many other branches of natural knowledge. The extreme accuracy of many of the anatomical details, and the sagacity and truth of the classification, contained in Aristotle's History of Animals, has been either abundantly shown, ostensibly, by Cuvier and Macleay, or may be gathered from many passages in their works. On one interesting subject, already mentioned in these pages, the History of Meteorites, which is intimately related both to Astronomy and Geology, and requires for its complete investigation the exercise also of considerable knowledge in Chemistry and Mineralogy, I have myself had occasion to institute an extensive examination of the relations of the ancients. This examination I have found highly useful, in conducting a detailed inquiry on the subject. The ancient and modern relations of the fall of iron and stones from the heavens, mutually illustrate and explain each other; and the former, when scrutinized by our present knowledge of the atmosphere and the laws of combustion, \&c., afford many points of information, which contribute to elucidate the intimate history of modern instances, in which these phænomena have been witnessed.

For those students, therefore, who may have to direct the critical pursuits of future times, and who may become engaged in the cultivation of Classical Literature for the sake of the knowledge to be derived from it, we have in the facts which have just been related, a still stronger reason than that already urged, why they should unite some degree of the knowledge of nature, especially in the departments comprehended under Natural History, with their acquirements in those languages in which the literature they are to investigate is composed. The actual knowledge of the ancients we can never become fully acquainted with, and never adequately appreciate, until profound scholarship shall be united with extensive acquirements in Physical Science, and both with the knowledge of what may already have been effected, in those departments of either study which bear reciprocally upon the other.

It must be remembered, however, that the scientific knowledge required in the investigation of ancient history, and generally in elucidating the relations of ancient authors, must be as precise and complete as it is extensive. Imperfect and merely popular information on the subjects of science, when applied to critical inquiries, will serve only to introduce confusion into statements originally clear, and to involve difficult points in still greater obscurity. An instructive example of this is presented by the main object of the researches of $\mathrm{Mr}$. Baily, which have already been cited, with which the history 
of the eclipse witnessed by Agathocles, became merely incidentally connected. In that history we have found an example of the benefits which Classical Literature may confer, in a direct manner, on the Physical and Mathematical Sciences; while in the circumstances we are about to relate, we shall perceive that the reciprocal advantages to be derived from those sciences, in the pursuits of the Chronologist and the Historical Antiquary, are not less considerable.

"There is probably no fact in ancient history," Mr. Baily observes, "that has given rise to so many discussions, and to such a variety of opinions, as the solar eclipse, which (according to Herodotus) is said to have been predicted by Thales, and which, owing to a very singular coincidence, put an end to a furious war that raged between Cyaxares king of Media and Alyattes king of Lydia.

"According to the account given by that celebrated historian, ' the contest had continued during five years, with alternate advantages to each party: in the sixth, there was $a$ sort of nocturnal combat. For, after an equal fortune on both sides, and whilst the two armies were engaging, the day suddenly became night. Thales the Milesian had predicted this phænomenon to the Ionians, and had ascertained the time of the year in which it would happen. The Lydians and the Medes, seeing that the night had thus taken the place of the day, desisted from the combat; and both parties became desirous of making peace.' The fact is here very clearly (and probably very justly) related: but, unfortunately, there is nothing, either in the statement itself or in the contiguous passages of the work, that will enable us to determine, with any degree of accuracy, the exact time wherein this singular phænomenon took place. And this is the more to be regretted, because the dates of several other events, recorded by the same historian, might be more easily ascertained, if the æra of this eclipse were correctly known; but which are now involved in much obscurity*."

Deprived of all information from the body of the work itself, chronologists have called in the aid of Astronomy to assist them in fixing the date of this remarkable phænomenon. For it must be evident, that if we could ascertain, by this means, that in any solar eclipse, which happened about that period, the centre of the moon's shadow passed over the country bordering on the two contesting empires where the battle was probably fought, (for Herodotus has likewise omitted to mention the place where the action occurred,) we might reasonably and

* Phil. Trans. 1811 ; or Phil. Mag. vol. xxxviii. p. 357-8. 
very fairly conclude, that that eclipse only was the one alluded to by the historian.

In this attempt, however, a great diversity of opinion has arisen; no fewer than seven eclipses having been fixed-upon by different writers, as the one in question; giving a distance of no less than forty-three years, from 583 B.c. to 626 B.c., between the extreme periods assigned to the event related by Herodotus.

We have now arrived at that stage of this curious inquiry, which shows that a full and precise knowledge only of natural phænomena is available in researches of this description; and that a deficiency of such knowledge was the source of these contradictions. The chronologists and commentators upon Herodotus who engaged in this discussion, among whom were Scaliger, Petavius, Usher, and Larcher, were sufficiently acquainted with Astronomy, and in particular with the phænomena of solar eclipses, to perceive that the date of the eclipse in question might be found by calculation. But they do not appear to have been aware that the sudden and complete darkness implied by the expression of Herodotus, that "the day suddenly became night," could have been occasioned only by a total eclipse. While the smallest portion of the sun's disk is uncovered by that of the moon, day-light continues, and though reduced in intensity, much less so than would be imagined by a person previously unacquainted with the phænomenon. But when the last portion of the sun is covered by the moon, in a total eclipse, darkness instantaneously ensues, as most correctly expressed by the words of the Greek historian, for which, however, (another corroboration of our argument, ) he has been ignorantly censured by some of his commentators.

"It appears to me," continues Mr. Baily, after stating these circumstances, "that an inattention to these singular facts has been the principal cause of the various opinions that have arisen respecting the time when this eclipse happened. For each chronologist, having a system of his own to support, has satisfied himself merely with ascertaining that a solar eclipse did take place in the year that he had assigned for it; and which eclipse he supposed might be visible in that part of the world bordering on the two hostile countries: but without taking into his account the magnitude of the eclipse at the place where the battle is supposed to have been fought. Now, since the territories of the two belligerent powers were probably separated by the river Halys, (which was the case in the subsequent reign, although we have no authentic information that it was so at the period now under consideration,) 
and as the battle was probably fought on the confines of these two empires, I think it will be evident from the preceding extracts, [describing the phænomena of the diminution of light in solar eclipses, as mentioned above,] that no solar eclipse could be the one mentioned by Herodotus, unless it was central and total in some part of Asia Minor; that is, the centre of the moon's shadow, in such total eclipse, must have passed over that part of Asia Minor where the contending armies were engaging. Consequently the fact is capable of being verified or disproved by the present state of our knowledge in astronomy."

The attention of the learned seems first to have been fixed to this point by M. Th. S. Bayer. He consulted an astronomical friend, M. Fred. Christ. Mayer, who showed, that none of the five eclipses, which, down to his time, had been fixed upon by chronologists, could possibly be that alluded-to by Herodotus. $\mathrm{He}$ found, by appropriate calculation, that the eclipse which took place on May 18th, 603 в. C., was the only one that was at all likely to be the right. Not many years after, an English Astronomer, the Rev. G. Costard, arrived, independently, at nearly the same conclusion; but by introducing an important correction into his computation, allowing for the moon's acceleration, he evinced, at the same time, that in this eclipse, her shadow could not pass over any part of Asia Minor. Notwithstanding this circumstance, however, the date assigned by Mayer continued to be received as the true date of the "battle of the eclipse," by all succeeding chronologists ; although it must be evident, even from the data furnished by Mr. Costard, that the eclipse which then took place could not be total anywhere near the place where the battle was fought. M. Volney, it is true, in his Chronologie d'Hérodote, published early in the present century, discarded this eclipse; and fixed upon that of February 3rd, 626 в.c., but without taking any means of ascertaining whether that could have been total at the scene of conflict.

Such was the condition of this inquiry, when it was taken up by Mr. Baily, who brought to its determination all the resources which modern astronomy could furnish. None of the previous calculations, either on the affirmative or negative side, could be regarcled as possessing much weight, at the time he undertook to set the question at rest ; since they had been formed from tables which the subsequent improvements in astronomy had shown to be exceedingly defective and incorrect. In order, therefore, to leave no part of the inquiry undetermined, he computed the course of the moon's shadow for each of the seven eclipses which had severally been as- 
signed as the true one; and whileheproved that not one of them could have been central in any part of Asia Minor, three of them, he found, (including that selected by M. Volney, in opposition to all preceding chronologists,) were merely annular, or presented the moon entirely upon the sun's disk, surrounded by its margin like a ring, in which case little diminution of light ensues. He thus proved, from the most correct evidence which the present state of astronomical science affords, that not one of the eclipses mentioned by the authors alluded-to, could possibly be that which is recorded in so singular a manner by Herodotus.

Mr. Baily however, being resolved not to leave the subject in the same degree of doubt in which he found it, took the pains to calculate all the solar eclipses that were likely to have been visible in Asia Minor, from the year 650 B.c., to 580 в. с. ; but in this period of seventy years, he found only one eclipse that was central in, or near, any part of that Peninsula. This happened on September 30th, 610 B.c. It was central and total to part of Asia Minor, Armenia, and Media: and the path of the moon's umbra lay in the very track in which the two hostile armies probably met. For it passed over the very mouth of the Halys, just at the point at which Crosus, the immediate successor of Alyattes, crossed that river in order to attack the Median Empire.

This decision of the Astronomer, therefore, established for the Historian, the date of $610 \mathrm{~B}$. C. for the termination of the war between Alyattes and Cyaxares. The application of the entire subject to that which I have recited it to illustrate, is obvious. The chronology of Herodotus required an astronomical investigation for its establishment; and when that investigation was instituted by a man of science accurately versed in the branch of astronomy concerned, a satisfactory result was immediately obtained; while the failure of previous attempts, shows that nothing but complete and solid scientific knowledge can be effectual in such inquiries*.

\footnotetext{
' Having given so full an account of the investigations recorded or contained in Mr. Baily's paper, I must not omit to quote the last paragraph in it, in which he mentions the effect upon his researches of the alteration in the Lunar Tables, which the account given by Diodorus, of the eclipse in 310 в.с., had led him to suggest, and which was subsequently introduced by the French Astronomers, as mentioned in a former page of this memoir. It will be perceived that the only ultimate effect of this alteration, with regard to the eclipse of 610 в . c., would be to indicate that the supposed site of the battle must be changed. "Such an alteration," Mr. Baily observes, " as is here suggested, would somewhat vary the position of the route of the moon's umbra, in all the eclipses which have been the subject of this paper; but in none of them would it alter the conclusions which have been drawn fro:a them, except perhaps in the one (September 30 th, 610 в.c.) which I
} 
The foregoing illustration is immediately related to the third point of view, under which I have proposed to regard the advantages of uniting classical with scientific attainments, which is, the direct utility of the latter in conducting the more profound class of inquiries into the history and literature of past ages. In these, scientific knowledge, both mathematical and physical, may become available, either as direct means of research, or as habituating the mind to the methodical use and combination of the logical instruments common to every species of intellectual inquiry; and which may all be referred to analysis, comparison, induction, and generalization.

Among the most splendid and interesting discoveries in Archæology which have yet been accomplished, must be ranked the recovery of some of the lost works and lost authors of ancient Greece and Rome, in the examination of what have been termed Palimpsest Manuscripts, or Codices rescripti, by M. Angelo Mai, Librarian of the Vatican*; the discovery of the method of deciphering the Hieroglyphics of Egypt, by the late Dr. Young, with its further development and extensive application by MM. Champollion; and the translation of the $\mathrm{Cu}$ neiform or Arrow-headed inscriptions of Persepolis, which has

have supposed to be that mentioned by Herodotus. In this particular case the path of the moon's umbra might, by such a correction, be thrown so much further north, as to prevent the eclipse being total in any part of Asia Minor. But still it would remain the only one that can be at all adapted to the account given by Herodotus; since there is no other that could possibly be central in, or near, any part of Asia Minor, from the year 650 в. с. to 580 в.c.; a period which far exceeds the probable limits of time wherein this singular phænomenon must have taken place, so as to be reconcilable to any received system of chronology."

* The Codices rescripti are manuscripts, which at periods long subsequent to those in which they were written, were erased, more or less effectually, so as to allow of another work being written upon the same material, usually parchment or vellum. Whether this practice, which appears to have prevailed very extensively in the darker ages, arose from the scarcity of materials for writing, or merely from the indolence and bigotry of the monastic scribes, is uncertain. In many cases the more ancient work has been erased, in order to make room for one far less valuable : thus, in some cases, the life of a Popish saint, or a collection of fables, has been substituted for a rhetorical treatise, or an historical narrative, by a Greek or Roman author, and the latter have occusionally taken the place of an ancient copy of the Gospels. M. Mai, following, but with far greater success, the example of previous scholars, has ingeniously revived the erased work, in many instances, so as to be able to read and transcribe it; and he has thus effected the restoration of various works suppesed to be lost, among which are the Books of Cicero De Re Publicâ, and the Epistles of the scarcely less celebrated orator Fronto, of whose writings little more was previously known, than a few scattered sentences preserved in the works of other authors. "An Historical Account of the Discoveries made in Palimpsest Manuscripts," from the pen of Archdeacon Nares, will be found in the Transactions of the Royal Society of Literature, vol, i. p. 122. 
resulted from the successive labours of certain philologists in Denmark, Germany, and France. With the first of these achievements in ancient literature the subject now before us is unconnected; but Dr. Young's researches afford a striking proof of the power and efficacy of profound scientific knowledge in exploring and developing recondite literary truth; while the progress of the discovery that the Cuneiform characters are those of a dialect nearly related to the Zendic, or ancient language of Media, may be regarded, perhaps, as showing, with what comparative difficulty such researches are brought to a successful conclusion, when the peculiar tone of mind imparted by scientific knowledge is wanting.

The train of research by which Dr. Young succeeded in withdrawing the veil of mystery in which the Literature of Ancient Egypt had been for nearly twenty centuries concealed, had much more resemblance to a profound investigation in natural philosophy, than to an ordinary inquiry in philology. Dr. Young's attainments were almost universal: "Mathematics in the most abstruse recesses of modern improvements ; astronomy, theoretical and practical ; experimental and mechanical philosophy; chemistry; natural history; ancient and modern languages; philology; in addition to the regular practice of medicine; were carried to such an extent [by him] that each might have been supposed to have exclusively occupied the full powers of his mind*" Mere scholars, of equal or perhaps of superior acquirements, had repeatedly attempted to solve the great Egyptian ænigma, but had relinquished their endeavours in despair; and hence we may infer that Dr. Young was greatly indebted, for his success, and especially for the rapidity with which the fundamental steps of his discovery were established, to the attainments in the mathematical and physical sciences which he united with his profound and varied learning. And if such attainments were thus mainly contributive to success, in a philological inquiry conducted by a man distinguished by such powerful talents as Dr. Young, they must, a fortiori, be still more necessary to persons of inferior natural ability, who may be led to undertake the elucidation of recondite subjects in ancient literature. The modern discoveries in Egyptian Literature have not yet become a branch of popular information; and a mere reference to the researches of Dr. Young, will, therefore, be insufficient to support the opinion I have advanced. On this account I will here introduce a rapid view of the history of

* Mr. Davies Gilbert's Address to the Royal Society, at the Anniversary Mecting in 1829. 
his inquiries, and of the analytical process by which he deciphered the characters that had so long baffled the ingenuity of the learned.

Among the specimens of Egyptian art which the remarkable events in the political world, attended by the successive occupation of Egypt by two hostile armies from Europe, ultimately became the means of securing for the British Nation, was a huge broken block of black stone, which had been discovered by the French, in digging for the foundation of Fort St. Juiian, near Rosetta, and called from this circumstance the Pillar of Rosetta, or the Rosetta Stone. On this stone, which is now deposited in the British Museum, are the remains of three inscriptions; the first in Hieroglyphics, the second in what have recently been termed the enchorial characters of Egypt, and the third in Greek. On the circulation of a correct copy of these inscriptions, by the Society of Antiquaries, several of the best scholars of the age, in particular Porson and Heyne, employed themselves in completing, illustrating, and translating the Greek text. This proved to be a decree in honour of Ptolemy Epiphanes, who reigned in Egypt from 205 B.c. to 182 B.C.; and the inscription ends with the information that the decree was ordered to be engraved in three different characters, the sacred letters, (or Hieroglyphics, " the letters of the country," (or enchorial characters,) and the Greek. It was evident, therefore, that the Hieroglyphic inscription was here accompanied by a Greek translation, and hence great expectations were excited that a key to the former would be found in this precious relic of antiquity.

M. de Sacy, a distinguished orientalist of Paris, and M. Akerblad, a Swedish diplomatist, equally attached to philological researches, made some progress in identifying the sense of the several parts of the second inscription; but they scarcely at all considered the sacred characters; and it was left for British learning and industry, in the person of Dr. Young, to convert to permanent profit a monument, which had before been a useless, though a glorious trophy of British valour.

I have remarked that the method which Dr. Young adopted for the solution of this problem in Archæology, resembled rather an investigation in mathematics or in physics, than a philological inquiry; and to this circumstance $I$ have in a great degree attributed his success. That such was truly the character of his method, will be manifest from the following sketch of it, in the abstract, as given by Dr. Young himself.

"Every analysis of an unknown object of this nature must unavoidably proceed, more or less, by the imperfect argumentation sometimes very properly called a circle, but which 
in such instances, may be more aptly compared to a spiral, or to an algebraical approximation; since, by assuming certain incorrect suppositions, not too remote from the truth, we may render them, by means of a continual repetition of the calculation, more and more accurate, until at length the error is rendered wholly inconsiderable; and in this manner we often satisfy the conditions of a problem, which it would be impracticable to solve by a more direct method *."

Such being the mode of research determined upon, the grounds for assuming the suppositions which were to be the first re-agents employed, (to adopt a term from the phraseolog, of Chemical investigation,) were only to be found in what the Greeks and Romans had handed down to us of the history, mythology, religious ordinances, customs and civil institutions of Egypt. For this purpose Dr. Young examined, compared, and brought together into a proper form for his use, everything important on these subjects which had been preserved; and he also made himself familiar with the remains of the old Egyptian language, as they are preserved in the Coptic and Thebaic versions of the Scriptures. Thus he arranged the apparatus requisite for the investigation. Being thus prepared for the inquiry, he proceeded (in the year 1814) first to examine the enchorial inscription, and afterwards the sacred characters, on the pillar of Rosetta. By an attentive and methodical comparison of the different parts with each other, he had sufficiently deciphered the whole, in the course of a ferw months, to be able to send to the Society of Antiquaries a translation of each of the Egyptian inscriptions considered separately, distinguishing the contents of the different lines with as much precision as his materials would then enable him to obtain + .

The parallelism of Dr. Young's process for deciphering the Egyptian inscriptions on the Rosetta stone, with a process in experimental science, directed specifically to the object of ascertaining the cause of some particular phænomenon, will however be rendered more fully evident by reciting his own detail of its progress.

" Having acquired some preliminary notions of the mythology and history, and chronology and institutions, of ancient Egypt, we may proceed to the discussion of its written language and literature, as far as they are likely to be recovered from existing monuments; and, first of all, we must inquire into the best mode of obtaining some satisfactory conclusions

* Article Egy pt:- Supp. Encyc. Brit. vol. iv. p. 43.

+ Dr. Young's "Account of some recent Discoveries in Hieroglyphical Literature and Egyptian Antiquities," p. 11. 
from the invaluable inscriptions in honour of Ptolemy Epiphanes; which contain the only authentic specimen in existence of hieroglyphical characters expressly accompanied by a translation.

"The block or pillar of black basalt, found by the French in digging up some ground at Rosetta, and now placed in the British Museum, exhibits the remains of three distinct inscriptions; and the last, which is in Greek, ends with the information, that the decree, which it contains, was ordered to be engraved in three different characters, the sacred letters, the letters of the country, and the Greek. Unfortunately a considerable part of the first inscription is wanting: the beginning of the second, and the end of the third, are also mutilated; so that we have no precise points of coincidence from which we can set out, in our attempts to decipher the unknown characters. The second inscription, which it will be safest to distinguish by the Greek name enchorial, signifying merely the characters 'of the country,' notwithstanding its deficiencies near the beginning, is still sufficiently perfect to allow us to compare its different parts with each other, and with the Greek, by the same method that we should employ if it were entire. Thus, if we examine the parts corresponding, in their relative situations, to two passages of the Greek inscription in which Alexander and Alexandria occur, we soon recognize two well-marked groups of characters resembling each other, which we may therefore consider as representing these names; a remark which was first made by M. De Sacy, in his letter relating to this inscription. A small group of characters, occurring very often in almost every line, might be either some termination, or some very common particle: it must therefore be reserved till it is found in some decisive situation, after some other words have been identified, and it will then easily be shown to mean and. The next remarkable collection of characters is repeated twenty-nine or thirty times in the enchorial inscription; and we find nothing that occurs so often in the Greek, except the word king, with its compounds, which is found about thirty-seven times. A fourth assemblage of characters is found fourteen times in the enchorial inscription, agreeing sufficiently well in frequency with the name of Ptolemy, which occurs eleven times in the Greek, and generally in passages corresponding to those of the enchorial text in their relative situation: and, by a similar comparison, the name of Egypt is identified, although it occurs much more frequently in the enchorial inscription than in the Greek, which often substitutes for it country only, or omits it entirely. Having thus obtained a sufficient number of common points of 
subdivision, we may next proceed to write the Greek text over the enchorial in such a manner that the passages ascertained may all coincide as nearly as possible; and it is obvious that the intermediate parts of each inscription will then stand very near to the corresponding passages of the other.

"By pursuing the comparison of the inscriptions, thus arranged, we ultimately discover the signification of the greater part of the individual enchorial words; ........ The degree of evidence in favour of the supposed signification of each assemblage of characters may be most conveniently appreciated, by arranging them in a lexicographical form, according to the words of the translation; the enchorial words themselves not readily admitting a similar arrangement: .....

"It might naturally have been expected that the final characters of the enchorial inscription, of which the sense is thus determined with tolerable certainty, although the corresponding part of the Greek is wanting, would have immediately led us to a knowledge of the concluding phrase of the distinct hieroglyphical characters, which remains unimpaired. But the agreement between the two conclusions is hy no means precise; and the difficulty can only be removed by supposing the king to be expressly named in the one, while he is only designated by his titles in the other. With this slight variation, and with the knowledge of the singular accident, that the name of Ptolemy occurs three times in a passage of the enchorial inscription, where the Greek has it but twice, we proceed to identify this name among the sacred characters, in a form sufficiently conspicuous, to have been recognized upon the most superficial examination of the inscriptions, if this total disagreement of the frequency of occurrence had not imposed the condition of a long and laborious investigation, as an indispensable requisite for the solution of so much of the enigma : this step, however, being made good, we obtain from it a tolerably correct scale for the comparative extent of the sacred characters, of which it now appears that almost half of the lines are entirely wanting, those which remain being also much mutilated. Such a scale may also be obtained, in a different manner, by marking, on a straight ruler, the places in which the most characteristic words, such as god, king, priest, and shrine occur, in the latter parts of the other inscriptions, at distances proportional to the actual distances from the end; and then trying to find corresponding characters among the hieroglyphics of the first inscription, by varying the obliquity of the ruler, so as to correspond to all possible lengths which that inscription can be supposed to 
have occupied, allowing always a certain latitude for the variations of the comparative lengths of the different phrases and expressions. By these steps it is not very difficult to assure ourselves, that a shrine and a priest are denoted by representations which must have been intended for pictures of [the] objects denoted by them; and this appears to be the precise point of the investigation at which it becomes completely demonstrative, and promises a substantial foundation for further inferences. The other terms god and king are still more easily ascertained, from their situation near the name of Ptolemy.

" The most material points of the three inscriptions having been thus identified, they may all be written side by side, and the sense of the respective characters may be still further investigated, by a minute comparison of the different parts with each other." *

The foregoing detail, I submit, bears out the representation with which I introduced this particular subject. The process described is analogous, in almost every step, to a profound and extensive inquiry in Physics. The experimental investigation of a complex phænomenon in Chemistry or Natural Philosophy; an inquiry into the mode of formation of a rock, distinguished by remarkable mineral characters and organic remains; or the determination of the affinities and analogies, throughout the known animal or vegetable kingdom, of a group of animals or of plants; - would be conducted by methods logically corresponding, in a specific manner, with that adopted by Dr. Young.

I must now briefly advert to the deciphering of the Cuneiform or Arrow-headed characters of Persepolis, accomplished, I believe, without the aid of any particular acquirements in Science. The abstract method of inquiry to be employed was radically the same as in the instance just related, as the object was equally unknown with the former, or even still more so, since none of the inscriptions was accompanied by a version in a known language, and since no external aid, whatever, was to be expected; neither the Greek, the Latin, nor the Persian writers ever mentioning these inscriptions or characters. Considering the immense complexity of the Egyptian subject, however, there can be no doubt that the object of Dr. Young's researches was by far the most difficult of attainment.

The means employed in this investigation were purely literary and historical; they were applied, however, with great sagacity, by the antiquaries who successively adopted them.

* Supplement to the Encyclopædia Britannica, art. EGYPT: vol. iv. p. 53,54 . 
The inquiry was commenced by Professor O. G. Tychsen, of Rostock, in 1798, and continued by Professor Münter, of Copenhagen, in 1802. They ascertained that the Persepolitan inscriptions were alphabetical, that the words were divided by the elementary arrow-head placed obliquely, and that the inscriptions were to be read from left to right; they also pointed out the probability that a frequently recurring group of characters, which has since proved the key to the whole system of writing, as well as to the language, would be found to answer to the word king, but without deciding in what language. Nearly coeval with the researches of Münter, were those of Grotefend, Professor in the Gymnasium of Frankfort on the Maine, by whom the investigation was carried to a much farther extent. By a process purely teitative, he deciphered the names of Xerxes and Darius Hystaspes, and by applying the approximate alphabet so obtained, he found that the group which Tychsen and Münter conceived to represent the word king, might be read into the word for that dignity in the Zendic or ancient Median language; an affiliation of which was peculiar to ancient Persia, properly so called, and to the Persian nation, mistress of Asia, subsequently to the reign of Cyrus. By pursuing the same system, he produced entire readings and translations of several of the inscriptions at Persepolis.

The previous studies of Profe:sor Grotefend, however, had not included that of the ancient languages of the East, and he was acquainted with the Zendic language only through the imperfect works of Anquetil du Perron. It hence followed that many of the words and phrases into which he had read the Persepolitan inscriptions, presented forms and grammatical combinations which were not to be found either in the Zendic or in any other ancient dialect ; and that the meanings he ascribed to some of them were equally foreign to those of the really corresponding words of that language; while he often attributed also a different value to the same characters, when occurring in different parts of an inscription. On these accounts his explanations, when first divulgerl, did not gain the assent of philologists in general, and were scarcel-y known to the literary world ; although two eminent orientalrsts, M. de Sacy, of Paris, and M. von Hammer, of Vienna, appear to have provisionally concurred in them. A republication of them, with additions, in 1815, was equally unsuccessful; and from a passage in Dr. Young's account of his own discoveries in Hieroglyphical Literature, it may be gathered, that, - deeply interested as he was in all such inquiries, - he was ignorant, at so late a period as the year 1823 , of the advance which M. Grotefend had made in deciphering the cuneiform charac- 
ters*; from which it may with great probability be inferred, either that he was unacquainted with Grotefend's researches, notwithstanding his extensive reading in the philological literature of Germany, or that the really valuable part of those researches was so disguised, by the imperfections already mentioned, as to have made no impression on his mind. Either fact would support the inference that M. Grotefend's explanations had not been generally received.

In this state of the inquiry it was entered upon by M. Saint Martin, of Paris, a zealous and skilful orientalist, who, founding his investigation on what Grotefend had done, but conducting it by a very different method, and with additional resources, succeeded in proving, demonstratively, what had only imperfectly appeared from the labours of the German Professor, showing that the language expressed by the class of Persepolitan characters examined, if not actually the Zendic, is the ancient Persian dialect nearly related to it; and determining, on satisfactory grounds, various philological and historical questions connected with the subject. His results were published in 1823, and have established the deciphering of one class of the Persepolitan inscriptions, as a permanent contribution to archæological literature + .

'The four successive decipherers of the Cuneiform inscriptions, possessing and prepared for the undertaking by extensive learning alone, were thus occupied for the space of twenty-five years, in producing about the same amount of aggregate explanation, which a single inquirer, furnished, in addition to the requisite learning, with the peculiar analytical and inductive logic imparted by scientific research, had effected, with respect to the Egyptian Hieroglyphics, in a few months.

The deciphering of the Egyptian Hieroglyphics, and that of the Cuneiform characters, cannot, be regarded as rigorously comparable; but if we are authorized in concluding, from the history of Dr. Young's researches, that his profound attainments as a Mathematician and a Natural Philosopher, were mainly instrumental in procuring his rapid and complete success; we may also infer, that the tardiness, and the comparative indecision, in some of its earlier stages, of the Persepolitan inquiry, were owing, in some considerable degree, to the want

* See "Account," \&c.; as before quoted, p. 53. Collateral evidence to the same effect will be found in the article "EGYPT". p. 51 .

+ The above sketch of the progress of the Persepolitan inquiry has been drawn up chiefly from a paper in the Asiatic Journal for September, 1823, containing translations of parts of M. Saint Martin's essay, and from a paper, by the Rev. Mr. Kenrick, of York, in the Philosophical Magazine for May, 1829. 
of that combination of scientific with philological knowledge, in the minds of the investigators, by which Dr. Young was so eminently distinguished, and to illustrate the utility of which is the object of the preceding details.

Such are the considerations which have induced me to urge the importance, of combining the Knowledge of Nature with the pursuits of Classical Literature. I cannot however quit this subject without acknowledging, on the other hand, the inestimable advantages which have accrued to the Physical sciences, especially within the present century, from so many of their cultivators having been prepared for their study, by that Academical Education, in which Classical Literature forms so considerable a department. A member of the University of Oxford, some years ago, cited the case of the contributions of the Oxford School of Geology to that science, as affording "a striking and satisfactory proof," "in opposition to the misrepresentations of shallow sciolists", that "the institutions of academical education are far from unfavourable to the cultivation of the physical sciences, and that an ignorance of the rules of classical composition, and of the languages, and philosophy of polished antiquity, are by no means essential advantages in researches of this nature: it has been rather seen

-Quid mens rite, quid indoles

Nutrita faustis sub penetralibus

Posset." *

In addition to the implied explanation here given of the use of academical education in preparing the mind for the study of physics, it may be observed that there are two specific and direct sources of that utility: viz. the finished instruction in mathematics, and in the ancient languages of Greece and Rome-in Classical Literature and Philology, which the students receive. The former species of knowledge, by imparting that of form, in all its relations, and that of the imaginary points, lines, and planes, to which the various accidents of extension are referred, as well as by the nomenclature with respect to form and quantity, which it conveys, gives accuracy to observation, and corresponding precision and facility to description. The latter, by the acquaintance it communicates with the etymology, and the etymological signification, of the words we have derived from the dead languages, as well as by the extensive knowledge of words themselves which it conveys, enables the philosopher either to employ accurately definitive terms, selected from among those already

"Conybeare, "Outlines," Introduction, p. xlviii. 
in use, or to construct new ones, which the progress of science may render necessary, in order to convey, without periphrasis, a knowledge of new facts, or of new results arising from the combination of those already known. To the science of Geology, among others, these remarks are particularly applicable. The success with which it has of late years been cultivated in England, and the knowledge which has been acquired by that means of the physical structure of the British Islands, must be attributed, next to the establishment of the Geological Society of London, to the activity with which the science has been pursued, by students of the Universities of Oxford and Cambridge. The Reliquice Diluviance of Professor Buckland, a work which has displayed, in so interesting a manner, the remains of an epoch when our forests were traversed by the lion, the tiger, the hyæna and the elephant, and from which so much satisfaction has been derived with regard to the physical records of the Deluge, is one of the fruits of the Oxford School of Geology. Mr. Conybeare's Outlines of the Geology of England and Wales, and Professor Daubeny's History of Volcanos, are examples from the same source. The extensive researches in almost every considerable group of our rocks, of the gentleman who now fills the chair of the Geological Society, and who is a distinguished ornament of the University of Cambridge (Professor Sedgwick), are proofs of a similar nature. With these also we must associate the still more extensive researches of the same geologist upon the Continent, pursued in concert with $\mathrm{Mr}$. Murchison, another active member of the Geological Society. How far they can be regarded as affording proofs of some of the positions advanced by Mr. Lyell, in his late work, remains for discussion; but it would certainly appear from them, in conjunction with the continental researches of Messrs. Lyell and Murchison themselves, that the series of processes to which the globe has been subjected, may at least be compared to an ascending spiral or helix, in which every portion of a new volution corresponds with some portion of that which has preceded it. For the earth appears to have undergone several successive changes of surface, each of which has given rise to a class of distinct but strictly analogous rocks, characterized at the corresponding terms of each series by analogous mineral and organic contents. The deposition of common salt and the development of carbonaceous matter from vegetables, or efforts towards them, for example, seem to have taken place at every great æra in the formation of the secondary strata, as well as at several æras in that of the tertiary beds.

Many of these contributions of the Cambridge School of 
Geology will be found in the Transactions of the Geological Society of London; others in the Transactions of the Philosophical Society of Cambridge.

Nor is the success of Geological Science in the hands of those who have received what is sometimes termed, per cxcellentiam, "a regular education," without many parallels in other branches of physical knowledge; and the works of the Rev. W. Kirby, Mr. W. S. Macleay, and Mr. Vigors, on Entomology, Ornithology, and the Philosophy of Zoology in all its departments, may be cited as proofs of the fact.

The proposed consideration of the intrinsic utility of the Knowledge of Nature, as conveyed by the Physical Sciences, is now complete. It remains for me briefly to describe what has been attempted, in the introduction of those sciences into the general system of Education pursued in the Schools of Hazelwood and Bruce Castle. The tendency of the preceding arguments and illustrations is to show the utility of some degree of scientific knowledge to persons of every class, and of every destination in life. In accordance with this truth, the department of "Physical Science", in the Schools, has been extended more or less to all the pupils. Many of these are destined by their friends for commercial occupations, others for professions, and some will become the possessors of hereditary affluence. Many, on quitting the Schools, will have finished their education; others will then enter the Universities. Such departments of science therefore have been selected for instruction, as appeared likely to be most generally useful, and to receive, in the greatest degree, the approbation of the parents or friends of the pupils, and that of the public at large. The principal aim has been, in teaching these subjects, to exercise the understanding in those forms of rational analysis and induction which are appropriate to the Physical Sciences, to excite an interest in the pursuits of science in general, and to communicate important fundamental truths. The amount of instruction in any of the higher branches of knowledge which can be imparted at School, being comparatively inconsiderable, it became the more necessary to render that amount as efficient as possible, by dwelling on the more prominent features only of each branch of knowledge entered upon. Some pupils, whose time was occupied in immediate preparation for entering the Universities, or in other exercises, agreeably to the instructions of their friends, could take but little part in Physical Science. Others however, some of whom are designed for the Medical profession, have devoted considerable time and attention to this department. 
The complete Course of Instruction in the Physical Sciences is designed to consist of the following departments; which will be taught nearly in the order in which they are here enumerated :

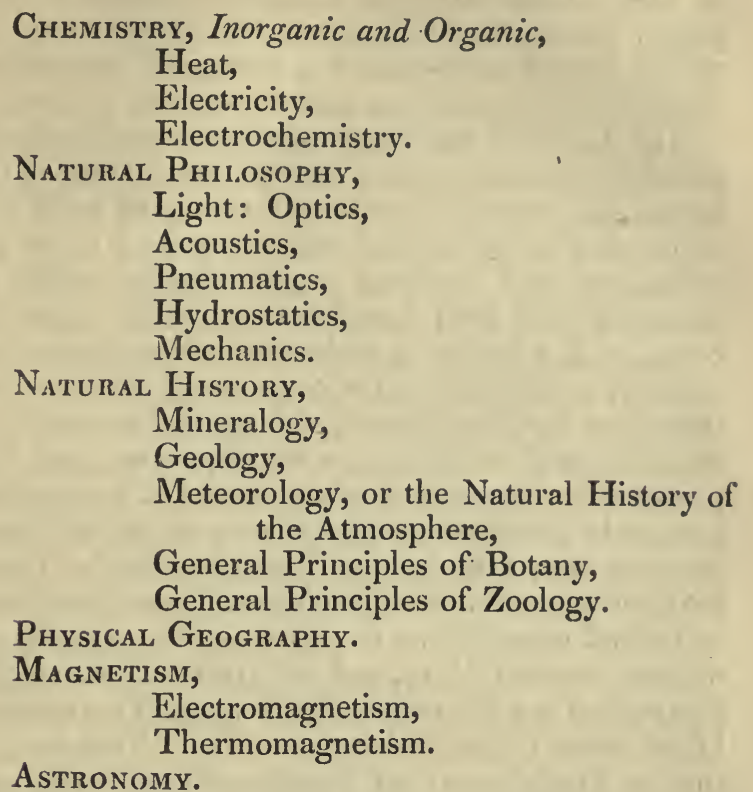

Much time will necessarily elapse before a complete Course of this description can be arranged for tuition; and to what extent the plan can be carried into effect, will depend in a great measure upon the degree of encouragement which the Conductors receive, in ascertaining how far the sentiments of the public, with respect to the Department of Physical Science, may be in unison with their own. Under any circumstances, also, there will always be many pupils, who, from the limited time they remain at School, or from the prescribed nature of their studies, will be prevented from attending the entire course. But such a Course is in progress, and selections will from time to time be made from it, according to the exigencies of the pupils, and the influence of those exigencies on the general routine of the Schools.

Hitherto the attention of the pupils, in this Department, has been directed chiefly to Chemistry, and the rudiments of Natural Philosophy; although Lectures, and Class-instruction to a limited extent, have also been given in some other branches, as will presently be noticed.

Two methods of instruction have been employed, in con- 
junction : those of Lectures, employing that term in the sense in which it is applied to the discourses on scientific subjects, which are delivered in the theatres of Public Institutions and of Medical Schools; and Lessons to classes of pupils. The former have been addressed to the entire school, or to several of the classes into which it is arranged, assembled together; the latter, of course, to a smaller number of boys.

The Lectures have in general been spoken from notes prepared for the express use of this department in the Schools, containing matter which would not have been offered when addressing a public audience, or pupils more advanced in education, and omitting many subjects which would with propriety have been introduced, on such occasions. On account of the routine in which the business of a school is necessarily conducted, and of the cornparatively small portion of time that can be allowed, during the session, for the construction and arrangement of apparatus and illustrations, philosophical propriety of arrangement has sometimes been purposely sacrificed to convenience of explanation. On this account, also, it has been the endeavour of the Teacher to employ such instruments and pieces of permanent apparatus as will admit experiments to be repeatedly exhibited with them, without sensible injury, and with little re-preparation. Of this description are the various forms of the Thermometer and the Hygrometer; the Pulse-glass; Dr. Wollaston's Cryophorus, or Frost-bearer, an instrument for freezing at a distance from the point where cold is applied, by means of the cold ensuing from the rapid evaporation of the water to be frozen; the miniature Steam-engine of the same philosopher ; and also his Elementary Galvanic Battery, by which a platinum wire may be ignited and fused, merely by dipping a single plate of zinc and a plate of copper into a dilute acid.

When Chemistry has been the subject, rarely more than two distinct experiments have been shown in each Lecture, that number, when fully explained, having been found as great as could with propriety be introduced. In the preparation and arrangement of apparatus and materials for the Lectures, as well as in the performance of experiments during their delivery, the Teacher has always been assisted by one or two boys, who may have evinced a particular taste for the exercises of this department, or whose friends have requested that their attention might be specifically directed to it. It has generally happened, from the last hour of "school" having been appropriated to the Lectures, that the preparations have been required to be made "out of school-hours"; and this has been voluntarily done, frequently in lieu of play, with much zeal and attention. 
It has been the practice to exhibit on the lecture-table, as far as possible, specimens, examples, or drawings, of every sensible object mentioned in the Lectures; and even when this could not be done, still to exhibit something approximating, in nature, or in appearance, to the objects described. In a public Lecture-theatre, where many smaller objects are necessarily indistinguishable to the majority of the audience, on account of the distance from which they must be viewed, the experience of every Lecturer shows this to be a point of much importance to the interest of his Lectures; and in a School-room, therefore, where the audience are comparatively near to him, it is still more important. For this purpose, as well as for the specific illustration of lessons in Geology and Mineralogy, a small collection of minerals, organic remains, and rocks, has been provided for each School; and whenever the crystalline form of any substance has been mentioned, care has been taken to exhibit a model of it, or at least of some geometrical solid of which it might be regarded as a modification. Quantities, such as the proportions in which the elements of chemical combinations are united, and numerical expressions of properties of every kind, such as specific gravities, equivalent numbers in Chemistry, angular dimensions, \&c., have always been shown in large characters on a diagram-board. The derivation of technical terms has always been explained, on using such terms for the first time : to encourage the pupils to make inquiries on this subject, on every suitable occasion, forms part of the Hazelwood System of Education. The length of each Lecture has varied from forty to fifty minutes, the remainder of the hour being allowed for the pupils to ask questions, respecting any of the subjects mentioned, receiving answers to them from the Lecturer. For this purpose, agreeably to a plan introduced into the Schools, some time since, in order to avoid the confusion attendant on their putting questions vivâ voce, the pupils write them upon slips of paper, or upon slates, which are then handed up to the Lecturer, who reads each question aloud, and replies to it, immediately. So pertinent and so justly applicable have been most of the questions addressed to the Lecturer on these occasions, that a very considerable degree of knowledge has been conveyed in answering them; and the answers have always been listened to with great attention, by the entire body of auditors.

Besides the principal series on Chemical Science, less extended Courses of Lectures have been given, on Geology, illustrated by Mr. Greenough's Geological Map of England and Wales, by Mr. De La Beche's Tabular and Proportional View of the Superior, Supermedial, and Medial Rocks, and G 2 
by drawings representing sections of strata, \&c.; on the Steam-Engine, as described in p. 15-17; on Meteorites, illustrated by a small collection of those remarkable substances in the possession of the Teacher, and by a series of transparencies representing the meteors from which they are projected; and on some detached portions of the Natural History of the Invertebrate Animals, especially of the Annulosa (including Insects and the Crab-tribe), as well as of some interesting groups of Tunicata, Radiata, and Acrita; illustrated by transparencies representing the animals, or parts of them, on a highly-magnified scale*.

For the purpose of more fully explaining the nature of the instruction which it has been endeavoured to communicate, in this department, as well as to assist in imparting, to those who may be but imperfectly acquainted with the objects of the Physical Sciences, some idea of the interest which attaches to those objects, I shall now give a somewhat detailed Syllabus of two Courses of Lectures on Chemistry, which were first delivered at Hazelwood, in the autumn of 1829 , but which were given at Bruce Castle, in the Spring of 1830, with various improvements, suggested by the experience I had then acquired, in adapting the truths of Chemical Science to the instruction of youth.

My object, at present, is to describe the progress which has been made in this department of the Education given in the Schools of Hazelwood and Bruce Castle, in terms exactly expressive of the reality; - not to state the beau idéal which might be imagined on the subject, nor even to describe what has been effected, in terms according only with what I may now see ought to be done. For what may yet be effected, the public can have no pledge; but from a bonâ fide statement of what has already been executed, they may form a judgement of the qualifications of the Teacher, and of the means of tuition placed at his disposal. In the following Syllabus, therefore, the subjects of the Lectures will be detailed, just in the order in which they have actually been considered, and in the manner in which their history has been examined; in both which I am aware that there are many imperfections, which it is my in-

* The pictorial illustrations employed in the Lectures on Meteorites, were those which had been previously used by the Teacher, in the Courses delivered by him upon that subject, at the Russell Institution, in 1825, the London Institution, in 1828, the City of London Literary and Scientific. Institution, in 1829, and the Birmingham Plilosophical Institution, in 1830.

Those with which the Lectures on the Natural History of the Invertebrate Animals were illustrated, formed part of the series employed in Courses, on the Animal Kingdcm, and on the Organization of Animals, given, respactively, at the London Mechanics' Institution, in 1827, and at the Russell Institution, in 1829 . 
tention to remedy, when called upon to repeat the Lectures. Some of these imperfections were necessarily consequent upon the novelty and recent introduction of the entire department, as a branch of the business of the Schools, and the inexperience, in this particular respect, of all the parties engaged. And it must be added, that many minutiæ, philosophically important, and to which it would be requisite carefully to attend, in the instruction of more advanced Students, must necessarily be disregarded, in a seminary for the general education of Boys.

The following is a Syllabus of a Course of Lectures on the Supporters of Combustion and the Simple Combustible Substances, comprehending part of what is called Pneumatic Chemistry, or the Chemistry of the Gases, which was delivered to the three Upper Classes of boys, at Bruce Castle, in the Spring of 1830. The extracts which are occasionally introduced, as well as those occurring in the next Syllabus, may be taken as specimens of the inanner in which the young auditors were addressed. The Lectures were given, in the last hour of school, every day, excepting Saturdays and Sundays, until the completion of each course.

Two Introductory Lectures were delivered on the nature and objects of Chemical Science, and the subjects stated above were then entered-upon in the following order. The ancient and long-prevailing opinion that atmospheric air was an elementary substance having been noticed, it was proposed experimentally to examine this opinion, with relation, especially, to the property possessed by the air of sustaining combustion. It was shown, by the combustion of phosphorus in a confined portion of atmospheric air, that it must consist of two very different gases or species of air; one of which allowed the phosphorus to burn, while the other manifestly extinguished it. These gases were then named,--Oxygen and Azote,-and the proportions, 21 of the former and 79 of the latter, by bulk, in which they are mingled to constitute the air, were stated, and shown in a diagram. The effects of heating lead and mercury in the air for a considerable time, in the absorption of the oxygen and the leaving the azote free, were described, and the oxides of those metals so produced, red-lead, and red oxide of mercury, exhibited to the classes. It was next stated that since these oxides would give out, if more strongly heated, the gas - the oxygen - which they had thus absorbed from the air, we might examine the properties of that gaseous substance in a pure state, free from the azote with which it is mingled in the air. The oxide of manganese, it was then observed, bearing the same relation to the metal manganese, that oxide 
of lead bears to the metal lead,-being the same thing with respect to that metal,-is usually employed for the purpose of obtaining this gas for experiment, on account of the quantity of oxygen which it contains, and the readiness with which it gives it off; specimens of oxide of manganese being exhibited. As the mode of obtaining oxygen by igniting the peroxide of manganese was inconvenient to exhibit, that by sulphuric acid and heat, using a glass retort, was preferred, for experimental demonstration; and the influence of oxygen as a supporter of combustion was exhibited, in its effect on a lighted match, a lighted taper, and inflamed phosphorus, compared with that of the air on the same combustibles.

The subject of Pneumatic Chemistry having thus been opened, the method of collecting and preserving gases by means of the hydro-pneumatic apparatus, or pneumatic trough, was explained; for the sake of familiar illustration a portion of air being blown into a transfer-jar standing over water on the shelf of the trough, by means of a pair of bellows, and then transferred to a bladder, and directed on the flame of a lamp by means of a blowpipe. The history of the discovery and the properties of OxYGEN Gas were then entered upon; those properties which could be numerically stated, as its specific gravity, compared both with hydrogen gas, as the lightest substance in nature, and with common air, being shown in a diagram. The effects of oxygen as a supporter of combustion, were then further exemplified, in the combustion of sulphur and iron, and the results examined; lastly, were mentioned the functions of oxygen in respiration*.

* The fact that a small animal, confined in oxygen gas, lives about three times as long as when confined in the same bulk of atmospheric air, was of course here stated; but that experiment was purposely omitted; as the Teacher was unwilling to familiarize his pupils with the pain to which the animal must necessarily have been subjected. For the same reason he has refrained, throughout his instructions, from making the slightest experiment on living animals, and from all in which even the appearance of suffering might have been produced, or in which it might have been supposed that the animal, though dead when made the subject of the experiment, rnight have previously suffered pain, in being prepared for it. Cruelty to animals, in all its degrees, is strictly prohibited by the Laws of the Schools ; and the Teacher's own view of the subject is this:-that when the reasoning faculties have attained their mature and cultivated activity, his pupils will be able to judge, to what extent the perlormance of experiments involving the suffering, or the death, of animals, may justifiably be carried; but until that state has been attained, no degree of knowledge derivable from such experiments, would compensate for the production in their minds of the basis for inhumanity, which might be formed, by their being accustomed to witness, with complacency, or with indifference, either the actual, or the apparent suffering, of the animals employed.

The Moral Philosophy of the wholesome popular impressions respecting 
Reverting to the experiment with which the course commenced, the properties of the gas remaining in the jar after the combustion of phosphorus in a confined portion of common air, - the Azote, - were examined; and the various other methods of obtaining that gas described. Its effect in extinguishing burning bodies was shown, and its history and properties were related; it being also stated to be the great characteristic element of animal-matter.

The analysis of the air we breathe having thus been effected, -its constituent gases having thus been separated from each other, and their respective properties examined,-it remained to confirm the conclusions which had been drawn respecting its

the effect upon the mind of early cruelty to animals, is as correct, as the $\mathrm{Na-}$ tural Philosophy with which it is commonly associated, is unfounded. It is perfectly true that the delight with which a child beholds the struggles of the impaled beetle, or the contortions of the mutilated worm, though innocent of intentional cruelty at first, will, if unchecked, lead to the infliction of torture upon animals bigher in the scale of organization, as the child's increasing years and strength enable him to subject them to his will; and that, by this practice, from the semblance to human sufferings which the increased sensibility and apparent intelligence of such animals cause them to exhibit, the man may at length become habituated to behold with complacency the sufferings of his fellow-creatures, or even to take pleasure in their infliction or aggravation. That such is the progress of cruelty too many proofs unhappily exist.

The modern discoveries respecting the want of concentration of nervous sensibility in insects and worms - of their diffused, and, as it were, diluted life - and the arguments which have been drawn from their constant exposure, in nature, to injury and mutilation, confirming the inference of their comparative freedom from pain, when organically injured, which is deducible from those discoveries, while, happily, they relieve us from conclusions regarding the animal world which would be derogatory to the Divine Benerolence, leave the injunctions of humanity, so far as the conduct of children is concerned, possessed still of their full moral importance.

Although we may be certain that Shakspeare mistook the appearance for the reality, when he said, that

.......... " " The poor beetle, that we tread upon,

In corporal sufferance finds a pang as great

As when a giant dies,"

and that the mere fact of its natural exposure to such a death would not otherwise be reconcilable with the beneficence which fills creation, yet as the bodily writhings and the endeavours to escape, of insects, and other lower animals, when injured or forcibly detained, are perfectly similar in appearance to those occasioned by the acute sufferings of animals of the higher classes, as Quadrupeds and Birds, the habit of taking pleasure in beholding them must be as injurious to the young mind, as it would be, were they equally the result of an exquisite sense of pain.

As the probable effect upon the immature mind of the practical cultivation of certain branches of Natural History is partially connected with the main subject of these pages, and may be an object of solicitude with many benevolent persons, I have thought that a statement of my own sentiments upon it might not be misplaced on the present occasion. 
composition, by synthesis - by mixing together these two gases, in the proper proportions, and ascertaining whether the mixture possessed the properties of atmospheric air. Accordingly, four measures of Azote and one of Oxygen being mixed, (as a near approximation to the actual proportions of 79 and 21) it was shown that a match, a taper, and inflamed phosphorus, immersed in it, neither burnt with increased splendour, as in Oxygen, nor were extinguished, as in Azote, but burnt just as they did in the air of the room.

In explaining the constitution of atmospheric air as a mere mixture of Oxygen and Azote, it became necessary to explain the difference between mechanical mixture and chemical combination. In mixtures, it was stated, that the properties are intermediate to those of the two elements, a statement accurately justified by the properties of atmospheric air, compared with those respectively possessed by Oxygen and Azotic gases; but that a chemical combination possesses properties altogether different from those of its elements, and acts upon other bodies in a manner peculiar to itself, not possessing the intermediate properties of its elements, but new ones, which are not exhibited by either of them. As examples, the five chemical combinations of Azote and Oxygen were referred-to, and the properties of one of them, the Deutoxide of Azote, or Nitrous Gas, a chemical combination of 14. Azote and 16 Oxygen, by weight, taken in particular ; its properties, not possessed by either of its elements, of extinguishing most burning bodies, but supporting the combustion of phosphorus, and of producing red fumes on mixing with the air, being experimentally shown. Red Lead, Sulphurous acid gas, Sulphuret of Iron, and Sulphate of Magnesia, were also named and exhibited, as examples of chemical combination.

Hitherto, the process of combustion, in every instance in which it had been exhibited in these Lectures, had taken place either in Oxygen gas, or in some mixture or combination containing it. "But there are," (besides Oxygen) it was now observed, "three other bodies, which, from the powerful manner in which they promote intense chemical action, attended by the evolution, or giving out, of heat and light, have been termed Supporters of Combustion; a term, however, which is one rather of convenience, than of absolute scientific truth, as I shall explain, in the course of our chemical inquiries.

"The other supporters of combustion, then, are the substances named Chlorine, Iodine, and Bromine, which are intimately related among themselves; especially by their all being coloured bodies, while Oxygen, as we have seen, has no colour, and is invisible; and they are all likewise found asso- 
ciated together, entering into the composition of different salts, in the waters of the ocean, from which source they are all [more or less directly] obtained;-Chlorine, on account of the important use of some of its compounds in the arts and manufactures, Iodine and Bromine, chiefly for the purposes of philosophical chemistry.

"As I purpose to combine a certain degree of systematic arrangement in my present course of lectures on Chemistry, with an endeavour to bring the subjects of science ' home to your business and bosoms,' by explaining the chemical history of those substances and processes which are of most importance to us all, I shall now introduce the consideration of Chlorine, Iodine, and Bromine, in order to complete our view of the bodies termed by chemists Supporters of Combustion." *

The discovery of ChLorine and the changes of opinion as to its nature were then briefly related, and a quantity of the gas prepared on the lecture-table from a mixture of oxide of manganese and muriatic acid, contained in a retort, and heated by the lamp-furnace; the chlorine being received, as usual, in vessels standing on the shelf of the pneumatic trough, but over warm water, because cold water absorbs the gas. The theory of this mode of obtaining chlorine being deferred, because it could not well have been understood without a previous knowledge of several subjects not yet examined, the principal properties of the gas were pointed out and exhibited; especially its greenish colour, its irrespirable nature (in which it so eminently differs from the supporter of combustion previously examined, Oxygen), its great weight or specific gravity ( $2 \frac{1}{2}$ times that of atmospheric air), and its characters as a supporter of combustion. In illustrating these characters, phosphorus, and the alkaline metal potassium were severally burnt in the gas, the phosphorus taking fire spontaneously, on immersion in it, and be-

* It was the wish of the Conductors of the Schools that the attention of their pupils, in the study of Chemistry, should be directed, chiefly, to the chemical history of those principles and processes, both of nature and of the arts, which are of universal interest and notoriety. But as, in the opinion of the Teacher, it was equally important to the success of the Department, as a branch of General Education, to enter upon the consideration of those subjects, in a truly scientific manner, he endeavoured to combine the object of the Conductors with his own, by adopting an arrangement which might admit of the attainment of both. Thus, in the Course above detailed, the subjects of pure science considered, comprising the Supporters of Combustion, Pneumatic Chemistry, the Simple Non-metallic Combustibles, and Combustion itself, were blended with the chemical history of atmospheric air, respiration, water, and the different kinds of fuel. A corresponding arrangement was adopted for the Lectures on Organic Chemistry subsequently delivered. 
coming converted into the chloride of phosphorus; the potassium also combining with the gas with intense energy, and becoming the chloride of that metal. The strict analogy of the formation and nature of this compound with those of the chloride of sodium, or common salt, naturally led to the expianation of the chemical constitution of that substance; and it was thus shown that Chlorine, the subject of the Lecture, enters in a large proportion (36 parts out of 60 by weight) into the composition of a substance which is very important in the preparation of food, and for many other purposes of common life. The action of chlorine upon quicklime was then noticed, and the chloride of lime, or Bleaching Powder, resulting from that action, exhibited to the classes; and the property of a solution of chlorine of destroying vegetable colours being also stated, and shown by experiment, the use of the cholride of lime, in the operation of Bleaching, was explained. Notices of the effects of chlorine in destroying contagion, and of its liquefaction by pressure, completed the subject*.-

"The next of the simple supporters of combustion which we have to consider, was discovered by $\mathbf{M}$. Courtois, of Paris, a manufacturer of chemical articles, in 1812. It was stated in the preceding lecture, that the three bodies, which, in addition to oxygen, form this class, viz. chlorine, iodine, and bromine, occur in nature associated together in sea-water, in the form of acids united with the alkali soda, constituting various salts. Now the various kinds of sea-wrack, or sea-weed, such as are called Fuci by naturalists, and indeed almost all the plants which naturally grow on the sea-shore, have the power of decomposing the sea-water, and of taking into their own substance some of the chemical bodies which it contains. Thus they retain, among them, the soda, and when they are burnt, the ashes which are left contain a considerable quantity of that alkali. On this account these plants are burnt in large quan-

* Four compounds of chlorine having thus been noticed, their composition was shown in a diagram by making the quantity of chlorine constant, 36 , and then stating the respective quantities of the other bodies uniting with it to form the chlorides; thus :

\begin{tabular}{|c|c|}
\hline Chloride & $\begin{array}{l}\text { Chlorine. } \\
\text { rus. . } 36\end{array}$ \\
\hline & n.... \\
\hline & Lime....... 36 \\
\hline
\end{tabular}

It was preferred to state the composition in these numbers, in order to familiarize the pupils to them, as the representative or equivalent numbers, or the atomic weights, of the bodies named; preparatory to the specific instruction to be given on that subject. 
tities in various parts of the world, for the purpose of manufacturing soda from their ashes. The crude or impure soda obtained by this means, called Barilla, in Spain, and some other countries, and Kelp in Scotland, also contains the Iodine, which the plants have abstracted from the sea-water; and by proper means the iodine is obtained from it in a pure state."

After this statement, lodine, as a solid supporter of combustion, was contrasted with gaseous Chlorine and Oxygen; and its properties were described. Since iodine, in this state, is several thousand times heavier than the air, being indeed much heavier than water, it would have been inconvenient to have compared its specific gravity with that of the air; and the opportunity was taken of making a few explanatory remarks on the subject of estimating the specific gravity of solid bodies, so far as its use in Chemistry is concerned, by comparing it in each instance with that of water; the specific gravity of iodine being thus stated to be $4 \cdot 946$, or very nearly five times as great as that of water. The beautiful vapour into which iodine is converted, on gently heating it, was exhibited, and also the effects of that substance in changing vegetable blue colours to yellow; its solutions in water and in alcohol were also exhibited; together with the test of its presence in any solution, arising from the property it has of forming a deep blue compound with starch. The results lately obtained by means of this and other tests, as to the detection of iodine in what are called mineral waters, as well as in that of the sea, and also in common spring water, were then explained; together with the presence and probable efficacy of iodine, in the waters drank for medicinal purposes at Bath, Leamington, Matlock, Buxton, and other places*. The intense spontaneous combustion ensuing on bringing iodine and phosphorus into contact, was exhibited, in illustration of the properties of iodine as a supporter of combustion; and the subject was concluded by noticing the use of this substance in curing certain disorders of the throat, and the alleged fact of its being the cause of the long established, but not understood, efficacy of burnt sponge, in the relief of such complaints; the sponge being stated to contain iodine, abstracted from the water of the sea in which it has been formed.

* The statements made on these subjects accorded with the views which have of late been generally entertained by chemists respecting them. From the facts, however, which have been detailed in Dr. Daubeny's "Memoir on the Occurrence of Iodine and Bromine in certain Mineral Waters of South Britain," recently published in the Philosophical Transactions, it is prohable that these views will require considerable modification. It will be found, perhaps, eventually, that Bromine, instead of Jodine, is the chief medicinal agent in many mineral waters. 
The remaining supporter, Bromine, was very briefly noticed; and the obvious distinctions between the four supporters of combustion then stated, for Teadiness of remembrance, as fullows: "OXYGen is a colourless and invisible gas; ChLoRINE is a greenish yellow gas; Iodine is a solid body; and Bromine is a liquid substance." Some explanatory remarks on Chemical nomenclature, or the system of expressive names given to the bodies which it is the object of chemistry to examine, suggested by the compounds of supporters with other bodies, named Oxides, Chlorides, Iodides, and Bromides, concluded the history of the Simple Supporters of Combustion.

The relations of atmospheric air to combustion, and the simple substances analogous to Oxygen, that constituent of the air which supports combustion, having thus been fully examined; its relations to respiration were next entered into, in order to complete its history. For this purpose it became necessary to impart some knowledge of another gaseous body, Carbonic acid gas.

The simple combustible Carbon being stated to be the principal constituent of all the substances commonly used as fuelor for the purpose of obtaining heat by their combustionwood, charcoal, common or mineral coal, and coke, were exhibited, as being chief sources or more or less pure varieties of carbon; the existence of that body in a crystallized and absolutely pure form, in the Diamond, being also mentioned. The experiment of burning charcoal in oxygen gas was made, in exemplification of the truth, that, when any of the bodies just named are burnt, either in the air, or in mere oxygen, the carbon they contain unites to the oxygen present, and becomes carbonic acid gas; thus exchanging the solid for the aëriform or gaseous state. The attention of the pupils was then particularly directed to the fact, on account of its im.portance in the chemistry of respiration, that, in this process, six parts of carbon, by weight, combine with sixteen of oxygen, and become twenty-two of carbonic acid, without increasing the bulk of the oxygen.

The ordinary mode of obtaining this aëriform substance for the purpose of experiment, by expelling it from pounded marble, or chalk, or any other variety of the earthy salt called carbonate of lime, by means of dilute muriatic acid, was next exhibited, and the theory of the operation explained, as was done in all cases of this nature. The properties of this gas, especially its great weight, and its power of extinguishing burning bodies, were experimentally illustrated; and the subject was concluded by an account of its mode of action in destroy- 
ing life, either when inhaled in a pure state, or when mixed, in considerable quantity, with atmospheric air. Its occurrence in mines and wells, as Choke-damp, was also noticed, and the means of removing it from wells and similar places, by means of lime-water, described, with some anecdotes in illustration of its fatal effects in such situations, and of the ease with which those effects might have been avoided*.

With this previous information, the alteration induced in the air by breathing was considered. The subject was opened by some particulars of the circulation of the vital fluid; and it was then explained in the following order: the purple colour of blood drawn from the veins is changed to the florid red of arterial blood, on its exposure to the air, and this change is more rapidly effected by its exposure to pure oxygen: the same obvious change takes place with the venous blood exposed, in the lungs, to the action of the air, in breathing: Dr. Black (the discoverer of the distinct existence of carbonic acid gas) first noticed that the air exhaled from the lungs contains a considerable quantity of carbonic acid: Dr. Priestley, some years afterwards, observed that air is rendered unfit for supporting flame or animal life, by the process of respiration, from which fact it was probable that oxygen is consumed during that process : the French chemist Lavoisier subsequently established the facts, that during respiration oxygen gas disappears, and that carbonic acid is evolved in its place; and it has since been ascertained, by our own countrymen Messrs. Allen and Pepys, that, in the respiration of man, the quantities of oxygen consumed, and of carbonic acid evolved, are equal ; so that the oxygen of the air is employed in withdrawing a portion of carbon from the venous blood. Each of these stages of discovery (excepting the last) was illustrated by the appropriate experiments, of detecting the presence of carbonic acid gas in respired air by its precipitating lime-water, ascertaining that respired air extinguisherl a taper, and observing the diminution in bulk of the respired air on removing the carbonic acid by lime-water.

After a brief general view of the Simple Non-metallic Combustible Bodies, the specific consideration of the more important of them (regarded with respect to the objects of the course of instruction here detailed) was commenced with that of HydROGEN. Hydrogen gas being prepared on the lecturetable, in the usual manner, by the decomposition of water effected by the affinities which come into play when iron or

* See the remarks offered in p. 36 , on the use of Chemical knowledge, in reference to this subject. 
zinc is acted upon by dilute sulphuric acid, its properties with respect to combustion were experimentally examined. The history of its discovery by Mayow, Hales, and Cavendish, in succession, was related. Being the lightest substance with which we are acquainted, it was compared with the metal Platinum, as being the heaviest, bulk for bulk, of all bodies yet known; 100 cubic inches of hydrogen gas weighing about $2 \frac{1}{4}$ grains avoirdupois; while the same bulk of platinum weighs $544,34.3$ grains, or about seventy-seven pounds and three-quarters; so that platinum is 242,000 times as heavy as hydrogen. This naturally led to the subject of aërostation, which was briefly treated of, so far as hydrogen gas is concerned; a small balloon, filled with it, being allowed to ascend from the lecture-table.

The discovery of the constitution of water, as a compound of hydrogen and oxygen, was then traced, as successively made out by Macquer, Watt (the improver of the Steamengine), Cavendish, and Lavoisier, and experimentally illustrated. And in exhibiting the composition of water by means of a diagram, the Theory of Volumes in Chemistry was noticed, in showing this fluid to be a combination of 1 hydrogen and 8 oxygen, by reeight, but of 2 hydrogen and 1 oxygen by volume or bulk.

In commencing the history of SUlPHUR or Brimstone, its existence in the earth in an uncombined state was first noticed, among the products of volcanos, in immense layers in rocks of porphyry, and also, occasionally, in some of the Superior or more recent strata composing the earth's crust. Its existence in combination with copper, lead, iron, and other metals was mentioned. Specimens of it were then exhibited, some of them native, or as occurring in the earth; and its more obvious properties and characters were explained. The effects of heat, in successively fusing it, changing its colour and consistency, and rapidly converting it into vapour, accordingly as the temperature is raised, were noticed. The advantage taken of its volatility by a moderate heat, in order to separate it from the bodies with which it is mingled in the earth, and further to purify it, was then mentioned, and the production of what are called flowers of sulphur, (sometimes, improperly, flour of sulphur, ) by this means, was cited, as an example of the chemical process of sublimation, which was performed before the classes; and the result of its operation on some other bodies also exhibited. Its combination with water (milk of sulphur), and its solutions in oil of turpentine and in alcohol being noticed, the properties of sulphur as a combustible were examined, its spontaneous inflammation 
when heated in air, and its more intense combustion in oxygen gas being exhibited; and the interesting fact stated and commented upon, that oxygen gas, in this process, unites with its own weight of sulphur without increasing in bulk; its specific gravity being of course doubled, in thus becoming sulphurous acid. 'The other compounds of sulphur with oxygen were briefly described, and sulphuric acid, as consisting of one of them, in union with water, exhibited, together with some saline combinations of the same body, as Epsom salts, (sulphate of magnesia, with water,) Heavy Spar, (sulphate of barytes,) Gypsum, (sulphate of lime, with water, ) Plaster of Paris, (mere sulphate of lime, being gypsum from which the water has been expelled,) \&c.

The successive, though original, but not independent discovery of Phosphorus, by Brandt of Hamburgh, Kunckel of Dresden, and our own celebrated countryman the Hon. Robert Boyle, was related, in introducing that substance as another of the simple combustibles, and the method of extracting it from bones was explained. Its Physical and Chemical properties were exhibited, and the pupils strongly cautioned against its careless use, on account of the extreme readiness with which it enters into combustion, the difficulty of extinguishing it when once inflamed, and the painful burns it inflicts when in that state. The combinations of phosphorus with the supporters of combustion, oxygen, chlorine, and iodine, were mentioned; and the preparation of phosphuretted hydrogen gas, which inflames, spontaneously, on coming into contact with oxygen, either pure, or as contained in atmospheric air, concluded the subject.

A portion of the history of CARBoN having been given before, when investigating the contamination of atmospheric air by carbonic acid gas, during respiration, the remainder of that subject was now entered into; the various mineral forms of Carbon, as the Diamond, Graphite (improperly called blacklead), and Anthracite or Stone-Coal (Welsh Culm \&c.), being described, and specimens of them exhibited. Carbon was stated to be the basis of the structure of all the beings belonging to the Vegetable Kingdom; and in connection with this statement, the various kinds of charcoal were considered, and those of vegetable carbon, (combined, however, with other elements,) altered by long-continued burial in the earth, as Lignite or Bituminous Wood, and Jet, also the Mineral Resins and the Bitumens, leading to Common Coal. Its existence in Animal-matter was noticed ; and the history of one of its compounds with oxygen, carbonic acid, having already been detailed, the subject, as well as this Course of Lectures, was 
completed, by the examination of the other compound of oxygen and carbon, termed carbonic oxide*.

To the three Lower Classes at Bruce Castle, Courses of Lectures were addressed, in the first half-year of 1830 , on Vegetable and Animal Chemistry; and, with some necessary adaptations, they were afterwards delivered to the Upper Classes : of these Lectures, the following is a Syllabus.

The Course on Vegetable Chemistry was commenced by an account of the Sugar Cane and its cultivation, followed by a description of the means employed for extracting the juice from it; a statement of the nature and composition of the juice, and an account of the method adopted for its conversion into the solid Raw or Moist Sugar,-various specimens of which, both of East-Indian and West-Indian manufacture, were exhibited to the classes.

The two kinds of saccharine matter contained in the juice of the cane and other sources of sugar, were then described, white sugar-candy, and the best loaf-sugar being named and exhibited as examples of the one,-the crystallizable, and molasses as an example of the other, - the uncrystallizable kind. The object of refining sugar, or that of the processes conducted by the Sugar-Baker, was stated to be the separation of the two kinds of sugar from each other, and the modified crystallization of theformer kind, for domestic use. Some particulars of the history of this art were given, that opinion being regarded as the most probable, which derives it originally from China.

A somewhat detailed account was then entered into of the process of refining sugar, founded chiefly upon the materials communicated to Mr. Brande by Mr. Daniell, and published in the "Manual of Chemistry" of the former chemist. It was illustrated by rough extemporary models of the implements, moulds, \&c., employed in the process, by specimens of the lime, albumen, and other substances made use of, and by numerical diagrams of the proportions of refined sugar yielded by given quantities of raw sugars of different samples.

Here were introduced some particulars of the method invented by the late Mr. Edward Howard, of conducting the evaporation of the syrup, or solution of raw sugar, which forms part of the process, in a vacuum, in order to avoid the dark

- The consideration of Boron was intentionally omitted in this view of the history of the non-metallic combustibles; on account of its not being an important body, so far as the chemistry of nature and of the arts is concerned, and of its not having any very important relation to the supporters of combustion or to the other comb ustibles. 
colour (arising from the development of the carbon in a portion of the sugar) which often ensues from the comparatively high temperature necessary to effect the evaporation, under the ordinary pressure of the atmosphere, as formerly conducted. In connection with this subject, the nature of ebullition or boiling was explained, and also the relations of the temperature at which it takes place, to the atınospheric pressure to which the boiling fluid is subjected, an illustrative experiment being performed, by means of a modification of the Pulse-glass, in which spirit of wine was made to boil violently, in a vacuum, merely by the heat of the hand applied to the instrument. 'The manufacture of sugar-candy was also described.

Some degree of general knowledge of the preparation and nature of the vegetable principle called Sugar having thus been imparted, the Classes were prepared to take an interest in the history of its use, which was next briefly examined; the notices of this substance occurring in the works of Strabo, Varro, Dioscorides, and other ancient authors, being mentioned, together with the allusions to it by old travellers, as manufactured in the East, its introduction into Western Europe during the Crusades, and the early cultivation of the Sugar-cane in Sicily. The question as to its being an indigenous production or not, of South America, was also noticed, and the affirmative opinion adopted, and supported by the citation of various authorities.

The natural history of Sugar being now resumed, a view was taken of the more important varieties which exist of this substance, in addition to that yielded by the Sugar-cane. The Sugar's of Beet, Grapes, and Honey were briefly advertedto, the manufacture of Beet-Sugar in France, and that of Grape-Sugar, by the chemist Proust, in Spain, being also mentioned. The history of Maple-Sugar was given somewhat more in detail, with an account of the tree (the Sugar Maple, Acer saccharinum) in which it is contained in the form of sap, and of the characters distinguishing it from Cane-Sugar. In the consideration of this subject the following remarks were introduced: "All the substances which result from organization, or which are formed by the vital forces of animals or vegetables, are peculiar in their nature in each organized being. 'Thus, although muscular fibre, or flesh, is afforded by many animals, and, in them all, consists of two animal substances, called fibrine and gelatine; while fibrine and gelatine are composed of azote, carbon, hydrogen, and oxygen, in every animal, yet the flesh of every class and indeed of every species of animals, is different. Thus, the flesh of the Mammalia is distinguished from that of Birds, and the flesh of Birds from that 
of Fishes; whilst that of the $\mathrm{Ox}$ is equally well distinguished from that of the Sheep, and the flesh of the Turkey from that of the Partridge. It is the same with the subjects of the Vegetable Kingdom; many different classes and genera, and, still more, different species of plants produce Wood, Gum, Starch, and Sugar; but the timber of the Oak is distinct in its nature and properties from that of the Fir, as is the gum of the Acacia from that of the Cherry-tree, the starch of Wheat from that of the Potatoe, and-which brings us to our present subject, the Sugar of the Sugar-cane from that of the Maple-Tree or the Beet-root." *

* The above statement, it may be well to remark, lest my views upon the subject should be misunderstood by proficients in chemistry and physiology, was made with reference to the substances which are known to us as results of organization only, and it was even confined to them, as they occur in nature, forming distinct organs, or parts of organic structures, or proximate chemical elements of them, in the form and peculiar condition in which they actually exist in organized beings. From the connection in which it was made in the Lectures, it would be understood in a general sense agreeing with this, by the young pupils to whom it was addressed. It is not applicable, at least in the form given in the text, to those earihy and alkaline salts which occur in the Mineral as well as in the Animal and Vegetable Kingdoms, and which can also be produced in the laboratory of the chemist, in a state as perfect as that in which they occur in nature. Nor is it applicable to all the compounds which result from the analysis of Animal and Vegetable fluids or textures, and which, in the present state of organic chemistry, must be regarded, provisionally, as the proximate chemical elements of those fluids or textures; but it is applicable, I apprehend, to all the proximate organic elements as they exist in the living structures (and to a certain extent after the death also) of the beings which they contribute to compose. Thus, although the sugar of milk, Cholesterine, and Urea, (and animal fat also, if the experiments of Bérard and Döbereiner on its artificial production be conclusive,) may be regarded as definite and stable compounds, since they are all crystallizable, yet as they exist in the living body secreting them, they will be different, I conceive, in every species of animal in which they are found; while to Fibrine, Albumen, Gelatine, and many other animal substances, the same reasoning is still more applicable. And though the pure woody fibre be known to consist of equal parts of water (or its elements) and carbon, in every kind of wood, yet, in the form or condition in which that principle enters into the composition of the wood of the various trees, it must be different in each species.

It would appear from an extensive review of the subject, that the definite compounds in which no metallic substance is essentially present (for there is no other character by which they can be universally designated) which exist in, or result from the analysis of, the subjects of nature, increase in stability and in number as we descend in the scale of organization, if we compare together the three kingdoms of nature, in this respect. Thus no principle of animal life, devoid of metallic elements, is of so stable a constitution or perhaps of so definite a nature, as the woody tibre and the sugar of vegetables; or, - to state the truth in the most cautious terms, it is far more easy to obtain such principles from vegetables than from animals; while the mineral kingdom is entirely constituted of definite and stable compounds. The paucity of such compounds in the animal king- 
An account was next given of the properties of pure crystallized Sugar, illustrated by specimens of sugar in that state,

dom will be still more apparent, if we exclude from consideration those which do not in reality form part of the healthy system. The four animal substances above mentioned, are perhaps the most definite combinations which are peculiar to animal chemistry ; but Cholesterine and Urea are merely the results of excretory operations, the manifest design of which is to remove useless or injurious matter from the system; and the sugar of milk forms part of a fluid which is not truly an element of the vital system of the animal producing it, but is intended to be digested and converted into principles more highly animalized, and (consequently?) less definite, in the stomach of its young. The only substance, among those above enumerated, which occurs as an element of the healthy system, is fat, and that is precisely the one, which, so far as our present knowledge extends, is the least definite of the whole.

The case, however, is different, whell, confining our attention to one of the organic kingdoms, we compare with each other different groups of animals or of vegetables, of higher and lower organization, respectively; for it is the highest of these only, in each kingdom, which furnish definite and stable principles of this kind. Thus nune but the Vertebrata and Annulosa, among Animals, appear to yield non-metallic compounds so definite and so stable as the Sugar of Milk, Urea, and Elytrine; while none but the Dicotyledonea and Munocotyledonea, which correspond to them in station aunong Vegetables, yield principles so definite and stable as the woody fibre, sugar, and starch. It is necessary, however, in tracing analogies of chemical constitution between subjects of the two organic kingdoms, to bear in mind the important fact, that although such analogies may as readily be discovered, and are as perfect, as those by which every considerable group in one kingdom, is represented by a group in the other, (as has been shown by Desfontaines, MacLeay, and Agardh,) yet the series of chemical substances which forms the organization of each kingdom is radically different. Thus, the phosphate and carbonate of lime, constituting, either separately, or in combination, the skeleton, in almost every group of animals, are represented, throughout the vegetable kingdom, by the woody fibre or lignin, or by some compound of carbon, oxygen, and hydrogen nearly related to that substance. If this essential difference of the series be not borne in mind, we shall be likely to overlook analogies where they really exist, and to imagine them where they have no real existence.

With respect to those products of organization which occur also in the mineral kingdom, or which can readily be produced by art, and to the composition of which an alkaline or earthy metal is essential, such as carbonate and phosphate of lime, other laws seem to prevail. When simple binary salts (as those just mentioned, for example) constitute animal textures; they appear to differ in their state of aggregation only, in each animal or group of animals. Thus, the carbonate of lime which forms the shell of the Chama Gigas among the Mollusca has nearly the structure of fine-grained saccharoid marble; while that which constitutes the tube of the Teredo gigantea, among the Annelida, is formed of fibrous crystals. When two or more such salts are united, or intimately mingled together, to form an animal texture, as in the bones and the teeth of the Vertebrata, the law which applies to the non-metallic compounds remains valid, and is manifested by a difference in the respective proportions of the salts. The bones of the Lion, for example, contain different proportions of phosphate and carbonate of lime from those of the Sheep; and the teeth of the Mammalia differ in the same manner from those of the Amphibia.

Probably the several modes of existence of the proximate constituents of H 2 
and by models of its crystalline forms. It was stated that the taste of sugar was nearly peculiar to it, among vegetable substances, but that the metallic salts called acetate of lead (sugar of lead) and nitrate of silver also possessed it, especially the latter. " " But in these salts," it was remarked, "6 the sweet taste is succeeded by a very nauseous one, while in sugar it is permanent and pure; remaining as long as there is any sugar acting upon the organs of taste, and remaining the same to the last." The pupils were cautioned, by reference to these facts, never to regard any particular taste or smell, or any other merely sensible property, as certain evidence of the presence of any particular substance, whilst that evidence should be unconfirmed by other tests.

Some preparative illustrations of the difference between a mere mixture and a chemical combination having been given, the chemical composition of sugar was now explained. It was stated to consist of Carbon (or Charcoal) and Water, as the most familiar mode of representing the subject; but in order that the pupils might not in any degree be misled by this statement, the constitution of the water entering into the composition of sugar, as being itself a compound of oxygen and hydrogen, was also stated, in the diagram exhibiting the relative proportions, in which the elements of sugar are combined. Dr. Prout's views on the nature of sugars being partially adopted, pure Cane-Sugar and Honey-Sugar were selected for description upon this occasion, as being the extreme terms of the series which is formed by the different varieties of this substance. An experimental proof, well known to chemists, of the existence of carbon in sugar, and of the sensible identity of that carbon with charcoal, was here introduced, by immersing a quantity of finely-pulverized loaf-sugar in concentrated sulphuric acid, when the carbon, being extricated in great volume by the action of the acid, rises up from the glass in which the experiment is made, in the form of an apparently

organized substances here alluded-to, may be connected with what Dr. Prout has termed Merorganization; and thus the fixed fat, sugar of milk, Cholesterine, and Urea, of animals, may be, in the crystalline state, the original definite principles, which, when merorganized, constitute, respectively, those elements of living animals to which we apply the same appellations; while lignin may, in like manner, be the definite basis (merorganized by water?) of wood, as Dr. Prout has stated sugar to be of starch. I am not aware of any saline compound which can be pointed out in a merorganized form, (unles 3 the carbonate of lime which occurs in certain Cryptogamous plants be an example,) but it seems probable, I think, that the siliceous concretion of the Bamba, called Tabasheer, may be merorganized silica, and in that case it will probably be found that the epidermis of the Graminece, \&c. consists rather of that substance, than of silica in an absolutely pure and mineral state. 
solid black pillar, being raised up by the evolution of gaseous matter, which in part becomes entangled in the spongy carbon. In conclusion, the substance from which Manna derives its flavour was distinguished from sugar. The subject of Sugar having been thus treated, to the great interest of the young auditors, evinced by their patient attention during each Lecture; and their pertinent inquiries after it, the history of Starch was next considered.

This was commenced by a general account of the nature of the feculce of Vegetables, and of the processes adopted for obtaining those of Wheat and the Potatoe, specimens of both varieties being exhibited, and of the former, in its natural condition, as well as in its coloured state as used for stiffening linen.

The five- or six-sided columnar form of starch, as usually manufactured, was particularly noticed; and the mode of production of such columns having become a subject of considerable interest in several branches of science, which might hereafter engage the pupils' attention, the formation of them in the mud of ponds drying-up by the sun, and their existence in the ore of iron called columnar clay-iron-stone, were also mentioned, in both which instances their production is referrible to the same cause as that which produces them in starchcontraction, from the removal, by evaporation, of the water previously mingled with the particles of the substance *. The chemical properties of starch were described and experimentally exhibited; including the test of its presence afforded by the circumstance of its forming a blue compound with iodinet,

* Having, in a paper on the remarkable natural excavations in granite, which have been called rock-basins, recently published in the Philosophical Magazine and Annals (vol. viii. p. 331.), alluded to the structure of the columnariron-stone of the Isle of Arran, as being of igneous origin, it may be proper to mention that the variety referred-to and exhibited in the Lecture was that which occurs in lenticular concretions, in the Stuffordshire coal-measures, the interior of which presents a columnar structure which must have been produced by contraction, in the manner described in the text.

It may also be useful to record in this place a fact which I have lately observed, with respect to the production of the prismatic or columnar structure, by the contraction consequent on desiccaporation. The floor of one of the Gymnasia at Bruce Castle having been made of stiff clay, which had not been properly tempered for the purpose, by the admixture of other materials, became divided by deep cracks, all over its surface, into incipient columns or prisms. But on repeated attentive examination of them, in every part of the floor, I could discover none but irregular trapezoidal and pentagonal columns, no indication whatever of hexagonal divisions being perceptible.

+ See the preceding Syllabus of the Course of Lectures on the Support ers of Combustion, p. 91 . 
and its conversion, by torrefaction, into the substance called British Gum, which, in common with other varieties of amylaceous matter resulting from the action of heat upon starch, has lately received the chemical appellation of Amidine. The varieties of Starch and Amidine used as articles of food were described, and specimens of them exhibited: these include, among others, Indian Arrow-Root, which is a pure starch, prepared from the root of the Marantha arundinacea; Sago, obtained from the pith of an East Indian Palm-tree, and Tapioca, from the root of a South American plant, the Iatropha Manihot, both which exist in the form of starch in the plants themselves, but are more or less converted into amidine by the heat employed in their manufacture. The vegetable principles called Gum and Gluten were then mentioned, the gum of the Acacia, termed Gum Arabic, and the gluten of Wheat, being taken as examples of them.

An important object of this Course was to explain the changes which either take place with, in nature, or are artifcially induced upon, the chemical principles of vegetation, by alterations in the proportions or in the arrangement of their ultimate constituents. It was commenced, accordingly, with the general view of the chief nutritive elements of vegetable matter, of which the foregoing is an epitome. Having thus prepared the way, the Physiological and Chemical history of Germination was entered upon. The chemical principles of seeds already described being again enumerated, the structure of seeds (chiefly of the Dicotyledonous class) was explained, enlarged drawings of the epidermis or outer skin, the cotyledons or seedlobes, and the germ, being exhibited in illustration, and each of these parts being demonstrated in actually germinating seeds. It was shown by these means, that the office of the radicle of the germ was to descend into the earth and form a root, that of the plumula of the same organ, to rise into the air and expand into stem and leaves; and that of the cotyledons to supply the young plant so produced with nourishment. A view was then taken of the conditions which are necessary in order to enable a seed to germinate, with respect to the presence of moisture and of oxygen, and to the preservation of a certain temperature, various facts being related in illustration of each condition, and the history of our knowledge on these points briefly traced. The changes in the condition and structure of the seed, which constitute germination, were next pointed out, as well as the chemical changes undergone by the substance of the cotyledons, consisting, essentially, in the conversion of the comparatively insoluble and innutritious starch which they contain into soluble and nutritive sugar, which is supplied to the grow- 
ing germ by vessels ramifying through the cotyledons, the distribution of which, also, was shown in an enlarged drawing. The chemical constitution of Starch, as a compound of carbon and water, was then explained, and its difference in properties from Sugar, ascribed, to a difference in the proportion and mode of existence of the water, in these two substances; the artificial production of sugar from starch, by the long-continued action of heated water, being related in illustration.

The history of Germination having thus been considered, the process of Malting was next described and examined, illustrated by specimens of raw and malted grain, and by diagrams showing the comparative composition of Barley in both states; the quantities of starch and gluten being diminish. ed, and those of sugar and gum increased, in the malted grain*. This subject naturally led to that of Brewing, in treating of which, the nature of the fermentation, or peculiar chemical change (consisting in the conversion of sugar into Alcolıol or pure spirit), by which Beer, Ale, Wine, and other fermented liquors are formed, was explained. The process of Distillation was experimentally illustrated, in showing the means of obtaining, from those fermented liquors, the peculiar fluid from which they all derive their invigorating, as well as, when misused, their intoxicating quality;-a portion of (white) Brandy being distilled from Port-wine, and its properties examined. In connection with this subject some particulars were here stated, derived from the researches of Mr. Brande, of the quantities of alcohol respectively contained in the different wines and other liquors. Some account was next offered of the method of procuring the various kinds of spirituous liquors, as Brandy, Rum, and Geneva, as well as of the mode of obtaining proof-spirit, and lastly pure alcohol, from them; the substances employed in the various processes described being exhibited on the lecture-table. The properties of Alcohol were then described, and experimentally illustrated, and those expressed by numbers, such as its specific gravity, and the specific gravity of its vapour, shown in diagrams. Particular notice was taken of its permanence in the liquid form, when exposed to the lowest temperatures with which we are acquainted, it being stated to be almost the only substance ordinarily liquid, which has never yet been frozen by artificial means, or observed to freeze in nature. Its use, accordingly, in the construction of

- Considerable difference of opinion existing among chemists with respect to the distinct existence (in Barley) of the principle called by Proust Hordcin, and the Teacher never having made any experiments on the subject himself, it was deemed best to omit mentioning it. Dr. Thomson regards it as being merely a modification of starch. 
Thermometers designed to indicate very low temperatures, was illustrated by reference to the Alcohol Thermometers employed by Captain Parry, during his winterings, in Prince Regent's Inlet, and Melville Island. The cold produced by the rapid evaporation of alcohol was shown by referring again to the pulse-glass (exhibited before in illustration of the subject of ebullition), in the cold felt by the hand which held that bulb of the instrument from which the evaporation took place. The colours communicated to the flame of alcohol by various saline substances were exhibited, as well as those substances themselves; its use in chemical lamps, on account of its giving no soot when burnt, was mentioned and experimentally illustrated, together with the great heat of its flame, as evinced by the ignition in it of solid bodies, and the phænomena of its slow combustion (without flame) on platinum wire. 'The history of alcohol was then terminated by the statement of its chemical composition, it being regarded (agreeably to the opinion of Gay-Lussac, ) as a combination of olefiant gas (the nature of which was illustrated by reference to the gas obtained from oil for the purpose of illumination, and which contains a large proportion of olefiant gas) and water, the separate elements of both, however, being also stated,thus :-

\section{ALCOHOL IS COMPOSED OF}

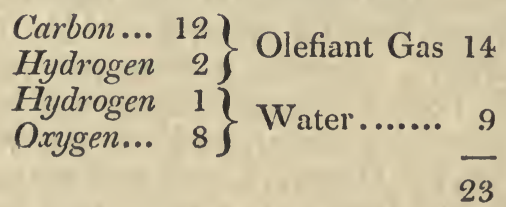

The Course was concluded by an account of the further change, which, under certain circumstances, takes place in the arrangement and relative proportions of the substances which compose sugar and alcohol, terminating in the production of Vinegar from them. The manufacture of vinegar from vinous liquors, and the phænomena which take place during that process were described; it being stated, that, although carbonic acid is evolved during the process, as in the vinous fermentation, "in that case, both the carbon and the oxygen composing the carbonic acid are derived from the sugar in the fermenting liquor; while in the process we are now considering, called the acetous fermentation, the carbon only is given out by the liquor, the oxygen being obtained from the air. It is on this account that while sugar is converted into Alcohol in close vessels, or at least in vessels which do not freely com- 
municate with the air, alcohol can be converted into Vinegar, only in vessels exposing the liquors containing it to the free action of the atmosphere." It was also mentioned that while the vinous fermentation appears never to take place in nature, ready-formed alcohol being never found in plants, the acetous fermentation does, - acetic acid, or the pure principle of vinegar, existing, ready-formed, in the sap of many plants, either uncombined, or united into a salt with the earth lime, or the alkali potash. Vinegar being the first acid substance which had formed a subject of the Course, the opportunity was here taken to explain the nature of the class of bodies termed Acids by chemists, and to exhibit the characteristic properties, of their sour taste, conversion of vegetable blue colours to red, and union with bases into salts ; the last-mentioned property being illustrated by reference to the action of vinegar upon carbonate of lime, which was experimentally slown, and also by the anecdotes, of the solution of a costly pearl, in Vinegar, by the celebrated Cleopatra, Queen of Egypt, (pearls being composed, chiefly, of carbonate of lime, ) and the use of Vinegar, by Hannibal, in facilitating the passage of his army over the calcareous rocks of the Alps, it being supposed that he might have employed it, to partially dissolve and soften a particular mass of limestone, which might impede his progress through some narrow pass. The nature of Acetic acid was next described and shown by experiments, and the salts which it forms, called acetates, such as acetate of lead, or sugar of lead, acetate of copper, commonly called verdigris, \&c., exhibited. The modification of acetic acid obtained from Ants, and termed Formic acid, was also noticed, and its use as vinegar by the Laplanders mentioned. In describing the composition of vinegar, its production from wood, by heat, (in the form of what is called pyroligneous acid) was alluded-to; and both wood and pure vinegar (or acetic acid) being regarded as compounds of carbon and water, the facility with which vinegar is produced from wood, by this means, was illustrated by showing how closely these substances approach to each other in the proportions of their elements; 100 parts of pure roood or lignin, consisting of 50 carbon and 50 water, and 100 parts of pure vinegar, or acetic acid, of 47 carbon and 53 water. But in order to explain in some measure, at the same time, how bodies so widely different in their obvious nature and properties, can be so nearly identical in chemical composition, pure wood was regarded, provisionally, as a combination of 3 atoms carbon 18 and 2 atoms water $18,=36$, while pure vinegar was stated to be (as deduced by Dr. Turner from Dr. Prout's analysis) a combination of 4 atoms carbon 24 and 
3 atoms water $27,=51 *$. In consequence of the frequent expression of the composition of bodies in atomic quantities, in this Course of Lectures, the pupils had by this time acquired, almost insensibly, a knowledge of the nature of the atomic or definite-proportional constitution of substances in chemistry ; and that the foregoing explanation was satisfactory to their minds, was evinced by the observations upon it, which were involved in the questions, proposed by them, after the Lecture in which it was given.

A resumé was finally given of the chemical nature of the vegetable principles, as consisting, essentially, of carbon and water; and the difference between Proximate and Ultimate elements or constituents, was explained, by reference, (among other compounds) to alcohol, the proximate elements of which appear to be olefiant gas and water, as before stated, while the carbon, hydrogen, and oxygen, of which that olefiant gas and water themselves consist, are its ultimate elements or constituents; some particulars being also related of the more complicated vegetable compounds.

* The atomic constitution here assigned to lignin, is deduced from Dr. Prout's analysis of that substance (Phil. Trans. 1827.), from which it appears to be composed, as stated above, of equal parts of carbon and water. For this deduction $I$ am alone accountable, as $I$ have not found an atomic composition assigned to lignin in any chemical work, though all chemists have of late regarded it as a definite principle.

It has often been remarked that Teaching is one of the most effectual modes of Learning, - that the endeavour to adapt any branch of knowledge to the apprehension of those who are ignorant of it, frequently leads to the discuvery of truths previously unknown to the instructor himself. This proved to be the case with me in the present instance : the consideration and comparison of the atomic constitution of lignin and that of acetic acid, into which I was led by the desire of explaining to my young auditors how it was that vinegar should be so readily producible from wood, first led me to perceive that a class of bodies might probably exist, in which the proportions of the elements were the same, but their atomic constitution radically different. How long the existence of such bodies may have been known to chemists, without having been distinctly enunciated, I am not aware; but since the probability of their existence occurred to me in preparing these Lectures, in the spring of 1830 , Berzelius has noticed this class of bodies, in his paper on what he has called isomeric substances, or those which consist,apparently, not only of the same proportions of their elements, but of the same respective numbers of atoms of them, but which, at the same time, possess entirely different properties, both physical and chemical. In that paper he has expressed an opinion that it will be expedient, in the further progress of chemical science, to designate, also, the class of bodies I have alluded to, by some distinctive and characteristic appellation.

It will probably be found necessary, in the further investigation of this subject, to ascertain how far Dr. Prout's doctrine of Merorganization bears upon it. It will be requisite, 1 apprehend, to distinguish those substances which truly belong to the class in question, from those, which, being merorganized, belong to it in appearance merely. 
The Course of Lectures on Vegetable Chemistry was succeeded by a similar course on the Chemistry of Animal Life, in which some of the most important parts of that branch of knowledge were familiarly explained, in the following order. The general nature of the organs of deglutition and digestion, especially in man, was described, drawings or prints of those organs being exhibited in illustration, and the latter process, as well as those of chylification and sanguification, embracing the entire operation of the conversion of food into blood, was explained. The chemical composition of animal substances was next noticed, and illustrated by a comparison of the results of the destructive distillation of vegetable and of animal matter, that of the latter being performed during the Lecture, and its results examined; Gelatine, in the form of isinglass, being the animal substance selected for the experiment. This naturally led to the chemical history of Ammonia, as the most important and characteristic result of the destructive distillation of animal matter; and since Vegetable bodies, it had been shown, might be regarded, in general, as being, essentially, compounds of carbon and water; so Animal substances, the ultimate elements of which are carbon, oxygen, hydrogen, and azote, (the hydrogen being always contained in them in appropriate quantity to form water with the oxygen, and ammonia with the azote, might be regarded, it was shown, as essentially consisting of carbon, water, and ammonia*.

* The statement that the hydrogen contained in the more important animal principles, (those which are neither acid nor oleaginuus,) is in such proportion, as to convert their oxygen into water, and their azote into ammonia, having been adopted from Gay-Lussac and Thenard, by Dr. Turner and other chemists, appeared to be sanctioned by their authority; it was eminently adapted to the purposes of these lectures by its simplicity, and its analogy to the statement already given of the constitution of the vegetable principles, and by the readiness with which it might consequently be retained in the memory : on these accounts it was made use of throughout this course on Animal Chemistry. But while the statement that the vegetable principles which are neither acid nor oily or resinous (together with one acid principle, - the Acetic), contain oxygen and hydrogen in the exact proportions for forming water, is rigorously accurate, the analogous statement, as above enunciated, respecting the corresponding animal principles, cannot be regarded, I think, in the present state of science, as fully established; and there seems reason to believe that it will be found inapplicable to more than one of the compounds which have been included in it by Gay-Lussac and Thenard. Dr. Turner has prefaced the division on Animal Chemistry of his "Elements " of that science, by a repetition of this statement; but out of the six analyses of the bodies to which it relates, some by GayLussac and Thenard, and others by Dr. Prout, which Dr. Turner has cited in the subsequent pages of that division, there is only one, that of fibrine, by the former chemists, which supports the statement. In four of the others there is an excess of hydrogen, and in the remaining one a deficiency of that principle. And although this discrepancy may be in some measure attri- 
The nature of ammonia was illustrated by reference to the various preparations of that substance and its salts, many of which, from the circumstance of their being obtained, at a former period, chiefly by the destructive distillation of the horns of Deer, (as they now are by that of the horns, hoofs, and refuse skin of animals in general,) have been called salts of Hartshorn, spirits of hartshorn, \&c.; and including common smelling salts, or the sesqui-carbonate of ammonia of Chemists.

The physiological nature and the chemical composition of the blood were next described, the opportunity being taken of explaining the history of Albumen, as the most important element of the blood, illustrated by experiments on the white of eggs, which consists of that principle nearly in a state of purity. The nature of the blood having thus been explained, the phænomena of its circulation through the body were detailed, accompanied by graphic illustrations of the organs concerned in that process. After the performance of a few experiments (similar to those made at the beginning of the Course on the Supporters and Combustibles, as described at p. 85) showing the existence of two distinct species of air in that which we breathe; and that one only of these-the Oxygen -is the supporter of life ; and after some preliminary information had been imparted on the nature of carbonic acid gas, also experimentally demonstrated, the alteration induced in atmospheric air, by respiration-consisting in the exchange of a portion of its oxygen for an equal bulk of carbonic acid, was experimentally shown. With this subject the Course was concluded, in which the composition, properties, and functions of the blood, as the great agent in building-up the animal frame, had thus been examined, together with the provision for preserving it in a fit state for the requirements of the body, (and also for the completion of the process by which chyle, or digested food, becomes blood,) by the action of the atmosphere.

During the entire period of the delivery of these Lectures, $I$ was required, by the arrangements adopted for the tuition of the various classes at Bruce Castle, actually to teach

butable to error's in the analyses, as minute accuracy in the analysis of organic bodies is so difficult of attainment, especially, perhaps, of such as contain azote in addition to hydrogen, yet the deviation from the rule, of albumen and urea, as evinced by $\mathrm{Dr}_{\mathrm{r}}$. Prout's analyses of those bodies, can scarcely, I conceive, be ascribed to that cause. Dr. Prout's forthcoming researches on the animal principles, in continuation of those already published by him on the composition of the simple alimentary substances, will probably remove the obscurity in which this subject is at present involved. 
five classes (each occupying an hour) every day, except Sundays, in addition to the Lecture given on five days of the week; and, at Hazelwood, the number of hours daily occupied in actual instruction has been, uniformly, still greater. Extensive collections of materials for the Lectures and a rigorous scrutiny of them, being therefore impossible, it became necessary to select and employ the best authorities, from which the instruction to be imparted might be derived. In the preparation of the Lectures on the Supporters of Combustion and the Combustibles, the principal authorities employed, were, the second edition of Mr. Brande's Manual of Chemistry, the second edition of Dr. 'Turner's Elements of Chemistry, and Sir H. Davy's Elements of Chemical Philosophy. I have in general united the detail of facts as given by Dr. Turner, with the arrangement of Mr. Brande: Sir H. Davy's Elements, although not perhaps the most perfect or the most valuable production of its illustrious author, was yet admirably adapted for the purpose I had in view, as well by the elevation of the philosophic spirit which pervades it, as by the simplicity and elegance of the statements it contains; for I have uniformly found, that the most profoundly philosophical views of the laws of nature, when properly explained and expanded into detail, are the best adapted for the comprehension of the young mind, and indeed for that of learners in general.

In the preparation of the Lectures on Vegetable and Animal Chemistry, the same authorities were used, with the addition of Sir H. Davy's Elements of Agricultural Chemistry, which is perhaps one of the most perfect works, on a particular department of a science, that has ever been produced, uniting comprehensive philosophic views with great accuracy of detail, and a just and beautiful application of the principles of Chemical science to the practice of the arts of Cultivation. I also endeavoured to bear in mind, throughout the preparation of this Course, the views partially developed by Dr. Prout, in his paper on the ultimate composition of simple alimentary substances, published in the Philosophical Transactions for 1827, to which I constantly referred, when treating of any of the subjects mentioned in it. Dr. Paris's Medical Chemistry, the notes accompanying Mr. Phillips's Translation of the Pharmacopoia of the Royal College of Physicians of London, Sir James E. Smith's Introduction to Physiological and Systematic Botany, and Dr. Fleming's Philosophy of Zoology, have furnished me with some information, on subjects particularly treated of in those works.

I have endeavoured, in the preparation or delivery of all my instructions, to unite with the statements derived from the au- 
thorities employed, the results of my own practical cultivation of several branches of science, together with the improvements received from time to time, during the progress of my instructions, by the departments of knowledge concerned,-for becoming acquainted with which I have been advantageously situated, in my connection with several of the Philosophical Journals published in London.

I have now to describe the mechanism of the Class-Instruction in Physical Science, which has been given at Hazelwood and at Bruce Castle. A room at each School having been converted into a Laboratory, for the preparation of the illustrations required in the Lectures, and fitted-up as a repository also for the apparatus, materials, specimens, drawings, \&c. employed in them, this has commonly been used as the Classroom for the department. In this room, each Class to which this species of instruction has been given, consisting of from about five or six to twenty boys, has assembled, at a certain hour, fixed throughout a considerable period; and either for one hour every day (Sundays excepted), or for two hours, according to the prescribed exercises of the individual pupils, and the general routine of the School for the time being.

Two distinct methods of Class-Instruction have been adopted; in one of which the Teacher instructs, usually by the combination of reading from some work, taken as a text book, with extemporary amplification; while in the other each pupil, having a book selected for his use, reads to himself, applying to the Teacher for assistance (always in as low a voice as possible, to avoid disturbing his class-fellows) whenever he finds a difficult passage, or requires any information on the subject.

In the former mode of instructing the Classes, the subjects of the Lectures have occasionally been re-considered by individual Classes, on the day following that of their delivery in the School-room; and this early re-consideration, in certain branches of science, has been found highly advantageous to the progress of the pupils. In this case, the Teacher has used his own notes for the Lecture, as a text-book, and the laboratory-table being prepared with the apparatus, specimens, \&c. employed in the Lecture, he has commenced the hour's instruction by recalling the subjects to the attention of the pupils, by questioning them, in succession, on the most important; and then leading them to discover for themselves, by appropriate questions, interspersed with fresh information, still more important truths in science, deducible from those already communicated in the Lecture. At suitable intervals the pupils are allowed to propose inquiries themselves, which are an- 
swered by the Teacher. More frequently, however, a work has been selected by the Teacher, as a text-book for Classinstruction, from which he has read to the Class, either the whole, or suitable portions selected for the purpose; interspersing the reading with observations and corrections of his 'own, and also frequently entering into detailed explanations of the author's statements, when they were of too profound or too complicated a nature, to be immediately apprehensible by his pupils; giving proper opportunities for receiving questions from them, and occupying a portion of every lesson, in ascertaining, by proposing questions himself, the degree of progress made by each pupil in the particular subject before him. The performance of Experiments, and the exhibition of specimens and drawings have been combined, as much as possible, with the oral instruction*.

Those portions of "Harry and Lucy," (forming part of Mr. and Miss Edgeworth's "Early Lessons,") which bear upon the truths of physical science, and are explained in that work in the most familiar terms, have been adopted for the

* It will readily be conceived that a very numerous series of pictorial representations will be required, for the adequate illustration of the Course of Instruction in the Physical Sciences, as stated in p. 81. On this account the foundation has been laid of a collection of prints and drawings, for the use of this department. Drawing is one of the regular branches of instruction in the Schools, and the Teacher has accordingly availed himself of the skill of some of those pupils who have attained a degree of proficiency in that art, in the preparation, under his superintendence, of large drawings and diagrams, expressly adapted to the illustration of his Lectures and lessons. From their pencils, exerted chiefly "out of school hours," or during intervals of comparative leisure, he has obtained copies, on a highly-enlarged scale, of the illustrative engravings contained in some of the more important classbooks. These have been employed in the lessons given from those works, and the pupils, having thus received explanations of the illustrations contained in them, will be qualified to understand the engravings themselves, when they meet with them in subsequent private perusal of the books. A series of drawings, many of them greatly enlarged, has also been commenced, of the instruments, machines, and natural objects described in some of those class-books which are not illustrated by engravings. Most of the pictorial representations employed in the Lectures have hitherto consisted, merely, of extemporary diagrams, drawn with white chalk upon black boards, also by some of the pupils ; but those with which the Courses on Vegetable and Animal Chemistry were illustrated, formed the commencement of a series of permanent drawings for this purpose, to which additions have since been made, consisting of sections of the instruments and apparatus employed in the Lectures, \&c. Large diagrams, in stong outline, of some of the Crystalline Forms which most frequently occur among minerals and salts, and coloured Geological sections, have also been prepared.

Many of these drawings were exhibited in the Public Lecture on this Department, delivered at Hazelwood, in October last, all the graphic illustrations employed in which, with the exception of the Transparency representing the Hylesinus Destructor, were from the pencils of the pupils. 
elementary instruction, in the manner just described. of the youngest boys. When they have advanced through this, the "Continuation" of the same work has been taught from, in which are explained the nature and use of the Thermometer, the Expansibility of the Air, the Elastic Force of Steam, the nature of a Vacuum, the Pressure of the Atmosphere, and the construction of the Barometer. For higher classes of boys the "Sequel" to the same work has been used, in which the Pump, the Air-pump, the Steam Engine, the manufacture of Gas, the Electrical Machine, the manufacture and refining of Sugar, and many other subjects of great utility and interest, embracing portions of the elements of many departments of science, are described or narrated with great perspicuity, and in a manner admirably adapted to the comprehension of the juvenile mind. In Chemistry, some of the Upper Classes have been taught from Dr. Turner's "Elements" of that science; and lower Classes from the "Conversations on Chemistry." In Mineralogy and Geology, the "Outlines," of the late $\dot{M}$. William Phillips have been employed; and a few lessons on Crystallography have also been given, in part from that work, and from the "Elementary Introduction to Mineralogy" by the same author, in part from notes prepared by the Teacher, and illustrated by a series of large models constructed by Mr. Larkin. These works have been employed, in preference, to a certain extent, to lessons drawn up or delivered extemporaneously by the Teacher, partly on account of the time which would necessarily have been occupied in preparing original lessons on erery subject; and partly in order that the Parents of the pupils might be made exactly acquainted with the means of instruction adopted. It would not be difficult to raise valid objections to this mode of proceeding, with respect to some of the works enumerated above, but it appeared to the Conductors of Hazelwood School, to be, upon the whole, the most eligible course that could be pursued. Whatever seemed defective or erroneous in the works thus employed, it has, of course, been the endeavour of the Teacher, to supply, or to correct.

The mode of Class-Instruction by private, or rather, silent study, has necessarily been limited to elder boys. The following works have been read in this manner:-

In General Physics, Dr. Arnott's "Elements of Physics," some of the "Treatises published by the Society for the Diffusion of Useful Knowledge, the Sequel to Harry and Lucy, Philosophy in Sport made Science in Earnest, and Millington's Epitome of Natural Philosophy:

In Chemistry, The Conversations on Chemistry, Mr.Brande's 
Manual, Dr. Henry's Llements, Dr. Turner's Elements of Chemistry, and his work on the Laws of Combination, and on the Atomic Theory, Dr. Paris's Medical Chemistry, Sir H. Davy's Agricultural Chemistry, and Mr. Faraday's Cleemical Manipulation*.

In Mineralogy and Geology, Phillips's "Outlines" of those sciences, Conversations on Mineralogy, and portions of Conybeare and Phillips's Outlines of the Greology of England and Wales.

In Natural History, the volume on Vegetable Substances (Timber-trees and Fruits), the Menageries, and the Insect Architecture and Transformations, of the Library of Entertaining Knowledge + .

It may now be proper to say a few words on the means employed from time to time, for the purpose of ascertaining, and also of rewarding and encouraging, the progress of the pupils, in these various exercises. With regard to the Lectures, this has been partly effected in the re-consideration of them by the Classes; and at suitable periods the entire number of pupils attending the Lectures, have had questions addressed to them, collectively, which they have been required to answer in writing, individually; and they have then taken rank in the department of Physical Science, according to the accuracy of their replies. With respect to the separate Classes, examinations have been instituted, every week, or every fortnight;

- An objection might perhaps be raised to the perusal of this work, on the apparently valid ground of the inutility of the mere reading of a train of minute directions for the performance of experiments. It has however been selected, spontaneously, by a pupil at Hazelwood, and another (designed for the medical profession) at Bruce Castle, for their own respective perusal, and has been read by them with great delight, as well as to their manifest improvement in the art of experimenting. The detail of manual operations is indeed in general interesting to boys, and many facts might be adduced, proving the utility of acquiring knowledge of this description, which becomes insensibly recalled by the memory, as the operations to which it relates are practised.

Dr. Turner's Elements of Chemistry, and Mr. Faraday's Chemical Manipulation, at one School, and Dr. Henry's Elements, together with Mr. Faraday's work, at the other, have been always kept in the Laboratory, for reference, and for the use of the assistants to the Teacher of Physical Science, and that of other boys who might be privileged to have access to it, out of school-hours.

+ At each School there is a Library of a general nature, from which every boy is permitted to borrow books for his own perusal in his leisure hours, and these Libraries contain some of the works enumerated abore, and also other scientific publications; sc that every one may select for his recreation such works as may be agreeable to his particular taste, and may also, if he pleases, convert his amusements into means of further advancement in his studies, whether in the Physical Sciences, or in any other department of Education. 
a certain degree of rank being taken, or lost, and rewards bestowed, according to the evidence of attention elicited by the examination. When a boy appears to be particularly deficient, he is associated with some others who are actually receiving the instruction already given, with comparative or temporary ineffect, to him, and is tlius again led through the subject; and this process is repeated until he has made the required amount of progress. Such, generally, are the methods which have been adopted; but to describe them fully would require me to enter into an explanation of some parts of the Hazelwood System, in detail, which is foreign to my present object, but which will be found in the work entitled " Public Education.-Plans for the Government and Liberal Instruction of Boys, in Large Numbers," which was published, a few years since, by the Conductors of the Schools.

The proposed objects of this Memoir being now fulfilled, it remains only to add a brief summary of the whole, and to offer a few concluding remarks.

The aspect which Society, at the momentous epoch in human affairs that we now behold and are all deeply concerned in, presents, with respect to the intellectual pursuit and the practical application of the Knowledge of Nature, has been succinctly reviewed. In connection with this subject, the rea-. sons which have induced the Conductors of the Schools of Hazelwood and Bruce Castle, to offer, for public approbation and support, a new Department of General Education, founded upon those sciences by which the Knowledge of Nature is conveyed, have been distinctly stated. The principal design of the foregoing pages has been, - not to propose the substitution of that Department for any of the branches of scholastic study hitherto pursued,-but to offer it for selection, to those who may perceive its importance, and to furnish the preparative means of reflecting the light of Natural Knowledge, on every other object of mental inquiry. The connection of the Physical Sciences with the principal subjects of intellectual contemplation, and with the chief branches of study which are now followed, has, accordingly, been traced. The utility of the Knowe ledge of Nature, in imparting the power of rightly apprehending some of the testimonies of Divine Revelation, on the one hand, and in protecting the mind from the fallacies of superstition, on the other, has been pointed out. The peculiar claims of the Physical Sciences, as constituting a branch of Education, to the attention, at the present æra, of those members of society, whose occupation it is, to extend the commerce of their country, or to increase its wealth by improving its manufactures, have 
been shown by the detail of a series of important facts. The utility of the Knowledge of Nature in the conduct of the ordinary affairs of life, has been exemplified, by cases of emergency, which may occur to persons of every station and of every rank. It has been seen, also, that the abstract philosophical history of nature-the profound cultivation of the Physical Sciences, considered merely as branches of interesting knowledge-daily becomes of the utmost importance to the welfare and the comfort of society. Some remarks have been offered, on the great increase of value which Mathematical Knowledge - the importance of which is universally admitted-may receive, by the addition of a commensurate acquaintance with the principles and beings of the material world. Interesting facts have been detailed, evincing the utility of uniting Natural Knowledge with the pursuits of Classical Literature : it has been seen that the investigation of Ancient History may correct the determinations of the Astronomer; that the Astronomer, in his turn, when all the ordinary means of Chronology have failed, may establish an epoch for the Historian; and that a peculiar fitness for the more profound class of inquiries into the Literature and Antiquities of former ages, is imparted to the mind, by the habits of induction which are appropriate to the study of Physics. Lastly, the plan and the methods of instruction in the Physical Sciences, as forming a portion of the business of the Schools, have been fully explained, and accompanied by an account of a prominent part of the instruction already given, which will have enabled those persons, who may previously have been imperfectly acquainted with the objects of natural science, in some degree to appreciate their interest and their utility.

It being the main object of this work, - not to assign an undue elevation to the Physical Sciences, in the scale of the relative importance of the different branches of Education,but simply to claim for them their just place in that scale, in harmonious connection with every other pursuit of the human mind, and every other means of preparation for the active concerns of human life, the argument has been insensibly extended, in the progress of the work, from the Education of Boys, to Education, understood in the most universal sense of that term. The foregoing representations are as fully applicable to the advanced instruction received by the students of Universities and Public Institutions for Professional Education, and to that, still more important, which the man who has entered upon the active duties of life, may bestow upon himself, as they are to the particular species of elementary instruction which was originally contemplated, and to suggest an ad- 
dition to which is the main design of these pages. This extension, however, of the original design, is in perfect accordance with the views of the parties who have concurred in this publication. Engaged in professional life, and necessarily devoting their specific attention, and confining their active exertion, to the occupations they have respectively adopted, they are desirous, notwithstanding, of doing this in the most liberal manner, and with constant reference to the higher institutions of the country, and to the higher cultivators and patrons of Education and of Science, who are engaged in upholding those institutions. The Universities of Oxford and Cambridge have already received their just meed of praise, in reviewing the advantages of Academical Education, in preparing the mind for the study of the Physical Sciences; and the founders of the University of London have prepared the way for a future still more complete union of knowledge applied to Liberal Education. The Conductors of the Schools of Hazelwood and Bruce Castle, and the Author of this Memoir, wish to be understood, as desirous of furnishing the means of elementary Education in every department of study pursued in the Universities and other great establishments of the country: To behold the students who have received their initiatory education under their care, become proficient and distinguished in the pursuits or professions which they may eventually adopt, under the Discipline and the Professors of those Institutions, will be at once the desired result, and the grateful reward, of their own labours.

To what extent the study of the Physical Sciences, at School, may profitably be allowed to take the place of any other branch of knowledge, is not for the Conductors or for the Teacher to decide; that point must be left, altogether, for the consideration of the friends of their pupils. They are only desirous of offering one remark upon this head. The most weighty objection, perhaps, which can be urged, by those who adequately appreciate the value of the Physical Sciences, to their adoption as a branch of General Education, is the space of time, already short, which the occupations of life, in many cases, permit to be devoted to the intellectual instruction of youth designed for them. This objection would apply, with the greatest force, to those who are destined for business or for commerce, many of whom terminate their education at School. Now it is precisely to youth of this class, it may be observed, that the study of the Physical Sciences will be most extensively useful, while, to them, the knowledge of the Dead Languages seldom can be important, and is in fact scarcely ever retained by them in after-life. With respect to pupils of 
this class, therefore, it is merely suggested, that the substitution of the Physical Sciences for the dead languages usually taught, or for one of them, might probably be advantageous. But how far this shall actually be done, must depend upon the instructions received by the Conductors, with respect to the eclucation of each of their pupils : in the absence of this, they will not consider themselves authorized to exchange any usual study for that of the new Department, however they may avail themselves of the latter, in filling up intervals of occasional or of comparative leisure.

As already intimated, the extent to which the Department of Physical Science can be introduced into the business of the Schools, involving both the amount of time devoted to it, and the rank of the instruction to be given, must depend, mainly, upon the specific value, with respect to Education, among the various branches of useful knowledge, which shall be assigned by the public to the scientific knowledge of $\mathrm{Na}$ ture. The parties concerned in the Schools of Hazelwood and Bruce Castle, offer some of their individual opinions upon the subject, for the acceptance of those whose offspring have been committed to their care, and for that of others who may approve of their general system of Education. Their part is thus performed,-their duty, in this respect, is discharged. They now solicit the attention of the public to what they have submitted for consideration; being convinced, that, whatever may be the result of the present effort, it must eventually be seen by mankind, that the cultivation (and, consequently, with respect to the young, the elementary cultivation) of ALL the Faculties of the Human Mind, is indispensable to the HAPPINESS of the Human RACE.

FINIS.

PRINTED BY RICHARD TAYLOR, PRINTER TO THE UNIVERSITY OF LONDON, RED LION COURT, FLEET STREET.

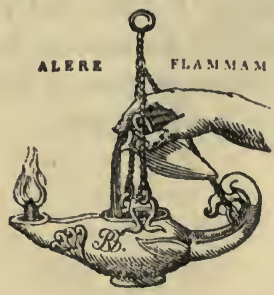




\section{HAZELWOOD SYSTEM OF EDUCATION.}

The following Wonks, illustrative of the System of Education pursued at Hazelwood and Bruce Castle, or employed in its practice, may be obtained of the publishers of this Memoir, and of J. Souter, St. Paul's Churchyard:-

PUBLIC EDUCATION. Plans for the Government and Liberal Instruction of Boys, in Large Numbers; as practised at Hazelwood School. Second Edition, 8vo. price 10s. $6 d$.

I.AWS OF HAZELWOOD SCHOOL. Edited by RowLAND and Frederick Hill. 8vo. price $5 s$.

THE FABLES OF PHÆDRUS, with a literal English translation; as used at Hazelwood School. 12mo. price 2s.6d.

DECERPTA MINORA, ex Justino, Cæsare, Nepote, et Eutropio. In usum Scholæ Hazelwoodianæ. 12mo. price 2s.

FRENCH EXERCISES; consisting of Easy Dialogues, partly in French for translation into English, and partly in English for translation into French. By F. C. Ruinet, Teacher of the French Language at Hazelwood School. 12mo. price $2 s .6 d$.

COURS DE THEAMES. Series of Grammatical Exercises, to be translated into French. By the same. 12mo. price $2 s .6 d$.

FRENCH EXERCISES, for The uSE of Schools : consisting of part of Miss Edgeworth's " Frank ;" firstly, translated into French, and, secondly, arranged for translation into French. Published with the consent of the proprietors of the original English work. 12mo. price 1s. 6d. serwed in Two Parts. 


M.H $6 / 4 / 44$ 



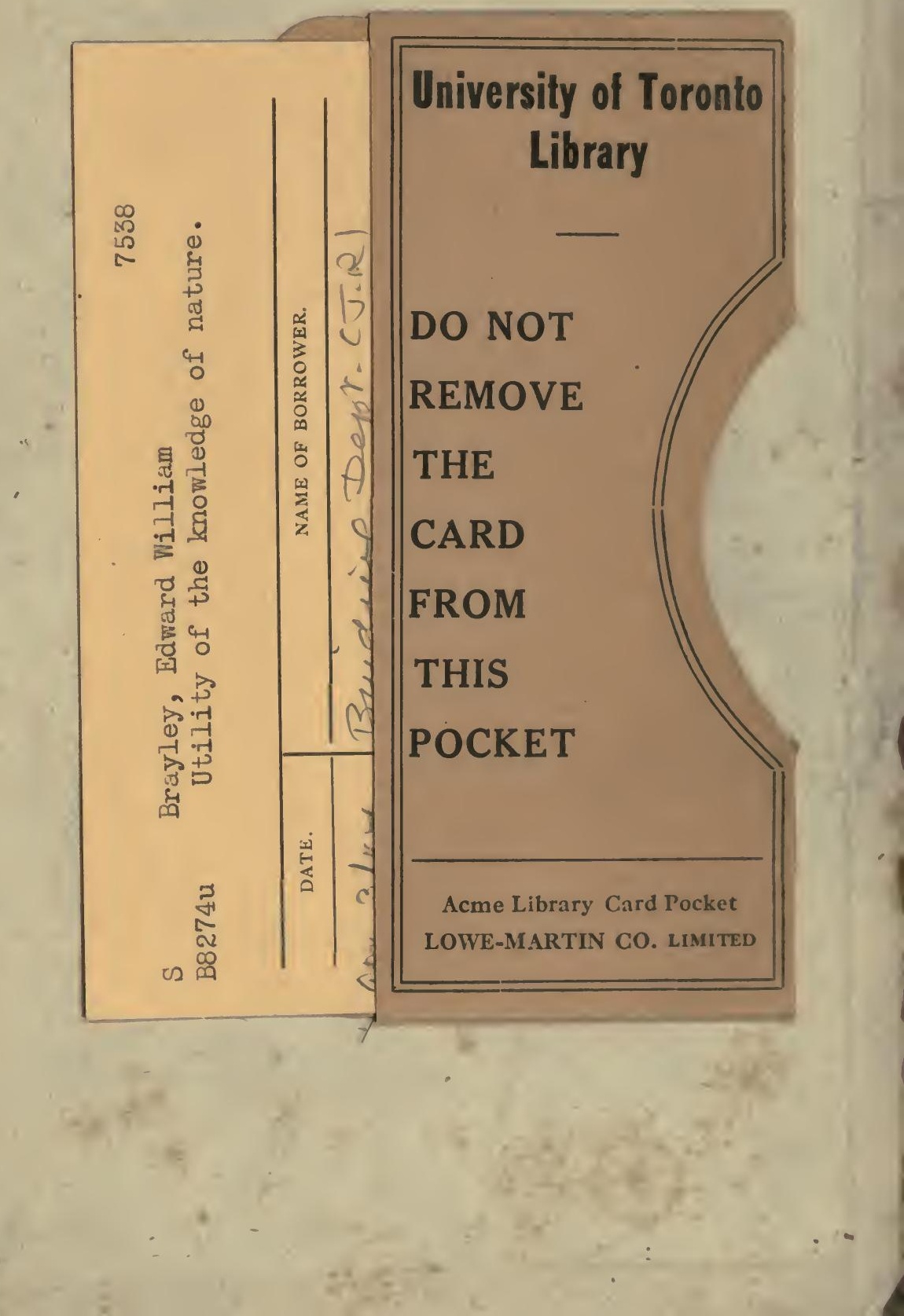




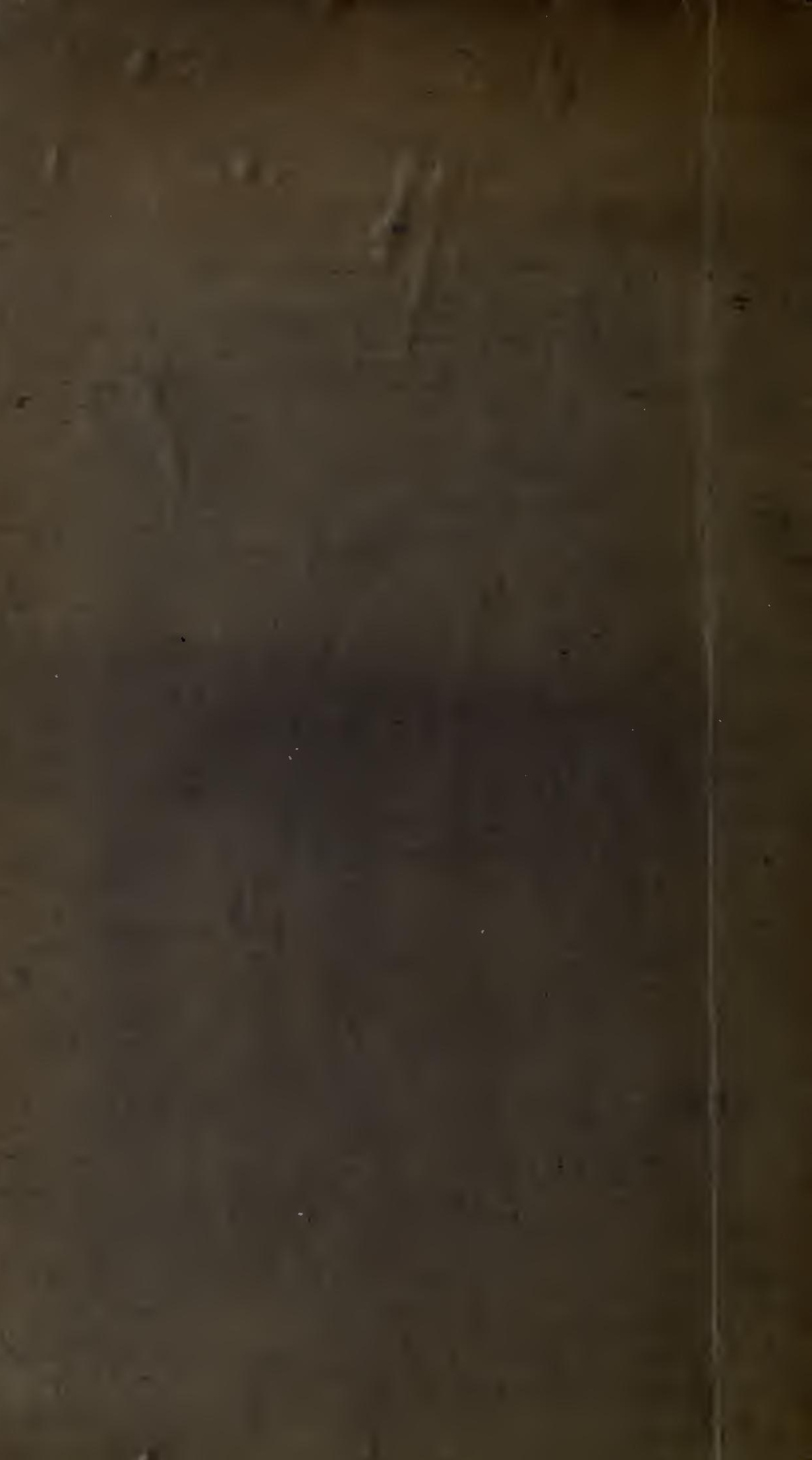

